DÊnnis Maluf Gambarine

VIBRAÇÃO INDUZIDA POR VÓRTICES EM CILINDROS FLUTUANTES COM BAIXA RAZÃO DE ASPECTO E DIFERENTES CONDIÇÕES DE GEOMETRIA NA EXTREMIDADE IMERSA 
Dênnis Maluf Gambarine

\section{VIBRAÇÃO INDUZIDA POR VÓRTICES EM CILINDROS FLUTUANTES COM BAIXA RAZÃO DE ASPECTO E DIFERENTES CONDIÇOESS DE GEOMETRIA NA EXTREMIDADE IMERSA}

Dissertação apresentada à Escola Politécnica da Universidade de São Paulo para a obtenção do título de Mestre em Ciências

Área de concentração:

Engenharia Naval e Oceânica

Orientador:

Prof. Dr. André Luís Condino Fujarra 
Este exemplar foi revisado e corrigido em relação à versão original, sob responsabilidade única do autor e com a anuência de seu orientador.

São Paulo, de de

Assinatura do autor:

Assinatura do orientador:

\section{Gambarine, Dênnis}

Vibração Induzida por Vórtices em cilindros flutuantes com baixa razão de aspecto e diferentes condições de geometria na extremidade imersa. / D. Gambarine -- versão corr. -- São Paulo, 2017.

$$
92 \mathrm{p} .
$$

Dissertação (Mestrado) - Escola Politécnica da Universidade de São Paulo. Departamento de Engenharia Naval e Oceânica.

1.Vibrações Induzidas por Vórtices 2.Cilindros com baixa razão de aspecto I.Universidade de São Paulo. Escola Politécnica. Departamento de Engenharia Naval e Oceânica II.t. 


\section{DEDICATÓRIA}

Aos meus pais, Rita de Cássia e Luiz Carlos, que nos seus atos cotidianos, proporcionaram: amor, carinho e abrigo sempre seguro e farto, dando bons exemplos de dignidade e não medindo esforços para minha formação. À minha namorada, Patrícia, pelo apoio e companheirismo em todos os momentos. Aos meus mestres por acreditarem no meu potencial, concedendo todo auxílio e dedicação. 


\section{AgradeCIMENTOS}

Ao Departamento de Engenharia Naval e Oceânica da Escola Politécnica da Universidade de São Paulo e aos profissionais do Tanque de Provas Numérico da Universidade de São Paulo, por disponibilizarem os recursos necessários para o desenvolvimento do trabalho.

À Petrobras e à Agência Nacional do Petróleo, Gás Natural e Biocombustíveis, pela bolsa de mestrado concedida durante o desenvolvimento desta pesquisa.

Ao Professor Doutor André Luís Condino Fujarra, pela orientação do trabalho e ao Doutor Rodolfo Trentin Gonçalves, pelo apoio nos experimentos e a toda dedicação ao meu trabalho.

À minha família, principalmente meus pais, minha irmã e namorada, que me acompanharam nesta jornada com muito apoio e paciência.

Aos meus colegas de curso Felipe Pierrobom e Fábio Amorim, pela parceria de projetos e ajuda no desenvolvimento deste trabalho. Ao Dr. Edgard Malta e Eng. MSc. Rodrigo Máximo pela ajuda na edição deste texto.

À equipe do Instituto de Pesquisas Tecnológicas do Estado de São Paulo, pela disponibilização do tanque de reboque para realização dos ensaios e todo suporte técnico que foi necessário para realização dos mesmos. 
"Live as if you were to die tomorrow. Learn as if you were to live forever.".

(Mahatma Gandhi) 


\section{RESUMO}

O crescimento da exploração do petróleo e gás em águas ultraprofundas fez com que a demanda por unidades flutuantes crescesse e, com isso, aumentasse a ocorrência do fenômeno de Movimentos Induzidos por Vórtices (ou VIM, de Vortex-Induced Motions) que age em plataformas com casco cilíndrico, como é o caso das monocolunas e spars. Efeito natural desse aumento nas ocorrências foi um maior interesse pelo fenômeno de VIM, simplificadamente investigado em cilindros lisos e curtos como os utilizados nesta pesquisa. A fim de contribuir com o conhecimento dos fundamentos fluido-dinâmicos nesta área, foram investigados quatro diferentes cilindros flutuantes de baixa razão de aspecto, todos caracterizados pelo valor típico de $\mathrm{L} / \mathrm{D}=2$ (comprimento imerso por diâmetro, onde $\mathrm{L}=$ $250 \mathrm{~mm}$ e $\mathrm{D}=125 \mathrm{~mm}$ ), mas com diferentes condições de arredondamento da extremidade imersa, estas caracterizadas por quatro razões distintas entre o raio de adoçamento e o raio do cilindro, especificamente $\mathrm{r} / \mathrm{R}=0,00 ; 0,25 ; 0,50$ e 1,00 . Com este objetivo de observar a resposta dos cilindros curtos sob efeito dos vórtices gerados em diferentes formatos de extremidade imersa, experimentos foram realizados no tanque de provas do Instituto de Pesquisas Tecnológicas do Estado de São Paulo (IPT), compreendendo velocidades de reboque entre 0,024 a $0,154 \mathrm{~m} / \mathrm{s}$, ou seja, uma faixa de números de Reynolds entre 3.300 e 19.200. Os resultados de amplitude adimensional de resposta observados na direção transversal mostram influência moderada das modificações na extremidade imersa, ligeiramente mais acentuadas no modelo com razão de arredondamento de $\mathrm{r} / \mathrm{R}=0,25$, sendo que para este caso, as amplitudes máximas ficaram abaixo daquelas exibidas pelos demais modelos, com uma tendência geral de queda para as velocidades de reboque mais altas. A variação da geometria da extremidade imersa também influenciou moderadamente os resultados de amplitude adimensional de resposta na direção longitudinal, onde o modelo com $\mathrm{r} / \mathrm{R}=$ 1,00 apresentou menores amplitudes nas velocidades mais altas. Por outro lado, a razão entre as frequências de resposta e as frequências naturais de referência mostraram comportamentos típicos, semelhantes aos encontrados em análises de VIV de cilindros longos montados em suportes elásticos com dois graus de liberdade. Além disso, a observação dos movimentos dos modelos no plano da superfície livre não indicaram mudanças significativas nas trajetórias em função do arredondamento da extremidade livre. No tocante aos coeficientes de força (arrasto e sustentação), as comparações entre os modelos foram semelhantes, mas os coeficientes para o cilindro sem chanfro $(\mathrm{r} / \mathrm{R}=0)$ mostraram-se maiores para grande parte das velocidades ensaiadas. Para o modelo com $r / R=1,00$, as força de arrasto e sustentação não se mostraram com a mesma intensidade do que aquelas nos demais modelos, o que, desta forma, se refletiu nos menores valores de coeficiente encontrados. Sob uma ótica geral, os resultados levam a crer que o modelo fluido responsável

pelas oscilações nos cilindros com $\mathrm{L} / \mathrm{D}=2$ não tem relação com a existência de vórtices de ponta e aresta, mas com a emissão de vórtices em forma de arco.

Palavras-chave: Vibração Induzida por Vórtices, cilindros flutuantes, baixa razão de aspecto, geometria da extremidade imersa. 


\section{ABSTRACT}

The oil and gas exploration in deep and ultra-deep water has increased in the past years, and at the same time, increasing the floating vessel demand, thereby the vortex-induced motion phenomenon (VIM) has been present for cylindrical hull structures, for example, spar and monocolumns floating units. The impact of this, enhance the VIM phenomenon interest with simplify investigations on smooth cylinders, as was used in the present research. In order to expand the knowledge, experiments were made in four floating cylinders with low aspect of ratio, L/D $=2$ (Length / Diameter) were tested with different free end corner shape types, namely by the relation between chamfer rounding radius $(\mathrm{r})$ divided by the radius of cylinder $(\mathrm{R})(\mathrm{r} / \mathrm{R}=0.0,0.25,0.5$ and 1.0$)$. For the initial case, $\mathrm{r} / \mathrm{R}=$ 0.0 represents flat tip and $\mathrm{r} / \mathrm{R}=1.0$ the semi-hemispherical tip. The aims were to understand the effect of different free-end types on VIV behaviour of cylinders. The floating circular cylinders, i.e. unit mass ratio $\mathrm{m}^{*}=1$ (structural mass/displaced fluid mass), were elastically supported by a set of linear springs to provide low structural damping on the system and allow six degrees of freedom. The aim is to understand the effects of the free end vortex in the cylinder movements, varying the free end shape. The experiments were carried out in a towing tank of IPT - Institute for Technological Research of the state of São Paulo, Brazil. The range of velocities tested is 0.024 to $0.154 \mathrm{~m} / \mathrm{s}$, and Reynolds number covered 3,300 $\leq R e \leq 19,200$. The nondimensional amplitudes results for transversal direction, show a moderated effect when the free end shape has changed, more significant in the $\mathrm{r} / \mathrm{R}=0.25$ case, where the maximum amplitudes present lower values compare with the others cylinders. For in-line nondimensional amplitudes, model with $\mathrm{r} / \mathrm{R}=1.00$ shown lower values for high velocities. On the other hand, the frequencies ratios between in-line/transverse and natural sistem frequency, presented typical VIV response for long cylinders with two degree of freedom. In addition, the trajectory observations in the XY plane have not illustrated differences for cylinders with rounded edges. Force coefficients outcome (drag and lift), the no-rounded edge case $(\mathrm{r} / \mathrm{R}=0.0)$, presented higher coefficients for the large proportion velocities. Furthermore, the model with a semi-spherical shape in the free end $(\mathrm{r} / \mathrm{R}=1.00)$, demonstrated the both force coefficients have not acted with the same severity as was observed for the others cylinders, and thus, the $r / R=1.00$ models has presented lowest values. In general, the present results suggest the answer for oscillation on $\mathrm{L} / \mathrm{D}=2$ models is caused by arc-type vortex shedding, not by the free end vortex effects.

Key words: Vortex-Induced Vibrations, floating cylinders, low aspect of ratio, free end shape. 


\section{LISTA DE FIGURAS}

1.1 Plataforma fixa do tipo gravidade. [Fonte: STATOIL] . . . . . . . . . . . 20

1.2 Principais tipos de plataformas para exploração no mar. . . . . . . . . . . 21

1.3 Chaminés industriais com supressores de VIV - strakes - em uma indústria no Alasca, EUA. . . . . . . . . . . . . . . . . 22

1.4 Plataforma flutuante do tipo Spar [Fonte: refineering.wordpress.com]. . . . 23

2.1 Bolhas de recirculação sendo formadas a jusante do cilindro. Fonte: (VANDYKE,

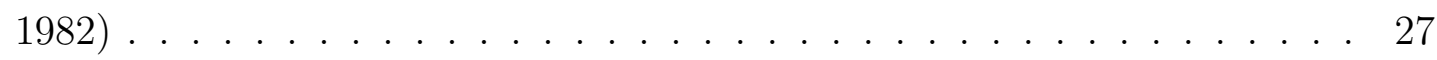

2.2 Esteira de Von Kármán: (a) regime laminar periódico e (b)turbulento. Fonte: $($ VANDYKE, 1982) $\ldots \ldots \ldots \ldots \ldots$

2.3 Relação entre número de Reynolds e o de Strouhal. (Fonte: (NORBERG, 2000)]. . . . . . . . . . . . . . . . . . . . 29

2.4 Caracterização qualitativa da sincronização. . . . . . . . . . . . . . . . . 29

2.5 Linhas de amarração e risers ligadas a unidades flutuantes do tipo semissubmersível e FPSO. [Fonte: www.offshore-technology.com]. . . . . . . . . 30

2.6 Principais plataformas flutuantes suscetíveis ao VIM. Tipos: (a) Semisubmersível, (b) monocoluna, (c) classic spar, (d) truss spar e (e) cell spar. [Fonte: (FUJARRA, 2013)]. . . . . . . . . . . . . . . 31

2.7 Correntes atuantes no Golfo do México [Fonte: (YUNG et al., 2004)]. . . . 32

2.8 Casco de uma plataforma do tipo spar com strakes helicoidais [Fonte: Imperial College, London]. . . . . . . . . . . . . . . . . . . . 32

2.9 Amplitude adimensional em função da velocidade da correnteza, sem a presença de strakes e com diferentes ocupações de strakes nas áreas externas do casco. [Fonte: (FINN et al., 2003)] . . . . . . . . . . . . . . 33 
2.10 No alto, modelos de plataforma spar com diferentes apêndices no casco; Abaixo, gráfico analisando as diferenças de amplitude para cada caso em função da velocidade reduzida. [Fonte: (RODDIER et al., 2009)] . . . . . 34

2.11 Esquema para oscilação em 1 grau de liberdade e 2 graus de liberdade. . 35

2.12 Sistema com um cilindro um grau de liberdade (1GL). [Fonte: (ASSI, 2005)]. 35

2.13 Amplitudes transversais de oscilação para dois cilindros com parâmetro de massa-amortecimento distintos. $m^{*} \zeta=3,28$ [Fonte: (FENG, 1968)] e $m^{*} \zeta=0,13$ [Fonte: (KHALAK; WILLIAMSON, 1999)] . . . . . . . . 37

2.14 Curva descrita por um cilindro livre para oscilar mostrado dua amplitude adimensional de deslocamento transversal pela velocidade reduzida. [Fonte: (JAUVTIS; WILLIAMSON, 2004)] . . . . . . . . . . . . . . . 38

2.15 Plataforma monocoluna sob ação de correnteza e realizando uma movimentação (indicada pelas linhas vermelhas) em formato de "8"típico do fenômeno de VIM. [Fonte: (Fujarra, 2013)] . . . . . . . . . . . . . . . . . . 39

2.16 Escoamento ao redor de cilindros fixos de baixa razão de aspecto: (a) $L / D>$ $(L / D)_{c r}$ e (b) $L / D<(L / D)_{c r}$ [Fonte: (KAWAMURA et al., 1984)]. . . . . 40

2.17 Tipos de esteiras geradas pelos cilindros curtos, segundo (SAKAMOTO; ARIE, 1983). . . . . . . . . . . . . . . . . . . 41

2.18 Cilindro fixo em uma placa plana e imerso a um escoamento [Adaptado de (SUMNER et al., 2004)] . . . . . . . . . . . . . . . . . . . . . . 42

2.19 Vórtices gerados junto aos cilindros curtos fixos, mas com ambas as extremidades imersas em escoamento fluido. [Fonte: (ZDRAVKOVICH, 1989)].

2.20 Vista lateral do escoamento em torno de um cilindro com $L / D=5$ : evidência clara do efeito de downwash. [Fonte: (PARK; LEE, 2000)]. . . . . . . . 43

2.21 Precipitação do óleo na superfície plana do cilindro mostrando a ocorrência de formação dos trailing vortices. [Fonte: (ROH; PARK, 2003)]. . . . . . . 44

2.22 Em (a), modelo topológico da emissão de vórtices na superfície plana da extremidade livre de um cilindro curto. Em (b), vista frontal mostrando os dois pares de vórtices contra-rotacionados nessa região: dois tip vortices ao centro e dois trailing vortices junto às arestas laterais. [Fonte: (ROH; PARK, 2003)] . . . . . . . . . . . . . . . . . . . . . 44 
2.23 Escoamento junto a quatro extremidades livres diferentes em cilindros com $L / D=6$ : (a) cilindro com arestas "vivas"; (b) cilindro com chanfro a 45 graus de inclinação; (c) cilindro com arredondamento de raio $5 \mathrm{~mm}$; (d) cilindro com extremidade semiesférica. [Fonte: (PARK; LEE, 2004)] . . . . 45

2.24 Síntese gráfica da emissão de vórtices junto aos cilindros curtos com $L / D<$ 2,5. [Fonte: (PATTENDEN et al., 2005)] . . . . . . . . . . . 46

2.25 Frequências de emissão de vórtices da extremidade livre do cilindro (Edge Flow) e do corpo principal (WakeFlow). [Fonte: (SOMEYA et al., 2010)].

2.26 Campo de velocidade adimensional na direção longitudinal ao escoamento, no plano vertical central do cilindro, e respectivas linhas de corrente, para diferentes razões de aspecto e numero de Reynolds. [Fonte: (GONçALVES, 2013)]. . . . . . . . . . . . . . . . . . 48

2.27 Amplitude adimensional transversal, $A_{y} / D$, como função da velocidade reduzida, Vr, para cilindros flutuantes com razão de massa $m^{*}=1,0$ e diferentes razões de aspecto. [Fonte: (GONçALVES, 2013)]. . . . . . . . . . . . 48

3.1 Extremidades livres usinadas em PVC . . . . . . . . . . . . . . . . 50

3.2 Marcação dos calados e locais de amarração nos cilindros. . . . . . . . . . . . 50

3.3 Cilindros finalizados: em (1), C1 - arestas "viva"; em (2), C2 - arredondamento $r / R=0,25$; em (3), C3 - arredondamento $r / R=0,50$; e em (4), C4 - arredondamento $r / R=1,00$.

3.4 Determinação da posição vertical do Centro de Gravidade (CG) dos modelos pelo método de apoio em lâmina. . . . . . . . . . . . . . . . . . . 52

3.5 Esquema para definição das dimensões dos modelos. . . . . . . . . . . . . . 52

3.6 Modelos posicionados no local de ensaio. . . . . . . . . . . . . . . . 53

3.7 Tanque de reboque do IPT com o carro dinamométrico principal (em azul), rebocando o carro secundário com os equipamentos experimentais (em amarelo). . . . . . . . . . . . . . . . . . . . . . 54

3.8 Esquema do aparato experimental montado no carro de reboque secundário do IPT.

3.9 Quadro para posicionamento do aparato experimental montado no carro secundário de reboque no tanque do IPT . . . . . . . . . . . . . . . . . . 56 
3.10 Desenho esquemático com as principais dimensões das molas de tração utilizadas nos experimentos. . . . . . . . . . . . . . 56

3.11 Aparato experimental completo para os ensaios (cilindro, molas, suporte e câmeras no carro secundário de reboque) . . . . . . . . . . . . . . . . 57

3.12 Resultado da avaliação quanto à não-linearidade das forças de restauração impostas aos modelos suportados no quadro de molas. . . . . . . . . . . . . 58

3.13 Sistema de medição de movimentos por rastreamento de alvos passivos da Qualisys ${ }^{\mathrm{TM}}$. Em (a), vista geral das três câmeras utilizadas nos ensaios. Em (b), detalhes de uma das câmeras utilizadas. . . . . . . . . . . . . . . . 59

3.14 Resposta do encoder para série temporal setada para velocidade de 125 $\mathrm{mm} / \mathrm{s} \ldots \ldots \ldots \ldots \ldots$. . . . . . . . . . . . . . . 60

4.1 Esteira sendo formada a jusante do cilindro . . . . . . . . . . . . . . 63

4.2 Comparação entre os métodos de determinação das amplitudes adimensionais de resposta devidas ao VIV em cilindros curtos. Fonte:(GONçALVES,

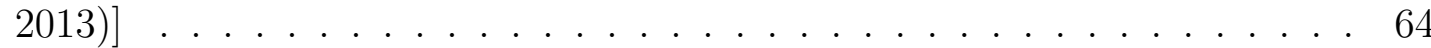

4.3 Exemplo de série temporal do deslocamento transversal adimensional. Gráfico referente ao VIV no modelo $\mathrm{C} 1$ com $V r=9,55 . \ldots . . . . .64$

4.4 Exemplo de série temporal do deslocamento longitudinal adimensional. Gráfico referente ao VIV no modelo $\mathrm{C} 2$ com $V r=2,50 \ldots$. . . . . . . . . . 65

4.5 Exemplo de registro simultâneo dos comportamentos nos 6GL do cilindro $\mathrm{C} 4$ em $V r=8,5$ : no alto, translações em X, Y e Z; ao centro, rotações de roll, pitch e yaw; e abaixo o registro da velocidade imposta pelo carro de

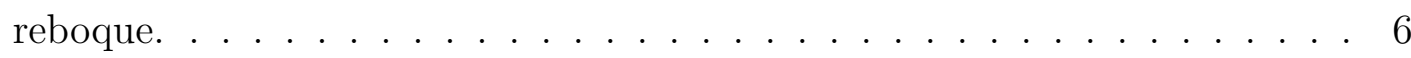

4.6 Amplitude adimensional transversal, $A_{y} / D$, como função da velocidade reduzida, $V_{r}$, para os cilindros curtos flutuantes: $\mathrm{C} 1, \mathrm{C} 2, \mathrm{C} 3$ e $\mathrm{C} 4 . \quad \ldots . .66$

4.7 Amplitude adimensional longitudinal, $A_{x} / D$, como função da velocidade reduzida, $V_{r}$, para os cilindros curtos flutuantes: $\mathrm{C} 1, \mathrm{C} 2, \mathrm{C} 3$ e $\mathrm{C} 4 . \quad \ldots$. . . 67

4.8 Amplitudes angulares do movimento de yaw, $A_{\text {yaw }}$, como função da velocidade reduzida calculada com base na frequência natural desse grau de liberdade, $V_{r}$, para os cilindros curtos flutuantes: C1, C2, C3 e C4 . . . . . 68 
4.9 Deriva adimensional, $u_{D} / D$, como função da velocidade reduzida, $V_{r}$, para os cilindros curtos flutuantes: C1, C2, C3 e C4. . . . . . . . . . . 69

4.10 Evolução do movimento no plano XY para cada um dos cilindros curtos flutuantes, apresentada conforme a variação da amplitude adimensional transversa em função velocidade reduzida. . . . . . . . . . . . . . . . . . . 71

4.11 Razão entre frequência de resposta transversal e frequência natural em águas paradas, $f_{y} / f_{0}$, como função da velocidade reduzida, $V_{r} \ldots \ldots$. . . . 72

4.12 Razão entre frequência de reposta longitudinal pela frequência de resposta transversal, $f_{x} / f_{y}$, como função da velocidade reduzida, $V_{r} \ldots \ldots . . \ldots 73$

4.13 Coeficientes de arrasto médio, $C_{x}$, apresentados como função da velocidade reduzida, $V_{r} \ldots \ldots \ldots \ldots \ldots \ldots \ldots \ldots \ldots$

4.14 Coeficientes de sustentação, $C_{y}$, apresentados como função da velocidade reduzida, $V_{r} \ldots \ldots \ldots \ldots \ldots \ldots \ldots \ldots \ldots$

4.15 Coeficientes de arrasto dinâmico, $C_{x-r m s}$, apresentados como função da velocidade reduzida, $V_{r} \ldots \ldots \ldots \ldots \ldots \ldots \ldots \ldots$

4.16 Ensaio de visualização do escoamento para o cilindro $\mathrm{C} 1, r / R=0.0$, para três diferentes números de Reynolds. . . . . . . . . . . . . . . . . 76

4.17 Ensaio de visualização do escoamento para o cilindro $\mathrm{C} 3, r / R=0.5$, para três diferentes números de Reynolds. . . . . . . . . . . . . . . . . . 76

4.18 Ensaio de visualização do escoamento para o cilindro $\mathrm{C} 4, r / R=1.0$, para três diferentes números de Reynolds. . . . . . . . . . . . . . . . . . . 77

A.1 Exemplo de registro dos ensaios de decaimento em surge realizados com o modelo C1. . . . . . . . . . . . . . . . . . . . 85

A.2 Exemplo de registro dos ensaios de decaimento em sway realizados com o modelo $\mathrm{C} 1$.

A.3 Exemplo de registro dos ensaios de decaimento em heave realizados com o modelo C1.

A.4 Exemplo de registro dos ensaios de decaimento em roll realizados com o modelo $\mathrm{C} 1$. 
A.5 Exemplo de registro dos ensaios de decaimento em pitch realizados com o modelo C1. . . . . . . . . . . . . . . . . . . . . . . 87

A.6 Exemplo de registro dos ensaios de decaimento em yaw realizados com o modelo C1. . . . . . . . . . . . . . . . . . . . 87

B.1 Amplitude adimensional na direção vertical, $A_{z} / D$, como função da velocidade reduzida, $V_{r}$, para cilindros flutuantes: C1, C2, C3 e C4. . . . . . . 89

B.2 Razão entre a frequência de oscilação na direção vertical e a frequência na direção transversal ao escoamento,$f_{z} / f_{o y}$, como função da velocidade reduzida, $V_{r}$, para cilindros flutuantes: C1, C2, C3 e C4. . . . . . . . . 89

B.3 Amplitude angular de roll, $A_{\text {roll }}$, como função da velocidade reduzida, $V_{r}$,

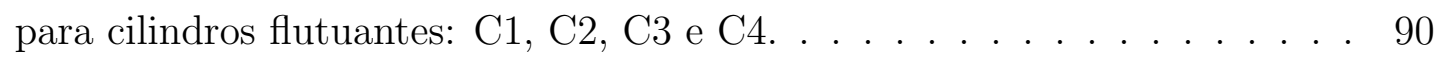

B.4 Razão entre a frequência de oscilação angular em roll e a frequência natural do sistema, $f_{\text {roll }} / f_{o}$, como função da velocidade reduzida, $V_{r}$, para cilindros flutuantes: C1, C2, C3 e C4 . . . . . . . . . . . . . . . . 91

B.5 Amplitude angular de pitch, $A_{\text {pitch }}$, como função da velocidade reduzida, $V_{r}$, para cilindros flutuantes: C1, C2, C3 e C4. . . . . . . . . . . . . 91

B.6 Razão entre a frequência de oscilação angular em pitch e a frequência natural do sistema, $f_{\text {pitch }} / f_{o}$, como função da velocidade reduzida, $V_{r}$, para cilindros flutuantes: C1, C2, C3 e C4 . . . . . . . . . . . . . . . 92 


\section{LISTA DE TABELAS}

2.1 Características do regime para escoamento uniforme em um cilindro. . . . . 27

3.1 Características dimensionais dos modelos. . . . . . . . . . . . . . 52

3.2 Parâmetros obtidos com base nos ensaios de decaimento. . . . . . . . . . 53

3.3 Dimensões principais do arranjo experimental montado no carro de reboque secundário no IPT. . . . . . . . . . . . . . . . . . . . . 55

3.4 Dimensões principais das molas de tração utilizadas. . . . . . . . . . . . 57

3.5 Intervalos de velocidade reduzida, velocidade dimensional nominal e número de Reynolds dos ensaios com os quatro modelos considerados. . . . . 61

3.6 Frequências naturais dos modelos ensaios. . . . . . . . . . . . . 61 


\section{SIGLAS}

1GL Um Grau de Liberdade

2GL Dois Graus de Liberdade

6GL Seis Graus de Liberdade

CFD Computational Fluid Dynamics, Dinâmica dos Fluidos Computacionais

CG Centro de gravidade

EPUSP Escola Politécnica da Universidade de São Paulo

FPSO Floating Production Storage and Offloading

EUA Estados Unidos da América

GoM Gulf of Mexico, Golfo do México

IPT Instituto de Pesquisas Tecnológicas do Estado de São Paulo

PIV Particle Image Velocimetry, Velocimetria por Imagem de Partículas

PVC Policloreto de vinila

rms Root Mean Square

TLP Tension Leg Platforms

TPN Tanque de Provas Numérico da USP

VIM Vortex-Induced Motions, Movimentos Induzidos por Vórtices

VIV Vortex-Induced Vibrations, Vibrações Induzidas por Vórtices 


\section{SIMBOLOS}

$\delta$ Espessura da camada limite do escoamento

$\rho$ Densidade do fluido

$v$ Viscosidade cinemática do fluido

$\zeta_{s}$ Coeficiente de amortecimento estrutural

$\zeta_{w}$ Coeficiente de amortecimento em água parada

a Aresta do quadro de sustentação das molas

A Amplitude de resposta

$A_{x} / D$ Amplitude adimensional na direção longitudinal

$A_{y} / D$ Amplitude adimensional na direção transversal

c Constante de amortecimento estrutural

C1 Cilindro com razão entre raios $\mathrm{r} / \mathrm{R}=0,00$

$\mathrm{C} 2$ Cilindro com razão entre raios $\mathrm{r} / \mathrm{R}=0,25$

C3 Cilindro com razão entre raios $\mathrm{r} / \mathrm{R}=0,50$

C4 Cilindro com razão entre raios $\mathrm{r} / \mathrm{R}=1,00$

$C_{x}$ Coeficiente de arrasto médio

$C_{x-r m s}$ Coeficiente de arrasto oscilatório

$C_{y}$ Coeficiente de sustentação

d Espessura do arame da mola

D Diâmetro característico

$D_{O} \quad$ Diâmetro da mola

$f \quad$ Frequência

$f_{0}$ Frequência natural do sistema em água parada

$f_{0 x}$ Frequência natural do sistema na direção longitudinal obtida em água parada

$f_{0 y}$ Frequência natural do sistema na direção transversal obtida em água parada

$f_{s}$ Frequência de emissão de vórtices

$f_{x}$ Frequência de oscilação na direção longitudinal

$f_{y}$ Frequência de oscilação na direção transversal

$F$ Força

$F_{D}$ Força de arrasto

$F_{L} \quad$ Força de sustentação 
$H$ Profundidade do tanque de reboque

$k$ Constante elástica da mola

$k_{x}$ Constante elástica na direção longitudinal

$k_{y}$ Constante elástica na direção transversal

$k_{x} / k_{y} \quad$ Razão entre constantes elásticas

$K_{G}$ Distancia entre a base e o centro de gravidade do modelo

$L$ Calado do modelo

$L_{O} \quad$ Comprimento da mola

$L / D$ Razão de aspecto

$L / D_{c r} \quad$ Razão de aspecto crítica

$L_{T}$ Comprimento do tanque de reboque

$m^{*} \zeta \quad$ Massa-amortecimento

$m^{*} \quad$ Razão de massa

$m_{d} \quad$ Massa do fluido deslocado

$m_{s} \quad$ Massa estrutural do sistema

M Massa dos modelos

$r / R$ Razão entre raios

$r$ Raio do adoçamento

$R$ Raio do cilindro

Re Número de Reynolds

St Número de Strouhal

$T_{n}$ Período natural do sistema em água parada

$T_{y}$ Período natural do sistema na direção transversal

$u_{D} / D$ Deriva adimensional

$U$ Velocidade do fluido

$V_{r} \quad$ Velocidade reduzida

$w$ Largura do tanque de reboque

$X$ Direção longitudinal ao escoamento incidente

$Y$ Direção transversal ao escoamento incidente

$Y / D_{\max }$ Resposta adimensional transversal calculada pela média entre picos

$Y / D^{*}$ Resposta adimensional transversal calculada pelo método do valor eficaz

$Z$ Direção vertical ao escoamento incidente 


\section{SUMÁRIO}

1 INTRODUÇÃOO

1.1 Contextualização do Problema de Interesse . . . . . . . . . . . . . . . . . 20

1.2 Definição Específica do Problema de Interesse . . . . . . . . . . . . . . . . 23

1.3 Estabelecimento do Objetivo . . . . . . . . . . . . . . . . . . . 24

1.4 Organização do Texto . . . . . . . . . . . . . . . . . . . . . . 24

2 Revisão Bibliográfica 26

2.1 Fenomenologia Geral . . . . . . . . . . . . . . . . . 26

2.2 VIV-VIM no Segmento da Engenharia Oceânica . . . . . . . . . . . . . . 30

2.3 Fenomenologia Específica . . . . . . . . . . . . . . . . . . 34

2.3.1 Graus de Liberdade . . . . . . . . . . . . . . . . . . . . . 35

2.3.2 Extremidade Livre em Cilindros Curtos . . . . . . . . . . . . . . . . 39

3 Metodologia de Ensaio 49

3.1 Descrição dos Modelos . . . . . . . . . . . . . . . . . . . . . . . . . 49

3.2 Descrição do Aparato Experimental . . . . . . . . . . . . . . . . . . . 54

3.3 Descrição do Sistema de Amarração . . . . . . . . . . . . . . . . . . . . . 55

3.4 Descrição do Sistema de Aquisição de Dados . . . . . . . . . . . . . . . . . 59

3.5 Descrição do Método Experimental . . . . . . . . . . . . . . . . . . 60

4 Resultados Experimentais $\quad 62$

4.1 Síntese . . . . . . . . . . . . . . . . . . . 62

4.2 Amplitudes Adimensionais de Resposta . . . . . . . . . . . . . . . . . 63 
4.3 Análise dos Movimentos do Plano XY . . . . . . . . . . . . . . . . 70

4.4 Frequências Adimensionais de Resposta . . . . . . . . . . . . . . . . . 71

4.5 Coeficientes de Força . . . . . . . . . . . . . . . . . . . . . 73

4.6 Experimentos de Visualização do Escoamento . . . . . . . . . . . . . . . . 75

5 Conclusões e Perspectivas $\quad 78$

REFERÊnCIAS BIBLIOGRÁficas $\quad 81$

Apêndice A - Ensaios de Decaimento

A.1 Descrição Geral . . . . . . . . . . . . . . . . . . . . . . . 84

A.2 Procedimento de Execução e Análise . . . . . . . . . . . . . . . . . . 84

Apêndice B - Amplitudes para os Demais Graus de liberdade 88

B.1 Descrição Geral . . . . . . . . . . . . . . . . . . . . . . . . 88

B.2 Respostas de Heave, Roll e Pitch . . . . . . . . . . . . . . . . . . 88 


\section{INTRODUÇÃO}

\subsection{Contextualização do Problema de INTERESSE}

Com cerca de 97,50\% do planeta Terra coberto por água, as engenharias naval e oceânica sempre tiveram importância fundamental no cenário mundial, não apenas em relação ao segmento de transporte marítimo, como também na exploração de petróleo e gás, onde os avanços conquistados alavancaram as novas tecnologias disponíveis atualmente.

Na engenharia oceânica, desde que as primeiras plataformas foram instaladas, em 1947 no Golfo do México, o setor não parou de crescer e desenvolver novas soluções para os desafios envolvidos na retirada de hidrocarbonetos de pequenas a quilométricas lâminas d'água. No Brasil, a primeira plataforma foi construída pela Petrobras em 1969, a denominada P-1, com a função principal de perfurar poços e o objetivo estratégico de promover o desenvolvimento industrial nacional com a produção de petróleo no mar. Daquele ano em diante, novos conceitos de plataforma foram gradativamente sendo criados e aprimorados, sempre na busca pela exploração em águas cada vez mais profundas.

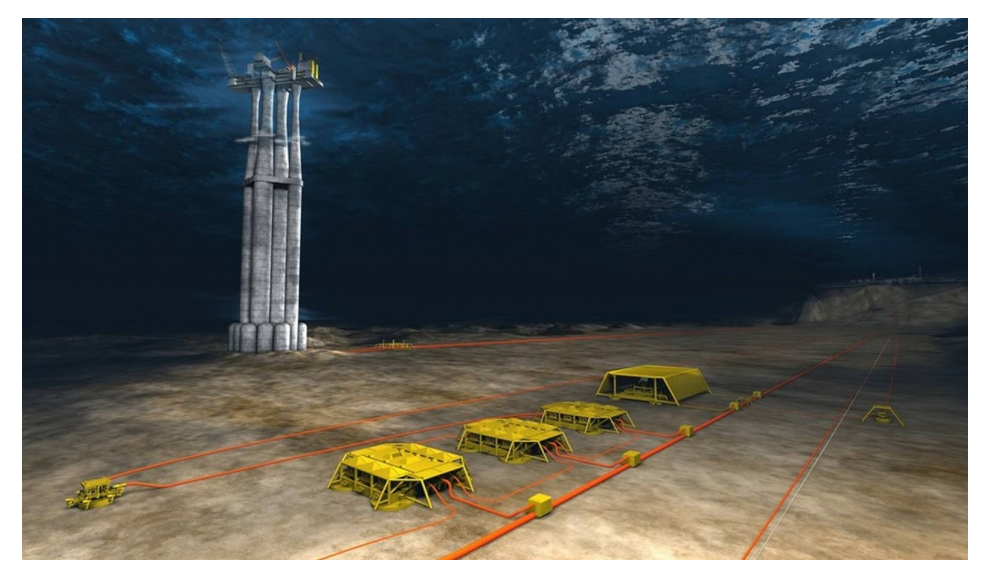

Figura 1.1: Plataforma fixa do tipo gravidade. [Fonte: STATOIL]

Inicialmente, devido às pequenas laminas d'água, cerca de 300 metros no máximo, as plataformas utilizadas eram fixas ao leito do mar. Focando na parte submersa, suas características eram marcadas por grandes estruturas treliçadas, com bases largas para garantir 
uma excelente estabilidade. Esta concepção, no entanto, exigia uma alta empregabilidade de aço para sua construção, acarretando altos custos para a indústria petrolífera. $\mathrm{Na}$ classe das plataformas fixas sugiram conceitos como: a jaqueta, a torre complacente, a plataforma auto-elevatória e a plataforma de gravidade - esta última ilustrada na Figura 1.1, a título de exemplo.

Com a busca pela maior produtividade de petróleo no mar, as áreas exploradas começaram a se afastar da costa, aumentando as lâminas d'água de maneira a impossibilitar a utilização de plataformas fixas em profundidade maiores do que 400 metros. A partir desse limite, região que caracteriza a exploração em águas profundas e ultraprofundas, surgiu a necessidade de desenvolvimento das plataformas flutuantes, ou seja, sistemas operando na superfície do mar e ancorados ao leito marinho por intermédio de um conjunto de amarras e âncoras.

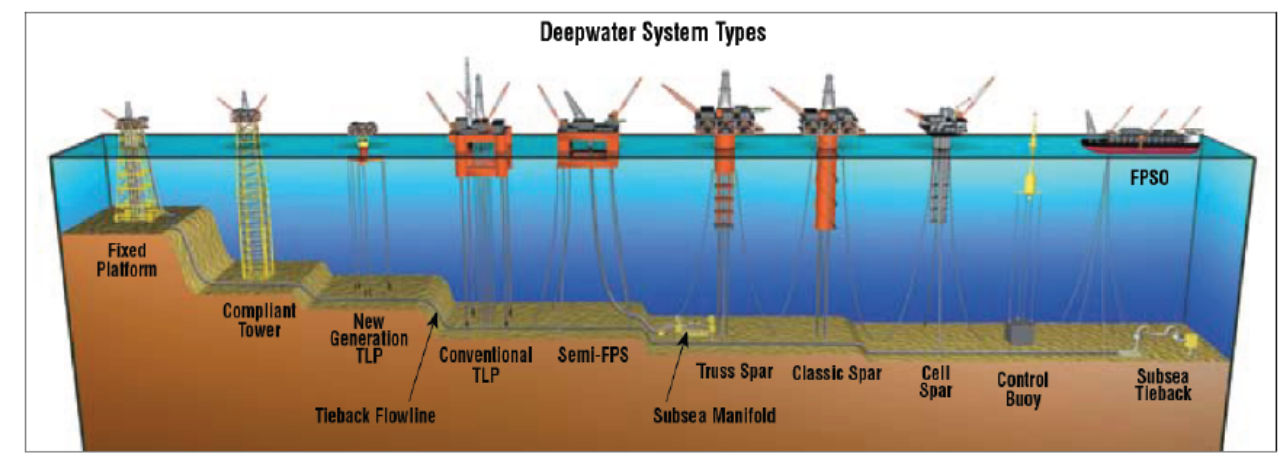

Figura 1.2: Principais tipos de plataformas para exploração no mar.

Atualmente, em relação à produção de petróleo e gás nas bacias de Campos e Santos no Brasil (esta última em camada pré-sal), as lâminas d'água ultrapassam os 2500 metros, tendo sua viabilidade produtiva estabelecida exclusivamente com a adoção das plataformas flutuantes. Assim sendo, as principais unidades flutuantes utilizadas têm sido (ver Figura 1.2):

- Os sistemas FPSO - Floating Production Storage and Offloading;

- As plataformas Semissubmersível;

- As plataformas TLP - Tension Leg Platforms;

- As plataformas Spar;

- E as plataformas Monocolunas.

Um dos problemas importantes com o surgimento das plataformas flutuantes foi a exposição dessas à correnteza marítima gerando as Vibrações Induzidas por Vórtices, ou 
simplesmente VIV (acrônimo do termo em inglês Vortex-Induced Vibrations), fenômeno que, de fato, é um problema bastante conhecido de interação fluido-estrutural na grande área mecânica.

Cumpre destacar que o VIV não é observado apenas em sistemas da indústria oceânica de petróleo e gás. Também pode ocorrer em outros sistemas de engenharia como, por exemplo, em condutores de trocadores de calor, em tirantes de pontes (suscetíveis a intensa movimentação pela incidência de ventos com altas velocidades) e em chaminés industriais (ver Figura 1.3, que mostra cinco chaminés dotadas de strakes, elementos que ajudam a diminuir a oscilação decorrente do VIV, maiores detalhes da fenomenologia são vistos no Capítulo 2).

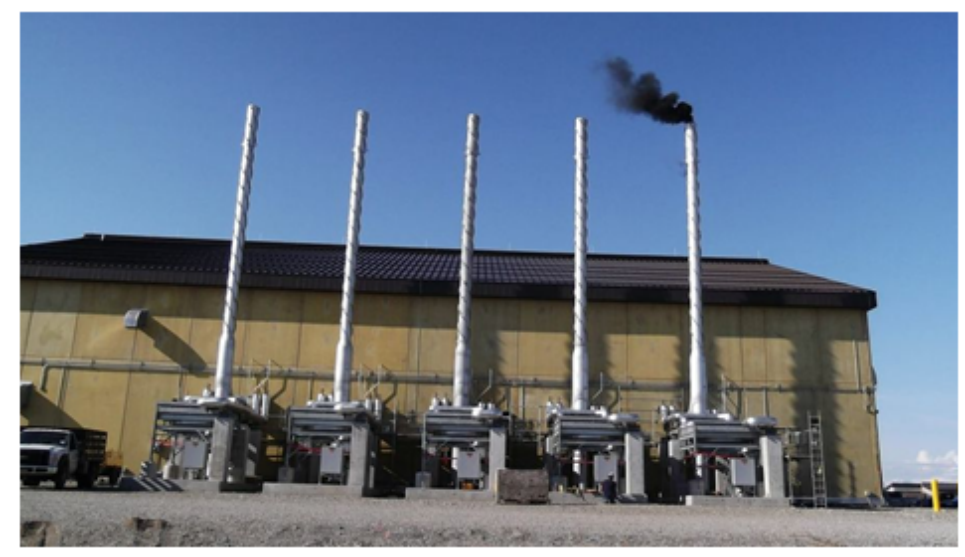

Figura 1.3: Chaminés industriais com supressores de VIV - strakes - em uma indústria no Alasca, EUA.

Independente do segmento da engenharia onde ocorra, o fenômeno de VIV tem sido intensamente investigado por conta dos inúmeros efeitos que parâmetros geométricos, inerciais, dissipativos e da própria excitação (escoamento fluido) desempenham sobre o mesmo. Portanto, é nesse contexto que a presente pesquisa se insere, buscando resposta para um aspecto fundamental que pode melhorar a compreensão do VIV em plataformas flutuantes. A próxima seção traz detalhes dessa motivação. 


\subsection{DEFINIÇÃo EspecíficA do Problema de INTERESSE}

Conforme exposto, a indústria de petróleo e gás no mar se viu obrigada a adotar as plataformas flutuantes como forma de viabilizar a produção em grandes lâminas d'água.

Esta solução, no entanto, gerou o inconveniente de expor essas plataformas à ação do fenômeno de VIV, que nesse cenário oceânico recebeu uma denominação particular em virtude dos grandes valores de períodos envolvidos - justificando a variação denominativa adotada: Movimentos Induzidos por Vórtices, ou simplesmente VIM (acrônico do termo em inglês Vortex-Induced Motions).

Assim sendo, em âmbito geral, este trabalho se dedica à análise indireta do fenômeno de VIM que atua em plataformas flutuantes mediante a ação da correnteza marinha. Importante lembrar que o VIM na plataforma flutuante impacta diretamente nos equipamentos que a ligam ao leito marinho, particularmente os risers e cabos umbilicais, fazendo com que a vida útil desses equipamentos diminua, levando ao desgaste prematuro e eventual colapso por fadiga.

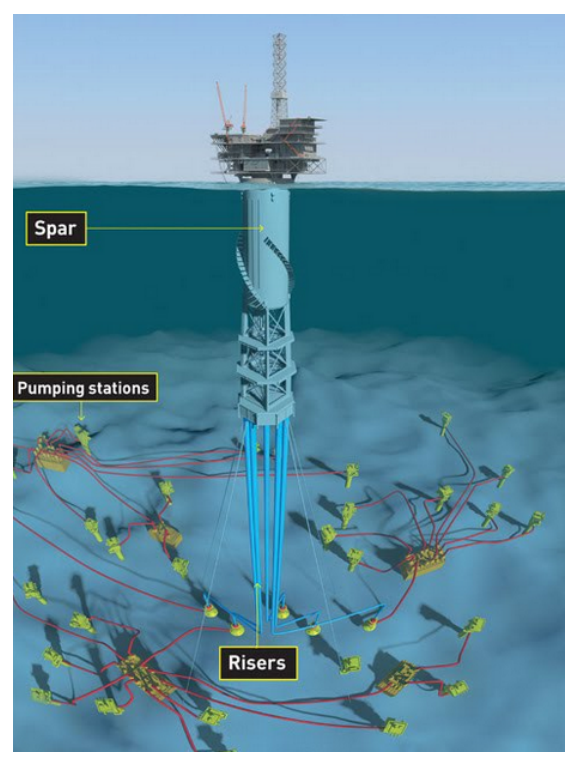

Figura 1.4: Plataforma flutuante do tipo Spar [Fonte: refineering.wordpress.com].

Em âmbito específico, sabe-se que cilindros livres e curtos - aqueles com pequena razão de aspecto $L / D$ (onde $L$ é o comprimento imerso e $D$ a dimensão característica da seção transversal) - apresentam um modelo complexo de emissão de vórtices responsável pelas oscilações. De acordo com trabalhos recentes, não há uma definição clara quanto à origem do fenômeno de VIV nesses casos, podendo estar associado à formação de um padrão de emissão de vórtices em forma de arco (arch-type vortex shedding), ou ter origem na alternância de vórtices que partem da ponta (tip vortices) e da aresta (trailing vortices), 
todos na extremidade imersa do cilindro.

No sentido de compreender melhor as respostas de VIV em cilindros flutuantes com uma pequena razão de aspecto e tentar buscar esclarecimento para o modelo fluido que dá origem ao fenômeno, o presente trabalho faz estudos mediante a modificação da geometria na extremidade submersa. Tais variações na geometria da extremidade imersa são uma tentativa de esclarecer o mecanismo de emissão de vórtices responsável pelo VIM em plataformas spar e monocolunas, tentando contribuir para o projeto e desenvolvimento de sistemas oceânicos como o ilustrado na Figura 1.4.

\subsection{Estabelecimento do OBjetivo}

Como foco principal este trabalho estuda as respostas devidas ao fenômeno de VIV agindo em cilindros flutuantes com baixa razão de aspecto, mediante a modificação da geometria na extremidade imersa.

Caracterizadas pelo gradativo arredondamento, quatro geometrias com razões distintas entre o raio de adoçamento e o raio do cilindro - especificamente $\mathrm{r} / \mathrm{R}=0,00 ; 0,25 ; 0,50 \mathrm{e}$ 1,00 - também são ensaiadas na busca por apontar o mecanismo de emissão de vórtices responsável pelo VIV em corpos flutuantes com razão de aspecto típica de $L / D=2$.

De antemão é importante destacar que, se o mecanismo de emissão responsável pelo VIV em cilindros curtos estiver relacionado com a alternância de vórtices que partem da ponta e da aresta, o gradativo arrendondamento da extremidade imersa deve indicar modificação sensível nas respostas. Do contrário, acreditar-se-à que, então, o mecanismo de origem do VIV esteja, de fato, predominantemente relacionado com a formação do padrão de emissão em formato de arco.

\subsection{ORganizaçÃo do TEXTO}

O presente texto inicia-se com esta introdução sobre o problema de interesse, seguida por sua definição específica e posterior estabelecimento do objetivo para a pesquisa como um todo.

Em seu Capitulo 2 é apresentada uma revisão bibliográfica dedicada ao escoamento em torno de corpos rombudos, que afeta decisivamente o campo de pressões próximo, bem como é dedicada aos fenômeno de VIV em cilindros longos e VIM em plataformas e 
cilindros curtos. Assim, divida em quatro seções, a revisão bibliográfica traz: o escoamento ao redor de cilindros fixos e livres para oscilar, com um ou mais graus de liberdade; a atuação e a importância do fenômeno de VIM na indústria oceânica; as principais características do fenômeno de VIV agindo em cilindros de baixa razão de aspecto e, por fim, os modelos de emissão junto à extremidade livre de cilindros curtos.

No Capitulo 3 é apresentada a metodologia de ensaio utilizada, ou seja, os principais materiais e métodos utilizados para investigar o fenômeno de VIV em cilindros curtos mediante a modificação da geometria na extremidade imersa dos mesmos.

O Capitulo 4, por sua vez, traz de maneira organizada uma síntese discutida dos resultados dos ensaios, iniciando com a comparação entre amplitudes adimensionais para as direções $\mathrm{X}$ e Y de oscilação, respectivamente longitudinais e transversais ao escoamento incidente, seguida pela apresentação das respectivas trajetórias no plano XY e pela apresentação das frequências adimensionais de oscilação. Além desses, também são apresentados resultados referentes às forças envolvidas (arrasto e sustentação), bem como algumas ilustrações junto aos modelos ensaiados.

A dissertação é finalizada com as conclusões do trabalho de pesquisa e a apresentação das perspectivas vislumbradas para uma eventual continuação da mesma. 


\section{Revisão BibliográficA}

\subsection{Fenomenologia Geral}

O fenômeno de Vibrações Induzidas por Vórtices (VIV) pode ser observado quando um corpo rombudo, livre para oscilar na direção transversal, é imerso em um escoamento de determinado fluido. Corpo rombudo, neste contexto, é todo aquele caracterizado pelo descolamento das linhas de corrente (ou separação da camada limite fluida) em grande parte de seu contorno, que geralmente acontece em duas regiões opostas, como no caso dos cilindros circulares. Mediante esse efeito da viscosidade do fluido, vórtices são formados a partir dos descolamentos, dando origem a um campo de pressões característico.

Importante destacar que a ocorrência de um gradiente adverso de pressão atuante na camada limite desacelera localmente o escoamento, resultando na separação mencionada. Assim, geometria do corpo e velocidade do escoamento têm influência direta nos locais onde ocorre a separação da camada limite.

Por sua vez, o campo de pressões formado da origem a duas forças principais: a de arrasto, que atua no sentido longitudinal à direção de incidência do escoamento, e a de sustentação, que atua na direção transversal ao mesmo.

Para melhor definição no contexto deste trabalho, exemplifica-se este comportamento fluido-elástico a partir de um cilindro circular de comprimento imerso $L$ e diâmetro $D$.

Antes disso, porém, cumpre destacar que os descritivos relacionados aos fenômenos de VIV e VIM apresentados nos próximos tópicos são feitos com base nos resultados encontrados em: (BLEVINS, 2001), (BEARMAN, 1984), (ASSI, 2005), (ASSI, 2009), (ZDRAVKOVICH, 1987), (FUJARRA, 2013), (GONçALVES, 2013).

Assim, sabe-se que todos os fenômenos viscosos relacionados ao escoamento incompressível no cilindro são regidos pelo número de Reynolds $R e$, definido como a razão entre forças inerciais e forças viscosas envolvidas no escoamento. Desta forma, o número de Reynolds é definido como mostra a Equação 2.1, sendo uma grandeza adimensional que relaciona 
parâmetros do corpo e do fluido - no caso dos cilindros circulares: o diâmetro $D$, a velocidade do escoamento incidente $U$ e a viscosidade cinemática do fluido $v$.

$$
\operatorname{Re}=\frac{U \cdot D}{v}
$$

Em um cilindro imerso em escoamento com baixos números de Reynolds, $5 \leq R e \leq 50$, é possível observar dois vórtices sendo formados a jusante do cilindro, Figura 2.1. Esses vórtices são constantemente alimentados pelo escoamento e, sem se desprenderem do cilindro, atuam como parte do mesmo. Tais estruturas fluidas são conhecidas na literatura como bolhas de recirculação, que crescem com o aumento do número de Reynolds. Nesta etapa, o escoamento é predominantemente viscoso, o que em conjunto com a parcela inercial do escoamento, promove a recirculação na porção à jusante do cilindro.

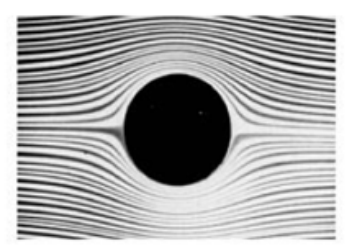

Sem separação

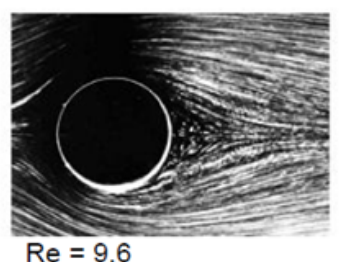

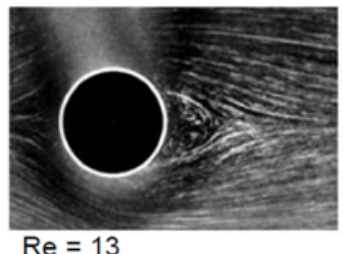

$\operatorname{Re}=13$

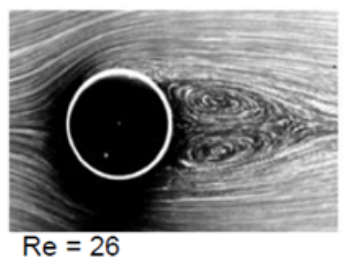

Figura 2.1: Bolhas de recirculação sendo formadas a jusante do cilindro. Fonte: (VANDYKE, 1982)

Tabela 2.1: Características do regime para escoamento uniforme em um cilindro.

\begin{tabular}{lc} 
Regime & Faixa de Reynolds \\
\hline Fluxo laminar & $\operatorname{Re}<1$ \\
Região de separação estacionária & $3-5<\operatorname{Re}<30-40$ \\
Esteira laminar periódica & $30-40<\operatorname{Re}<150-300$ \\
Regime subcrítico & $150-300<\operatorname{Re}<1,4 \cdot 10^{5}$ \\
Regime crítico & $1,4 \cdot 10^{5}<\operatorname{Re}<1 \cdot 10^{6}$ \\
Regime supercrítico & $1 \cdot 10^{6}<\operatorname{Re}<5 \cdot 10^{6}$ \\
\hline
\end{tabular}

Assim, em Achenbach e Heinecke (1981) são identificados seis tipos de regimes no escoamento junto ao corpo rombudo de seção circular, descritos conforme a Tabela 2.1. 
Com números de Reynolds superiores a 50, observa-se o aumento das bolhas de recirculação, até que em dado valor crítico ocorre a instabilidade desse modelo fluido, que dá início ao desprendimento alternado de vórtices de acordo com uma frequência bem definida, denominada frequência de desprendimento de vórtices $f s$.

Esse fenômeno de desprendimento alternado dos vórtices, por sua vez, constrói um padrão de emissão conhecido com "esteira de von Kármán", ilustrada na Figura 2.2 para os regimes laminar e turbulento.
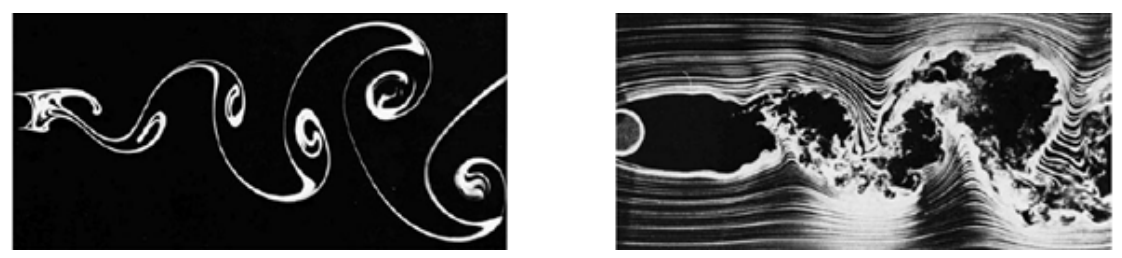

Figura 2.2: Esteira de Von Kármán: (a) regime laminar periódico e (b)turbulento. Fonte: (VANDYKE, 1982)

A frequência de emissão de vórtices é função do adimensional conhecido como número de Strouhal $S t$, que define a relação entre essa frequência e a escala de frequência característica do escoamento $U / D$.

A Equação 2.2 define de forma matemática o número de Strouhal. Em função da grande aplicação ao caso dos cilindros circulares, utiliza-se a variável $D$ em referência ao diâmetro, porém, no caso de outras geometrias de seção, essa dimensão será definida pela distância entre os dois pontos opostos onde são observados os desprendimentos de vórtices.

Para cilindros infinitos em escoamento bidimensional, tem-se o número de Strouhal variando em um faixa bastante estreita $0,18 \leq S t \leq 0,22$, segundo números de Reynolds que variam de $10^{2}$ a $10^{6}$.

$$
S t=\frac{f s D}{U}
$$

NORBERG, em seu trabalho de 2000, apresenta a relação entre o número de Strouhal com os respectivos números de Reynolds para cilindros estacionários; ver Figura 2.3.

Nos casos em que existe a liberdade para oscilar na direção transversal ao escoamento, sabe-se que o aumento gradativo da velocidade do escoamento eleva a frequência de emissão de vórtices até que essa atinja aproximadamente o valor da frequência natural do cilindro, colocando-o em oscilação.

Um aspecto particular, no entanto, difere este comportamento ressonante dos demais, 


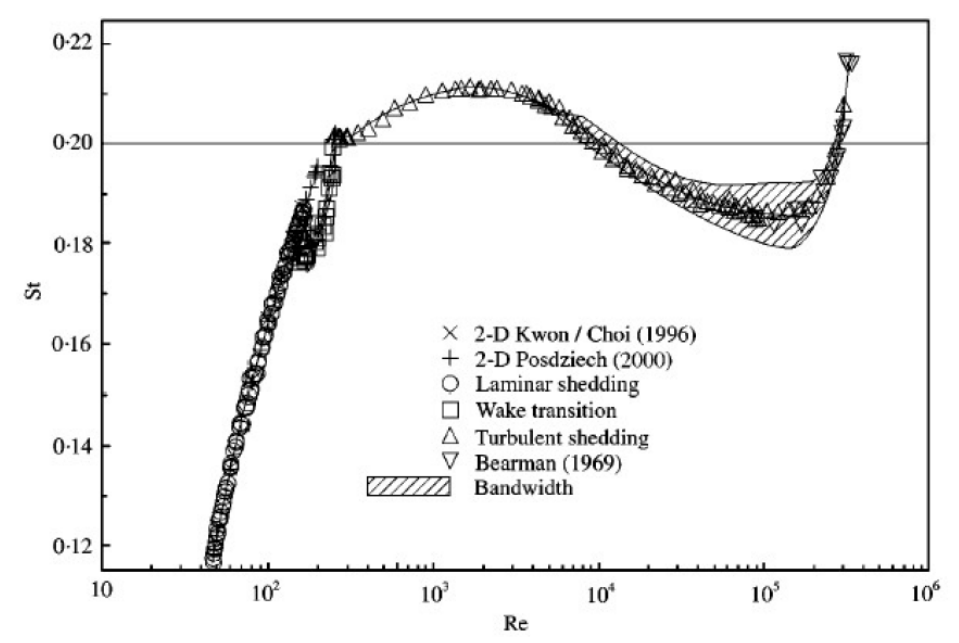

Figura 2.3: Relação entre número de Reynolds e o de Strouhal. (Fonte: (NORBERG, 2000)].

qual seja o fato de que, por uma faixa de velocidade superiores àquele que deu início às oscilações, a frequência de emissão se mantém aproximadamente igual à frequência natural do cilindro, $f s \approx f_{0}$.

Tal comportamento ressonante particular da emissão de vórtices em sistemas com liberdade de oscilar na direção transversal ao escoamento é conhecido como sincronização, ou lock-in, ilustrado na Figura 2.4.

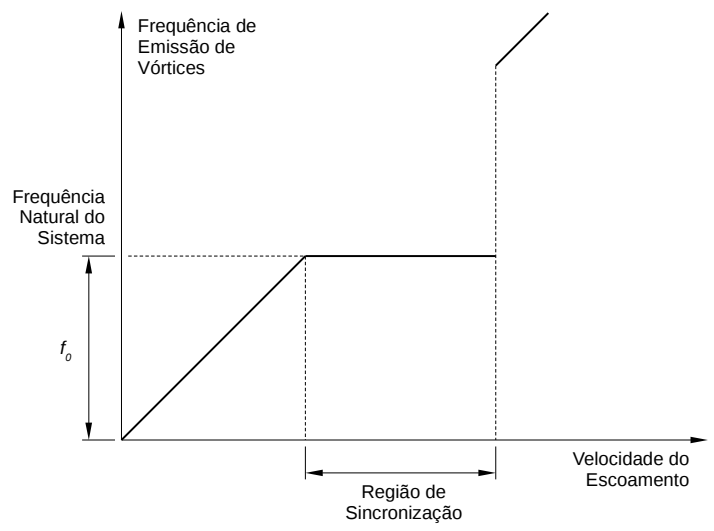

Figura 2.4: Caracterização qualitativa da sincronização.

Apresentados os parâmetros essenciais que descrevem a fenomenologia de interesse para este trabalho, o próximo tópico deste capítulo é dedicado à descrição da importância do fenômeno de vibrações/movimentos induzidos por vórtices para a indústria oceânica do petróleo e gás (particularmente nas atividades de prospecção, perfuração e produção). Na sequência, dois tópicos específicos são dedicados ao aprofundamento sobre o fenômeno de VIV agindo em cilindros com baixa razão de aspecto. 


\subsection{VIV-VIM NO SEGMENTO DA ENGENHARIA OCEÂNICA}

Os investimentos da indústria oceânica (também referida por seu termo em língua inglesa: offshore) tem promovido um grande avanço nas pesquisas relacionadas aos fenômenos de Vibrações Induzidas por Vórtices (VIV) e Movimentos Induzidos por Vórtices (VIM).

Assim sendo, como primeira ação descritiva desses fenômenos no cenário offshore, cumpre esclarecer as diferenças entre os dois fenômenos, VIV e VIM, ilustrando suas observações na exploração de hidrocarbonetos em ambiente marinho.

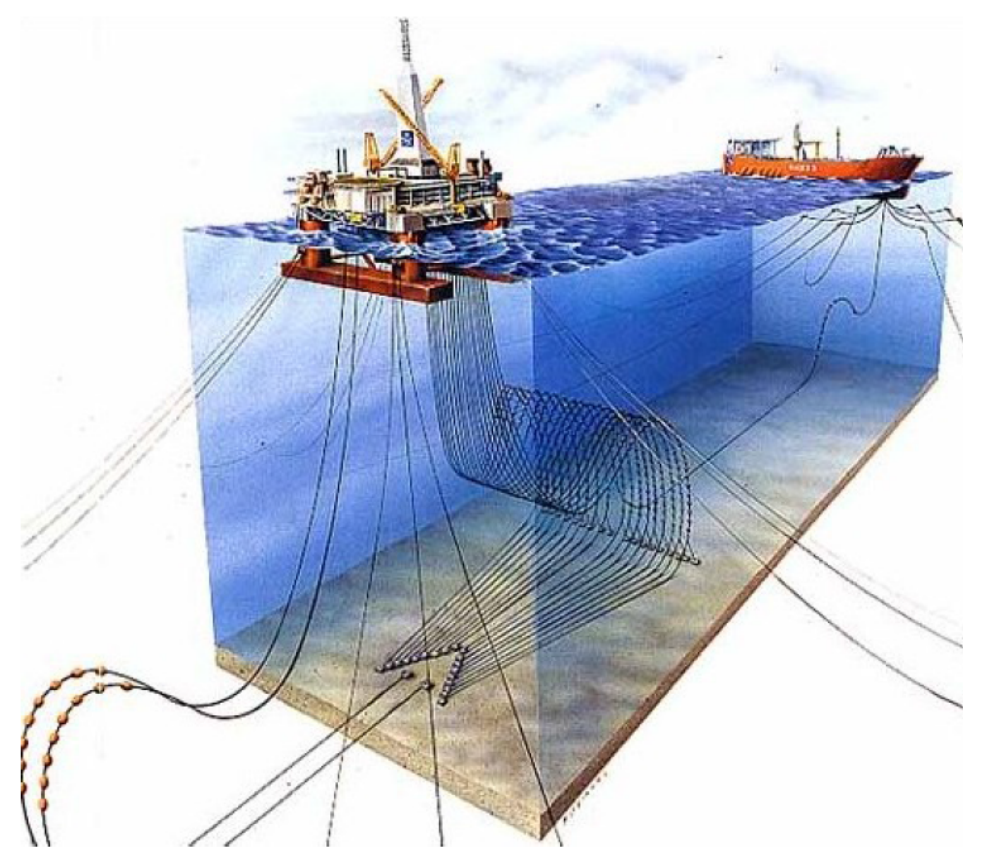

Figura 2.5: Linhas de amarração e risers ligadas a unidades flutuantes do tipo semissubmersível e FPSO. [Fonte: www.offshore-technology.com].

O fenômeno de VIV pode ser observado em diversas aplicações nas instalações oceânicas de grande esbeltez, principalmente aquelas destinadas à exploração de óleo e gás. Como exemplo típico, pode-se citar sua ocorrência nas linhas flexíveis conhecidas como risers, utilizadas para a elevação dos hidrocarbonetos a partir do leito ou também para a injeção de água nos reservatórios. A Figura 2.5 exemplifica a disposição dessas linhas que interligam a plataforma ao leito marinho.

O estudo mais completo da ação do VIV nas linhas oceânicas deve considerar não apenas sua característica unimodal típica, mas os efeitos promovidos pela geometria de lançamento (normalmente em catenária), pelo tipo de incidência da correnteza marinha (variável em intensidade e direção), a imposição de movimentos no topo, entre outros aspectos. Detalhes sobre efeitos desta natureza podem ser encontrados em trabalhos como: 
(PESCE, 1997), (MALTA, 2015), (TSUKADA; MOROOKA, 2016) e (FRANZINI et al., 2016). Tubulações submersas utilizadas para interligação de poços a equipamentos também são outro bom exemplo de estruturas oceânicas suscetíveis ao VIV, nesses casos o estudo do vão livre causado pelas imperfeições do solo marinho é de extrema importância para identificar a característica das vibrações promovidas pela correnteza e, então, estimar seus danos para a fadiga.

O fenômeno de VIM, por sua vez, foi incorporado à literatura no início da década de 90, decorrente da instalação das primeiras plataformas spar no Golfo do México. Em linhas gerais, hoje se sabe que o VIM possui a mesma fenomenologia do VIV, recebendo uma designação diferente devido principalmente à ordem de grandeza dos períodos atuantes nas plataformas. Nesses casos, a movimentação no plano da superfície do mar se deve à incidência de correntezas com magnitudes da ordem de $1 \mathrm{~m} / \mathrm{s}$, resultando em números de Reynolds bastante altos, $R e>10^{6}$. Além disso, as plataformas flutuantes exitadas pelo VIM apresentam seis graus de liberdade $(6 \mathrm{GL})$ e geometria típica com pequena imersão em água, ou seja, baixa razão de aspecto, $1 \leq L / D \leq 6$, como ilustra a Figura 2.6.
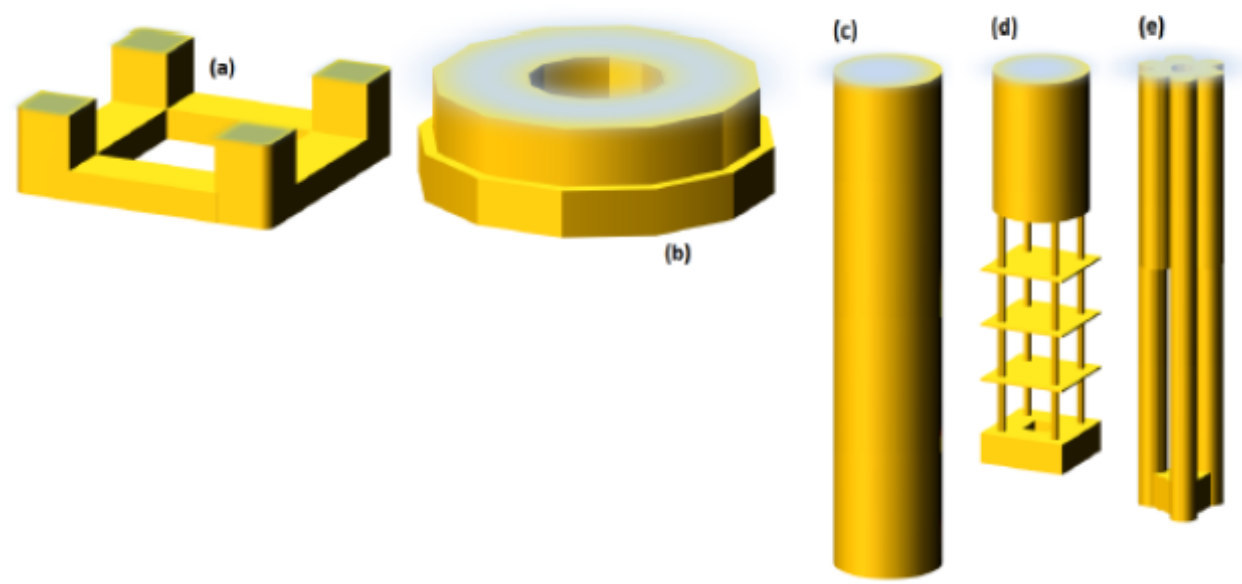

Figura 2.6: Principais plataformas flutuantes suscetíveis ao VIM. Tipos: (a) Semisubmersível, (b) monocoluna, (c) classic spar, (d) truss spar e (e) cell spar. [Fonte: (FUJARRA, 2013)].

No tocante ao VIM, HALKYARD publicou em 1991 um dos primeiros trabalhos voltados a análise em corpo flutuante de formato cilíndrico. Ainda assim, foi somente nos anos de 2000 a 2010, que ocorreu o maior aprofundamento científico sobre o assunto, tendo como exemplo os resultados publicados em (YUNG et al., 2004), que estabelecem o primeiro procedimento mais embasado de investigação do VIM em cascos de spar. O trabalho de YUNG et al. também relata a ação de duas correntezas características que são as principais causadoras do VIM no campo de Hoover (indicado pela estrela na Figura 2.7) - as 
denominadas eddy currents (correntes circulares que chegam a ter cerca de 322 quilômetros de diâmetro) e as loop currents (correntes que entram no Golfo pela Península de Yucatan e retornam para o Oceano Atlântico pela costa do estado da Florida.

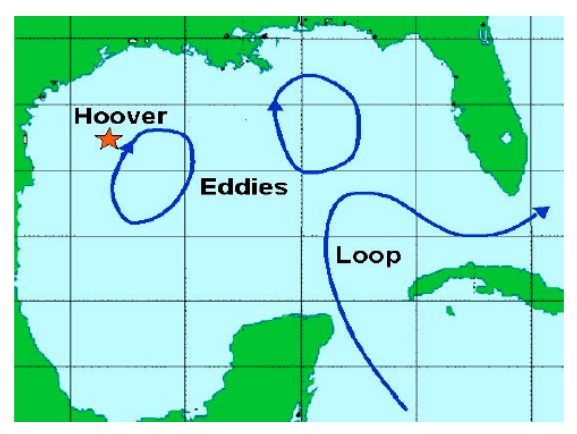

Figura 2.7: Correntes atuantes no Golfo do México [Fonte: (YUNG et al., 2004)].

De uma maneira geral, a importância do estudo do VIM se dá fundamentalmente para o entendimento e caracterização do fenômeno, elaborando meios que visem a mitigação de seu impacto sobre os subsistemas de risers, umbilicais e de amarração. Neste sentido, uma primeira proposição pode ser encontrada em (KOKKINIS et al., 2004), onde um procedimento para mitigar os efeitos do VIM é proposto com base no tensionamento das linhas de amarração de uma plataforma do tipo classic spar, também localizada no Golfo do México.

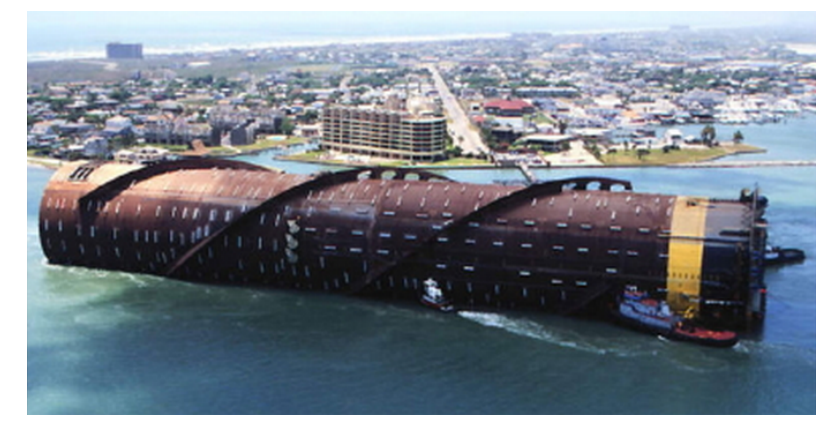

Figura 2.8: Casco de uma plataforma do tipo spar com strakes helicoidais [Fonte: Imperial College, London].

Buscando evitar grandes amplitudes de deslocamento com base em intervenções nos cascos das plataformas, em (FINN et al., 2003) e (FOURCHY; MIRZA, 2003) é proposta a anexação de elementos helicoidais no casco das plataformas spar, denominados strakes. Esses elementos fixam os pontos de separação do escoamento em diferentes posições ao longo do comprimento imerso da spar - o que não ocorre nos cilindros lisos -, resultando em expressivas reduções na amplitude transversal do corpo flutuante.

De maneira mais clara, os strakes são elementos estruturados em chapa reforçada de aço, moldados helicoidalmente e soldados no casco sujeito à correnteza. A Figura 2.8 mostra 
um casco de spar dotado de strakes na condição de transporte até o local de operação no Golfo do México, onde foi verticalizado.

Um dos testes encontrados em (FINN et al., 2003), graficamente sintetizado na Figura 2.9, mostra a atuação dos strakes na mitigação da amplitude de movimento na direção transversal ao escoamento. De acordo com o gráfico, percebe-se claramente que o aumento do comprimento recoberto por strakes aumenta a mitigação do VIM na spar.

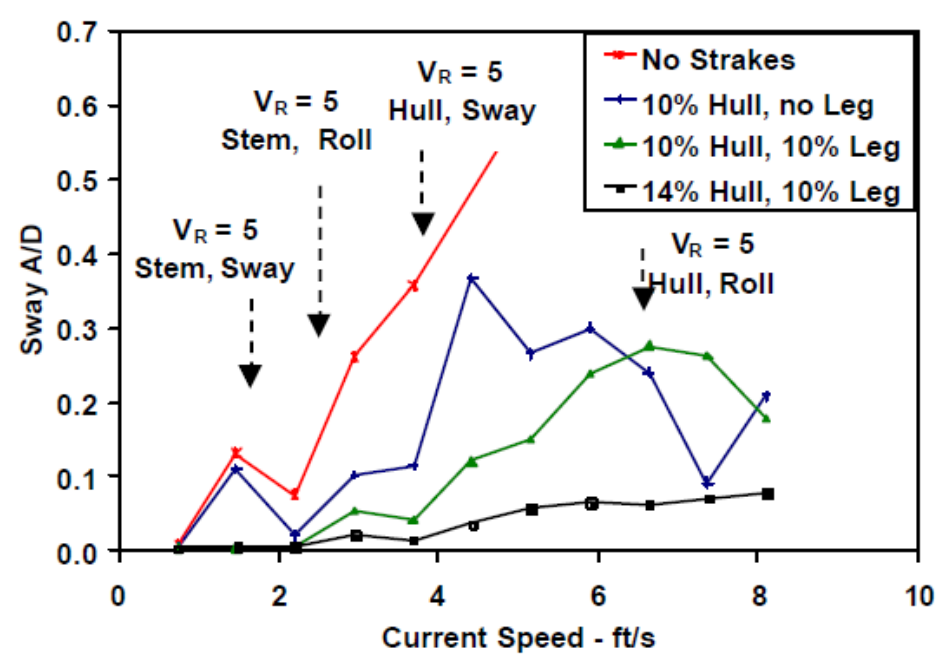

Figura 2.9: Amplitude adimensional em função da velocidade da correnteza, sem a presença de strakes e com diferentes ocupações de strakes nas áreas externas do casco. [Fonte: (FINN et al., 2003)].

Consolidada a eficácia dos strakes como mitigadores do VIM, deu-se início a sua aplicação no projeto e construção das plataformas, não sem grandes somas de recursos devido à enorme complexidade geométrica envolvida. Os altos custos envolvidos, por outro lado, mantiveram a busca por novas soluções de mitigação do VIM e, principalmente, por adaptações nas plataformas já operando sob ação dele.

Em (RODDIER et al., 2009) são apresentados experimentos com diferentes tipos de apêndices acoplados ao casco, testados em diferentes condições de escoamento e ângulos de incidência, contemplando números de Reynolds de regimes subcríticos até supercríticos. Na Figura 2.10 são ilustradas as versões de supressão estudadas: iniciando com a inclusão de ânodos de sacrifício e strakes (Variation 1); posteriormente, mantendo apenas os strakes no casco (Variation 2); em seguida, adicionando correntes, dutos e os strakes (Variation 3); e, por fim, considerando correntes, dutos, ânodos de sacrifício e strakes solidários ao casco (Base Case).

A Figura 2.10 também apresenta o gráfico das amplitudes adimencionais para as diferentes velocidades reduzidas ensaiadas e as quatro variações consideradas. De acordo com esse 


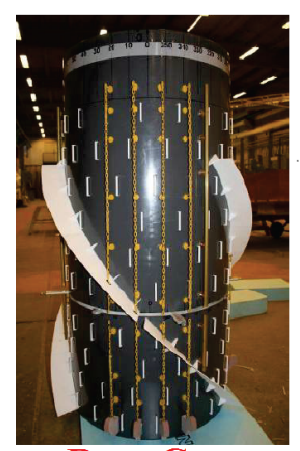

Base Case

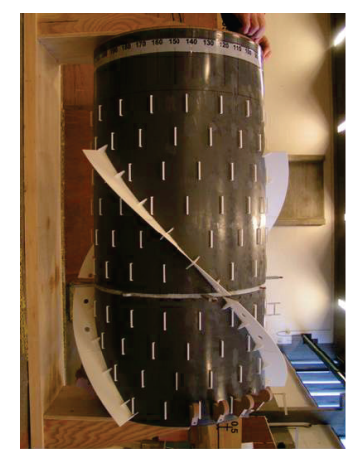

Variation 1

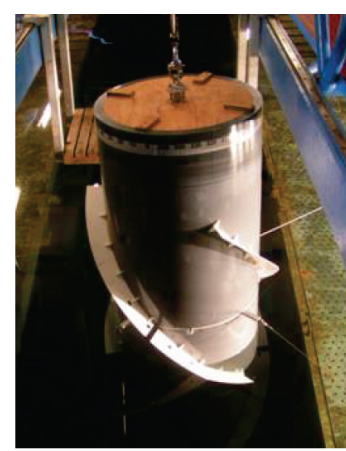

Variation 2

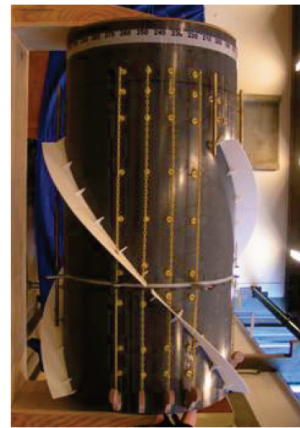

Variation 3

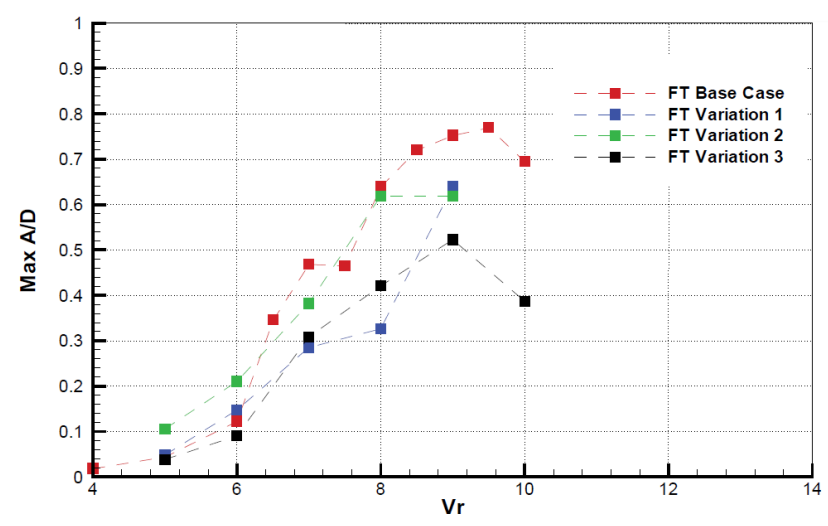

Figura 2.10: No alto, modelos de plataforma spar com diferentes apêndices no casco; Abaixo, gráfico analisando as diferenças de amplitude para cada caso em função da velocidade reduzida. [Fonte: (RODDIER et al., 2009)]

gráfico, o caso base (Base Case) apresenta as maiores amplitudes em comparação às respostas dos demais casos. Além disso, ânodos de sacrifício juntamente com strakes (Variation 1) apresentaram resultados similares ao modelo somente com strakes (Variation 2), exceção feita ao comportamento na região de velocidade reduzida igual a 8 . Por outro lado, o modelo com correntes, dutos e strakes (Variation 3) mostra o comportamento com menores amplitudes.

Apresentados os principais aspectos do fenômeno de VIV-VIM nos sistemas oceânicos que mais interessam a este trabalho (cilindros flutuantes com baixa razão de aspecto), os dois próximos tópicos se dedicam ao aprofundamento na caracterização fenomenológica que embasa os questionamentos precursores das investigações experimentais realizadas no âmbito deste mestrado.

\subsection{FenOMENOLOGia EsPeCíficA}

Esta seção trata especificamente do fenômeno VIV em cilindros sob circunstâncias que interessam a pesquisa mais adiante apresentada. 


\subsubsection{Graus de Liberdade}

Primeiramente, mostra-se importante descrever como respondem ao VIV os sistemas com um e dois graus de liberdade (1GL e $2 \mathrm{GL})$.

Inciando com o sistema de 1GL, onde o movimento do corpo acontece apenas na direção transversal ao escoamento, ver Figura 2.11, sabe-se que grande parte dos trabalhos relacionados ao estudo do VIV tratam este tipo de condição, ou seja, levam em consideração apenas força de sustentação atuante na direção transversal do cilindro.

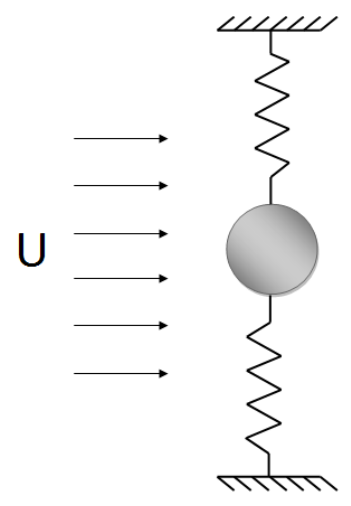

$1 \mathrm{GL}$

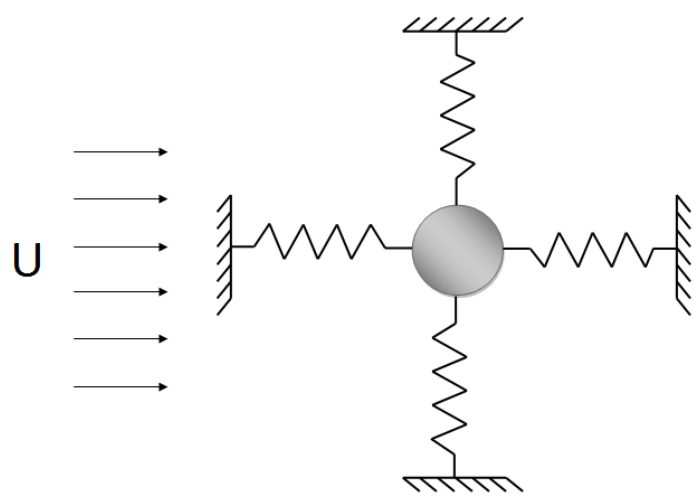

$2 \mathrm{GL}$

Figura 2.11: Esquema para oscilação em 1 grau de liberdade e 2 graus de liberdade.

Com a finalidade de equacionar esse movimento transversal ao escoamento (direção y), considera-se o problema do cilindro rígido com massa total $m$, amortecimento $c$ e constante de restauração $k$, forçado por $F(t)$ :

$$
m \ddot{y}+c \dot{y}+k y=F(t)
$$

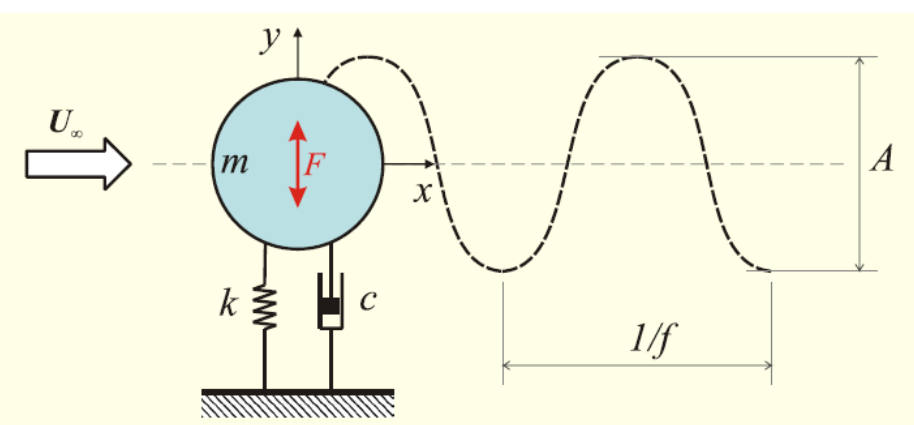

Figura 2.12: Sistema com um cilindro um grau de liberdade (1GL). [Fonte: (ASSI, 2005)].

A Figura 2.12 mostra uma vista de todo de um cilindro com comprimento $L$, destacando ao longo de um ciclo completo de seu movimento a amplitude $A$ e o período formado 
$T=1 / f$. Importante destacar que, conforme mencionado, no caso de 1GL, a forçante de interesse para a modelagem da dinâmica do sistema deve-se exclusivamente à força de sustentação $F_{L}$, usualmente caracterizada como função do coeficiente de sustentação, ou seja:

$$
F_{L}=\frac{1}{2} \rho C_{L} U^{2} D L
$$

Naturalmente, as flutuações no campo de pressão junto ao cilindro também dão origem a uma força de arrasto $F_{D}$, analogamente descrita como:

$$
F_{D}=\frac{1}{2} \rho C_{D} U^{2} D L
$$

informação importante para o tratamento feito mais adiante em relação à excitação simultânea das vibrações na direção do escoamento.

O gráfico da Figura 2.13 mostra comportamentos típicos da amplitude de resposta do VIV na direção transversal ao escoamento, apresentados como função da velocidade reduzida $U^{*}=V r$, parâmetro adimensional que relacionada a velocidade do escoamento com o produto da frequência natural do cilindro na direção transversal obtida em água $f_{0}$ e o seu diâmetro $D$ :

$$
V r=\frac{U}{f_{0} D}
$$

O mesmo gráfico da Figura 2.13 mostra também a influência de outro parâmetro importante para a resposta do VIV agindo em cilindros, qual seja a massa reduzida $m^{*}$, parâmetro adimensional de extrema importância que relaciona a massa do sistema em oscilação devida ao VIV,$m_{s}$, com a massa do fluido deslocado por esse sistema, $m_{d}$ :

$$
m^{*}=\frac{m_{s}}{m_{d}}
$$

De fato, segundo investigações mais recentes, não apenas a massa reduzida, mas o produto dessa pelo coeficiente de amortecimento $\zeta$ determinam a variação da amplitude na faixa de sincronização característica do VIV, $4 \lesssim V r \lesssim 10$.

Assim, nota-se que sistemas com menores amplitudes de resposta estão relacionados a valores maiores do produto entre massa reduzida e o coeficiente de amortecimento, exemplo de comportamento encontrado por FENG (1968) com experimentos de VIV no ar, enquanto sistemas com menores valores de $m^{*} \zeta$ exibem amplitudes de resposta maiores, como aqueles encontrados em (KHALAK; WILLIAMSON, 1999), a partir de ensaios em água. 


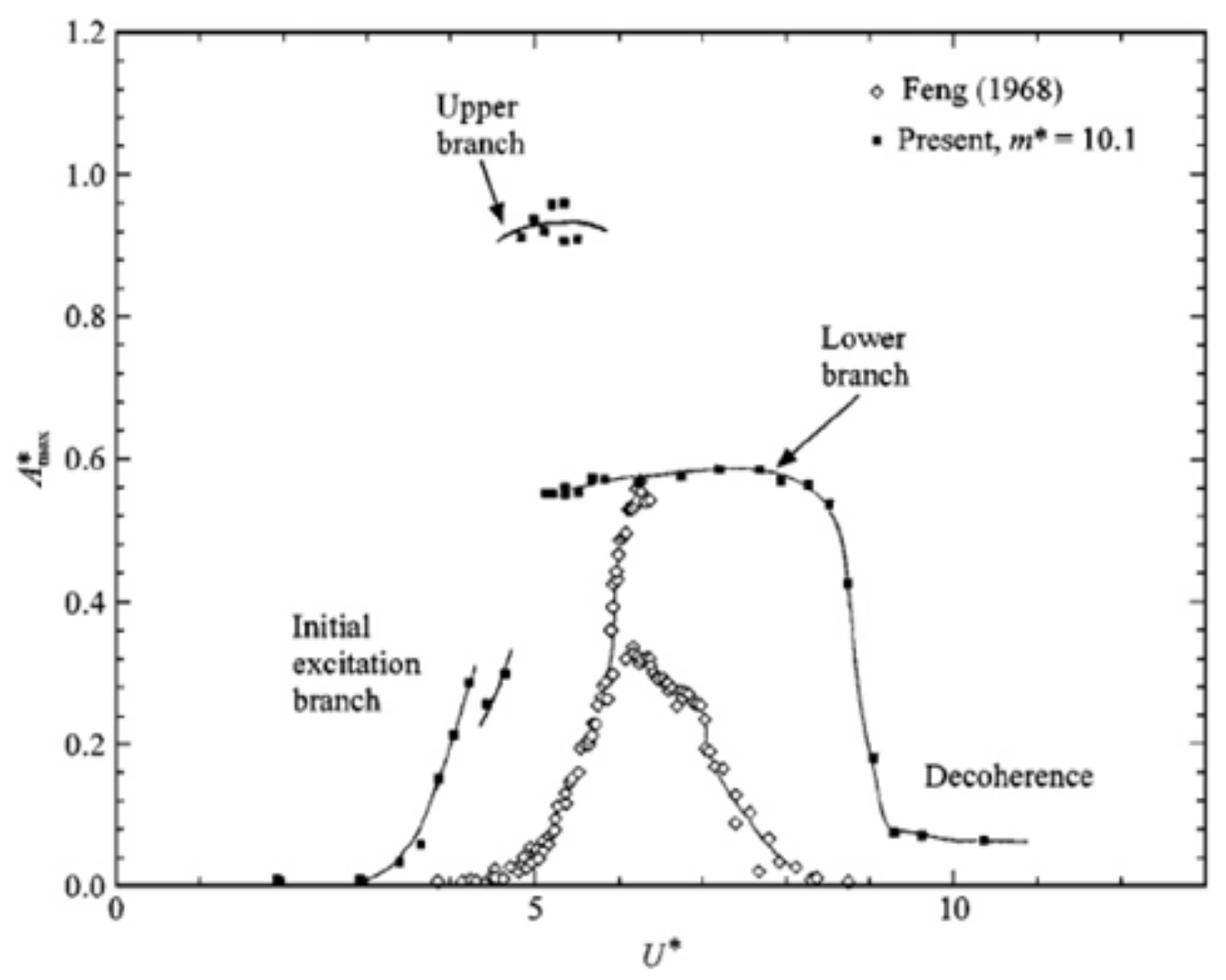

Figura 2.13: Amplitudes transversais de oscilação para dois cilindros com parâmetro de massa-amortecimento distintos. $m^{*} \zeta=3,28$ [Fonte: (FENG, 1968)] e $m^{*} \zeta=0,13$ [Fonte: (KHALAK; WILLIAMSON, 1999)].

Ainda em relação ao comportamento dinâmico dos sistemas com valores de $m^{*} \zeta$, notase uma distinção clara entre ramos de resposta dentro da faixa de sincronização. Desta forma, tem-se uma ramo inicial de resposta (initial branch, em 3,5 $\lesssim r \lesssim 4,5$ ), seguido do ramo superior, com as maiores amplitudes de resposta (upper branch, $4,5<V r \lesssim 6$ ), e, então, o ramo inferior nas velocidade mais altas da faixa de sincronização (lower branch, em $6<V r \lesssim 10)$.

Para os sistemas de 2GL, o fenomenologia da sincronização se mantém para as oscilações na direção transversal ao escoamento, mas com amplitudes ainda maiores em função de acoplamentos com as oscilações na direção do escoamento, cuja frequência característica é o dobro da frequência de emissão de vórtices.

O trabalho (JAUVTIS; WILLIAMSON, 2004) traz um bom exemplo do comportamento de cilindros com 2GL excitados pelo VIV, Figura 2.14. De acordo com essa figura, além dos ramos inicial e inferior, nota-se o surgimento de pequenas oscilações na região de $2,5<V r \lesssim 4$, anterior ao início da sincronização descrita para os cilindros com apenas 1GL. Tal região está relacionada ao grau de liberdade na direção do escoamento (direção X), 
excitado pelos padrões simétrico e assimétrico de emissão de vórtices nessas velocidades mais baixas de escoamento. Este acoplamento entre oscilações nos 2GL é claramente identificado pelas trajetórias em "formato de 8" no plano XY.

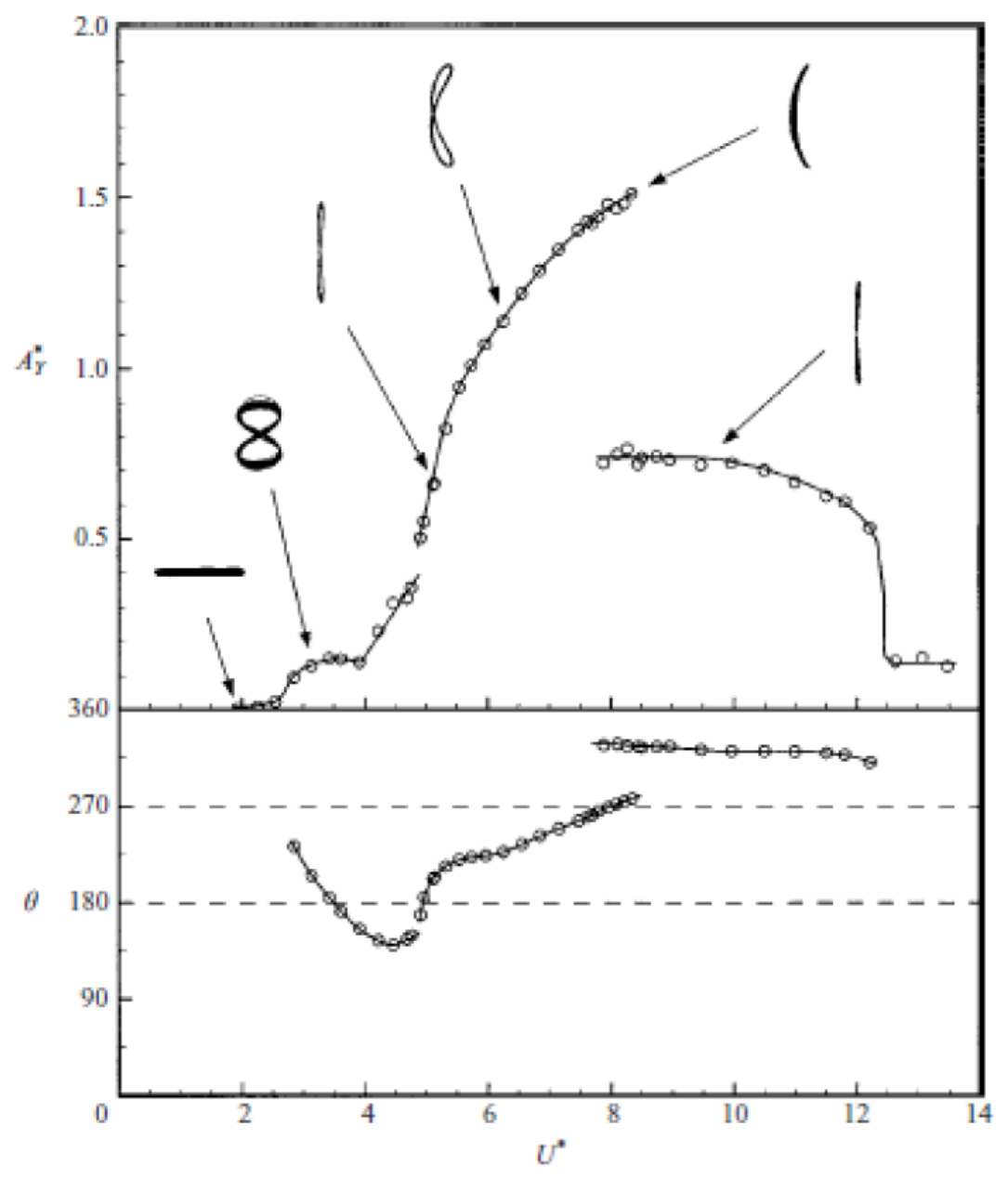

Figura 2.14: Curva descrita por um cilindro livre para oscilar mostrado dua amplitude adimensional de deslocamento transversal pela velocidade reduzida. [Fonte: (JAUVTIS; WILLIAMSON, 2004)].

Além disso, nota-se que as amplitudes na região do ramo superior (upper branch) se mostram ainda maiores, também motivadas pelo acoplamento entre oscilações transversais e longitudinais, só que neste caso, dentro da faixa de sincronização das oscilações transversais de maior amplitude (1,5 vezes o diâmetro do cilindro), o que também se traduz em trajetórias em "formato de 8" no plano XY.

Aplicada a uma unidade flutuante com 2GL e geometria cilíndrica aproximadamente circular, é possível observar o mesmo comportamento em termos das trajetórias na superfície livre (plano XY), o que corrobora a relação íntima entre os fenômenos de VIV e VIM. A Figura 2.15 mostra a incidência de correnteza em uma plataforma monocoluna, com destaque (em vermelho) para a trajetória em "formato de 8" devido ao VIM no plano da 
superfície libre.

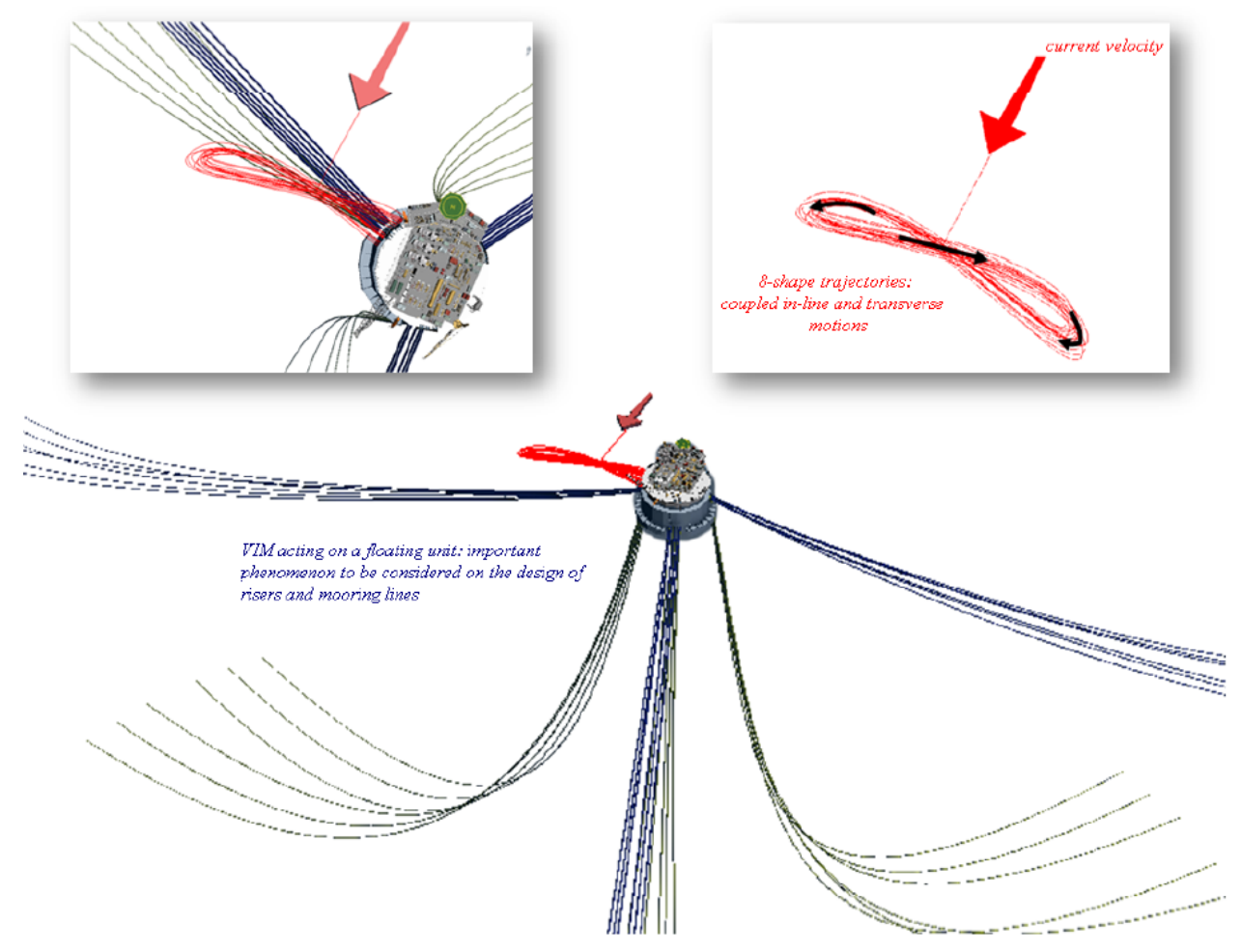

Figura 2.15: Plataforma monocoluna sob ação de correnteza e realizando uma movimentação (indicada pelas linhas vermelhas) em formato de "8"típico do fenômeno de VIM. [Fonte: (Fujarra, 2013)].

O próximo tópico desta revisão bibliográfica traz subsídios fenomenológicos a respeito dos modelos de emissão fluida junto aos cilindros curtos, ou seja, caracterizados por uma pequena razão de aspecto.

\subsubsection{Extremidade Livre em Cilindros Curtos}

Ainda no tocante à caracterização fenomenológica, há que se considerar que a razão de aspecto $L / D$, definida como a relação entre o comprimento e o diâmetro do cilindro, tem papel fundamental na definição dos padrões de emissão de vórtices.

Em linhas gerais, sabe-se que nos cilindros longos, $L / D>13$, a emissão de vórtices ao longo do comprimento é bastante correlacionada, com efeitos tridimensionais menos importantes, confinados à(s) pequena(s) região(ões) de ponta. Já para os cilindros com razão de aspecto $L / D<6$, os denominados cilindros curtos, observa-se que a emissão de vórtices a partir da extremidade livre afeta total ou parcialmente a emissão de vórtices ao longo do comprimento; mecanismo que será foco das atenções deste trabalho. 
Uma das primeiras proposições originais para o modelo de emissão tridimensional de vórtices junto aos cilindros curtos é apresentada em (KAWAMURA et al., 1984), baseada em experimentos com cilindros fixos de $1 \leq L / D \leq 8$. Entre os resultados apresentados pelo trabalho, chama a atenção a descrição de um par de vórtices emitidos a partir da aresta na extremidade livre do cilindro, os denominados trailing vortices, que interferem diretamente na esteira de von Kármán mais abaixo da ponta; mecanismo de influência conhecido como downwash, termo que na aeronáutica refere-se a uma mudança de direção do escoamento devido a uma perturbação aerodinâmica.
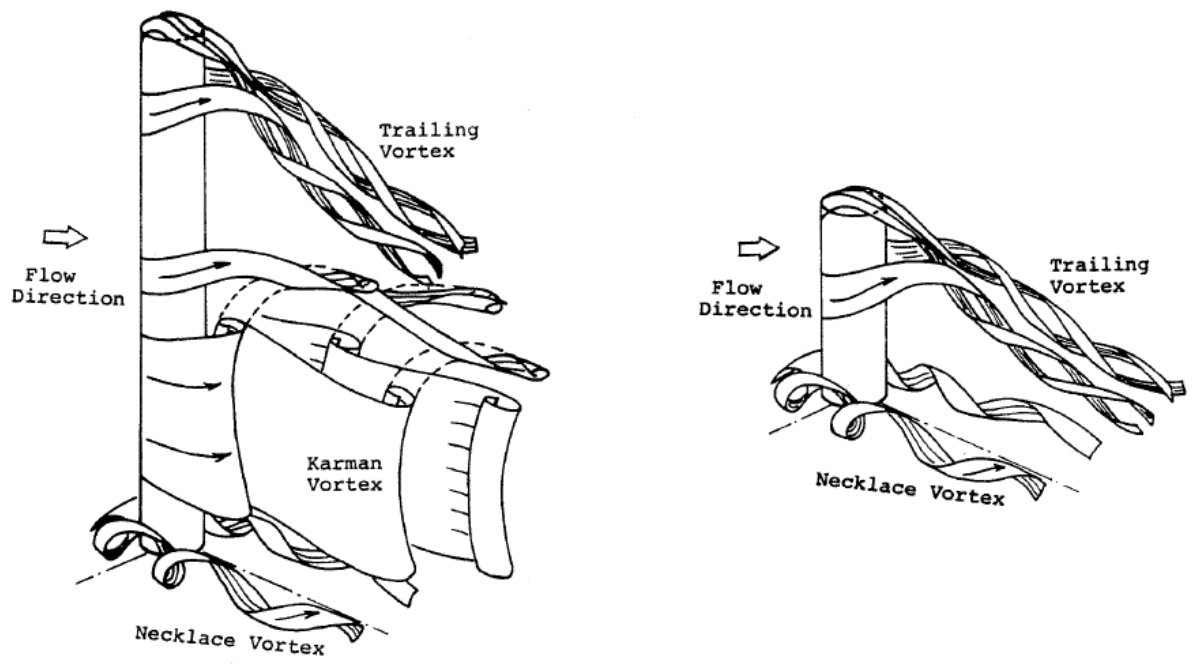

Figura 2.16: Escoamento ao redor de cilindros fixos de baixa razão de aspecto: (a) $L / D>$ $(L / D)_{c r}$ e (b) $L / D<(L / D)_{c r}$ [Fonte: (KAWAMURA et al., 1984)].

A partir da caracterização do efeito do downwash nos cilindros com $1 \leq L / D \leq 8$, KAWAMURA et al. definiram uma razão de aspecto crítica, $L / D_{c r} \cong 2$, a partir da qual a esteira de von Kármán era completamente extinta.

A Figura 2.16 ilustra o modelo fluido para dois cilindros de baixa razão de aspecto: um com valores de $L / D$ acima do valor crítico, portanto, passível de convivência com o padrão de von Kármán; e outro para valores de $L / D$ abaixo da razão de aspecto crítica, onde as emissões da extremidade livre dominam a região à jusante do cilindro. Importante salientar que esta fenomenologia se refere aos cilindros curtos fixos.

Outra conclusão importante do trabalho de (KAWAMURA et al., 1984), diz respeito à diminuição da força de arrasto nos cilindros curtos, quando comparada àquelas medidas usualmente em cilindros longos. Tal diferença é atribuída à diminuição da velocidade do escoamento próximo às bordas da camada limite, com isso propõe o acontecimento de uma mudança no local onde é observada a separação da camada limite, que é deslocada mais 
a jusante do escoamento, ocasionando assim, uma diminuição na velocidade de separação do escoamento na parede.

Praticamente concomitante aos trabalhos de KAWAMURA et al., um estudo com cilindros de seção quadrada ou circular, fixos e posicionados verticalmente em escoamento turbulento, é realizado por (SAKAMOTO; ARIE, 1983) em túnel de vento. De maneira geral, o propósito desse trabalho também foi a investigação do efeito da razão de aspecto no escoamento, observando a topologia e a interação dos vórtices formados junto aos cilindros curtos, bem como a influência da camada limite do túnel de vento nas frequências de emissão.

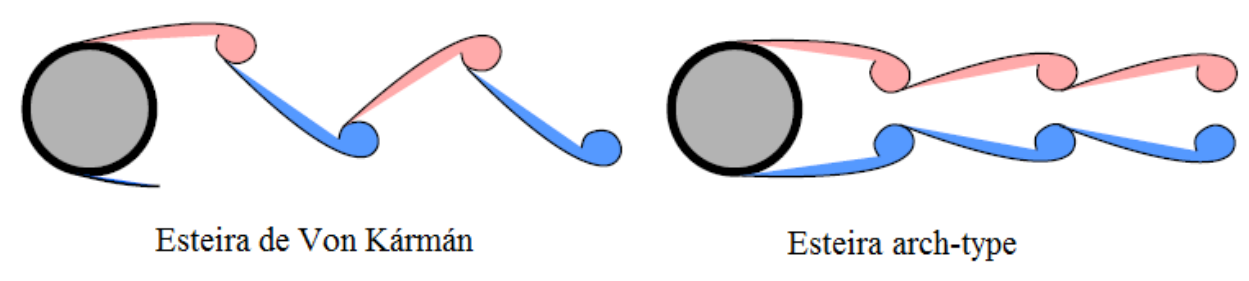

Figura 2.17: Tipos de esteiras geradas pelos cilindros curtos, segundo (SAKAMOTO; ARIE, 1983).

O que SAKAMOTO; ARIE acabaram observando foi que haveria uma diferença na forma como os vórtices são desprendidos junto aos cilindros curtos. Ao invés da esteira de von Kármán tradicional e alternada, os autores observaram que para os cilindros mais curtos a liberação de vórtices aconteceria de maneira simétrica, caracterizada por um padrão em forma de arco, ou os denominados arch-type vortices. A Figura 2.17 mostra a diferença entre os dois tipos de emissão, sendo que, segundo os autores, em $L / D_{c r}<2,5$ aconteceria a transição do padrão de von Kármán para o padrão em forma de arco.

Neste ponto é importante salientar que o foco das investigações iniciais com cilindros curtos era voltado para as grandes torres e chaminés em camada limite atmosférica. Sendo assim, a enorme maioria das investigações neste assunto eram desenvolvidas com base em cilindros curtos fixos em uma superfície plana estacionária. Os arranjos experimentais eram imersos totalmente em escoamento fluido, mantendo os cilindros parcialmente expostos à camada limite da superfície de fixação (definida segundo a espessura $\boldsymbol{\delta}$ ); a Figura 2.18 faz uma representação deste arranjo experimental.

A exemplo de (KAWAMURA et al., 1984) e (SAKAMOTO; ARIE, 1983), muitos trabalhos tiveram preocupação com os efeitos dessa camada limite e, portanto, compuseram uma descrição mais adequada da fenomenologia junto aos cilindros curtos fixos.

Outro tipo de arranjo para os ensaios com cilindros curtos fixos $(1 \leq L / D \leq 10)$ pode 


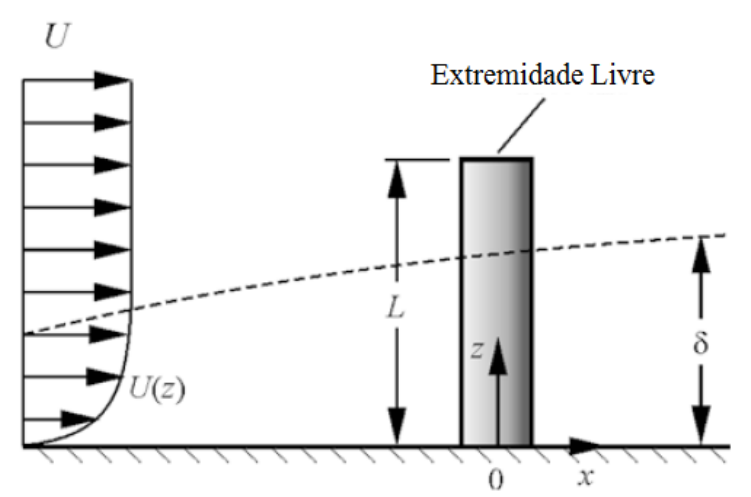

Figura 2.18: Cilindro fixo em uma placa plana e imerso a um escoamento [Adaptado de (SUMNER et al., 2004)].

ser encontrado em (ZDRAVKOVICH, 1989); ver Figura 2.19. Diferentemente do tipo de fixação adotado nos trabalhos anteriores, os autores desse trabalho consideram um arranjo onde os cilindros curtos têm ambas as extremidades expostas ao escoamento. Além disso, adotam também dois tipos de geometria para essas extremidades, com arestas "vivas" ou semiesféricas. Desta forma, além de investigarem o comportamento fluido no novo arranjo de fixação, estudam também o comportamento das forças atuantes no mesmo mediante a modificação da geometria nas extremidades dos cilindros.

Ainda em relação aos trabalhos de (ZDRAVKOVICH, 1989), a Figura 2.19 representa o escoamento descrito pelo autor, onde é possível observar um padrão de trailing vortices em ambas as extremidades do cilindro, semelhantes aos descritos em (KAWAMURA et al., 1984). Note que o escoamento próximo as extremidades, também conhecido como inflow, é "absorvido" pela zona de baixa pressão que se estabelece à jusante do cilindro, dando origem ao efeito de downwash descrito anteriormente.

Com o avanço da tecnologia, novos procedimentos de ensaios como o particle tracer method permitiram a obtenção de resultados e visualizações melhores do escoamento junto aos cilindros curtos. Em (PARK; LEE, 2000), por exemplo, uma investigação experimental importante dos efeitos da esteira em extremidades livres de cilindros finitos $(L / D=6$, 10 e 13) é conduzida em túnel de vento com $R e=20.000$ e também em canal de água circulante, onde a visualização do escoamento é conseguida via particle tracer method no cilindro engastado de $L / D=5$; ver Figura 2.20 .

Em (ROH; PARK, 2003) a topologia da emissão na superfície plana da extremidade livre de dois cilindros curtos com $L / D=1,25$ e 4,25 é investigada na busca por identificar e entender a ocorrência da separação nessa região. Para tanto, o trabalho faz uso de uma técnica baseada na iluminação laser dos cilindros recobertos por uma fina camada de 


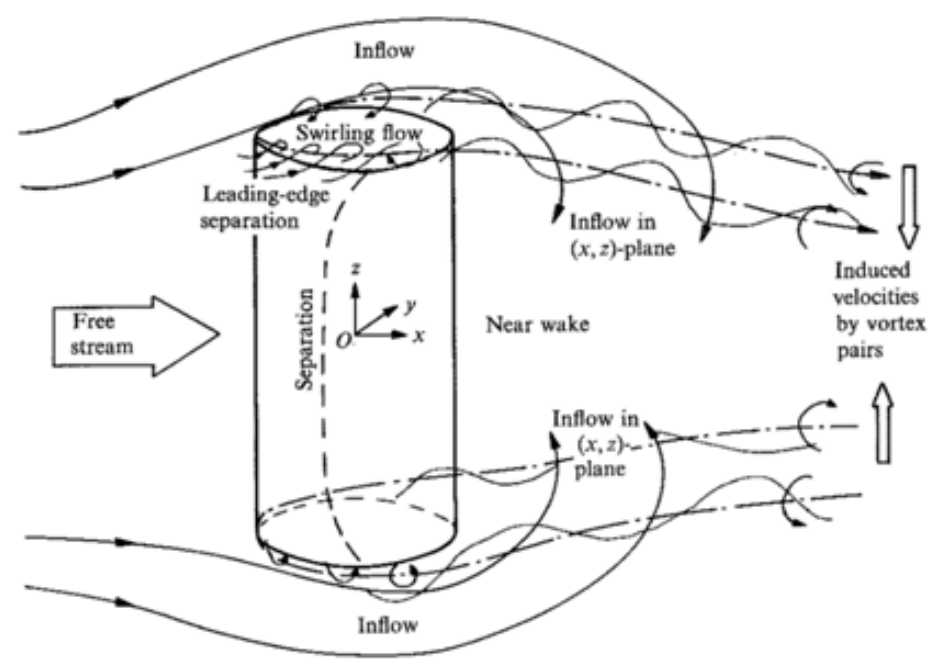

Figura 2.19: Vórtices gerados junto aos cilindros curtos fixos, mas com ambas as extremidades imersas em escoamento fluido. [Fonte: (ZDRAVKOVICH, 1989)].

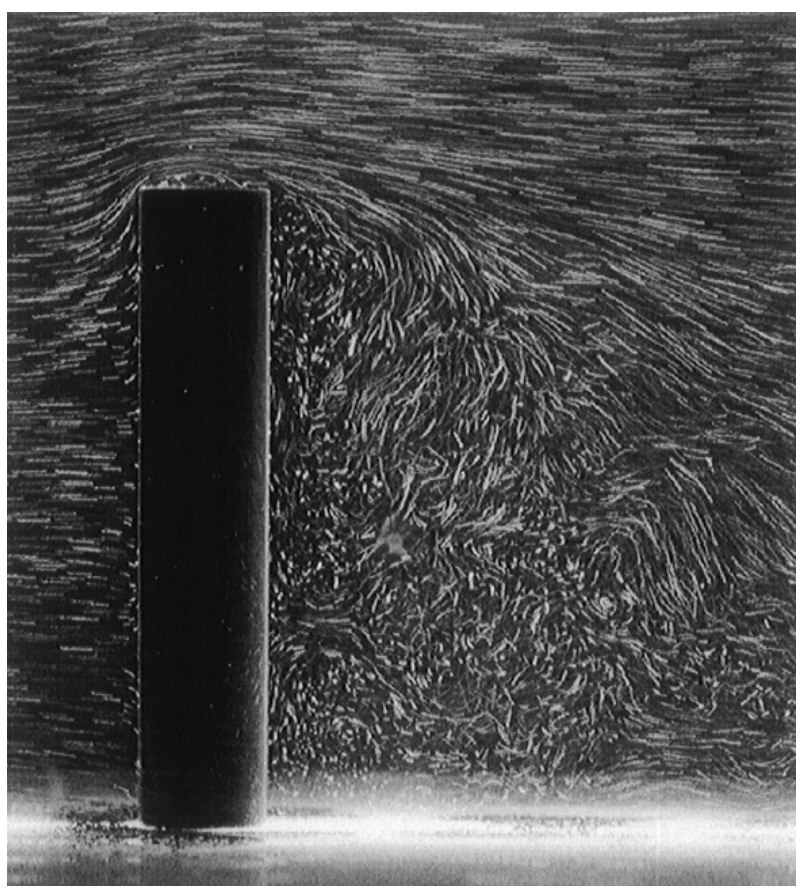

Figura 2.20: Vista lateral do escoamento em torno de um cilindro com $L / D=5$ : evidência clara do efeito de downwash. [Fonte: (PARK; LEE, 2000)].

óleo e material fluorecente. Os resultados assim obtidos confirmam aqueles descritos em (KAWAMURA et al., 1984) e descrevem ainda melhor o modelo fluido na superfície plana da extremidade livre, ver Figura 2.21, caracterizando o que na literatura se conhece como owl-face pattern.

De fato, o trabalho descrito em (ROH; PARK, 2003) é bastante abrangente quanto à ilustração do que qualitativamente acontece na superfície plana da extremidade livre. Segundo a Figura 2.22 (a), notam-se dois pares de vórtices contra-rotacionados simetri- 


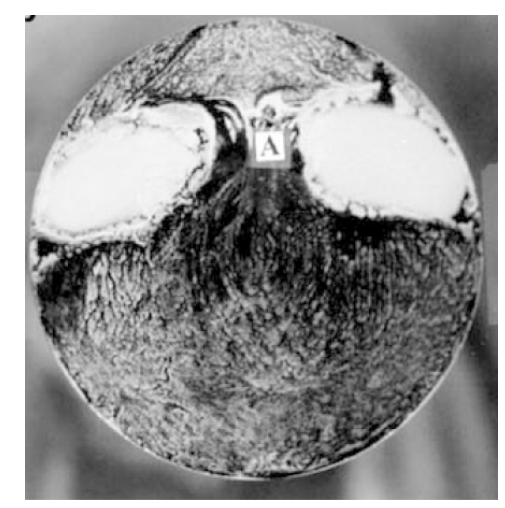

Figura 2.21: Precipitação do óleo na superfície plana do cilindro mostrando a ocorrência de formação dos trailing vortices. [Fonte: (ROH; PARK, 2003)].

camente dispostos em relação ao plano diametral longitudinal, cada par formado por um tip vortex e um trailing vortex que interagem entre si e promovem o efeito de downwash.
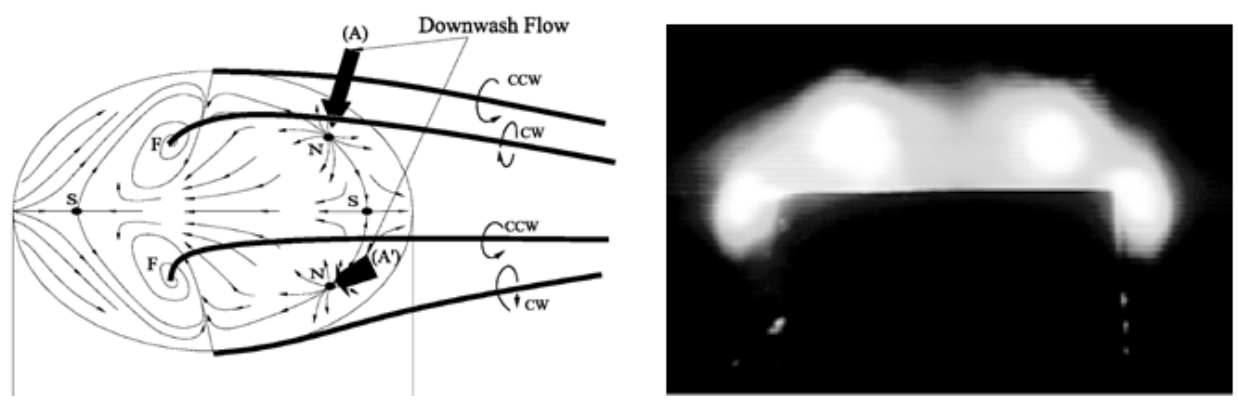

Figura 2.22: Em (a), modelo topológico da emissão de vórtices na superfície plana da extremidade livre de um cilindro curto. Em (b), vista frontal mostrando os dois pares de vórtices contra-rotacionados nessa região: dois tip vortices ao centro e dois trailing vortices junto às arestas laterais. [Fonte: (ROH; PARK, 2003)].

Além disso, na Figura 2.22 (b), tem-se uma vista frontal do cilindro no escoamento, onde é possível identificar os quatro vórtices gerados: dois maiores localizados na superfície plana da extremidade livre, os tip vortices, e dois menores nas arestas laterais, os trailing vortices.

Outra investigação que foi além das análises topológicas da emissão na extremidade livre é encontrada em (PARK; LEE, 2004). Nesse trabalho, cilindros finitos com razão de aspecto igual a 6 foram montados verticalmente em uma placa plana e submetidos a um escoamento subsônico realizado em um túnel de vento.

Quatro diferentes extremidades livres foram analisadas: a primeira, caracterizada por uma superfície plana integral e arestas "vivas"; a segunda onde se considera um chanfro a 45 graus; a terceira, onde a ponta é caracterizada por uma arredondamento com raio de 5 milímetros e a última onde a extremidade é caracterizada por uma semi-esfera de mesmo 

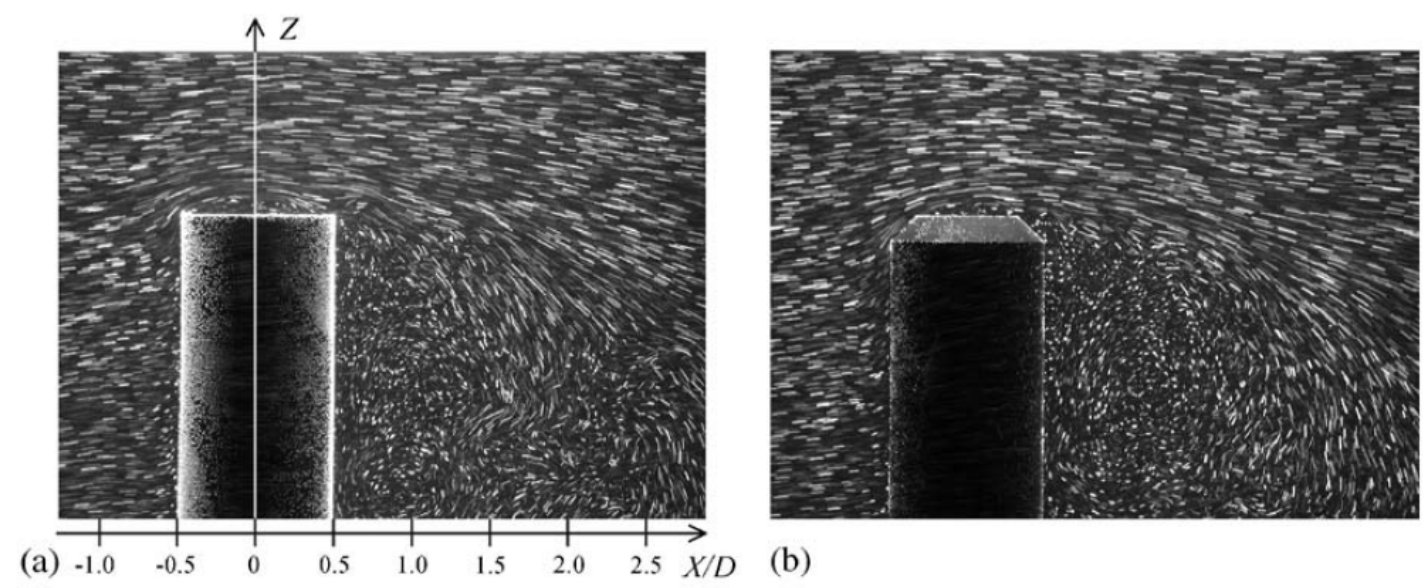

(b)

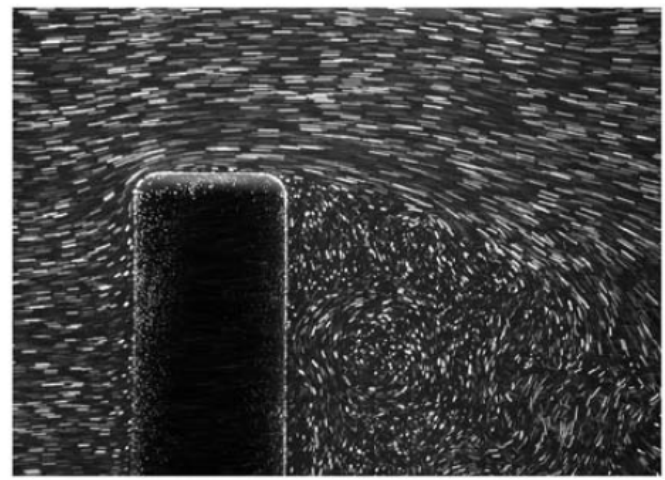

(c)

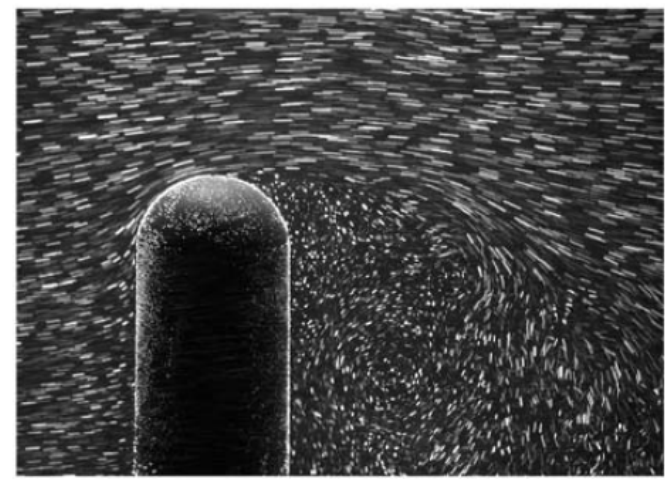

(d)

Figura 2.23: Escoamento junto a quatro extremidades livres diferentes em cilindros com $L / D=6$ : (a) cilindro com arestas "vivas"; (b) cilindro com chanfro a 45 graus de inclinação; (c) cilindro com arredondamento de raio $5 \mathrm{~mm}$; (d) cilindro com extremidade semiesférica. [Fonte: (PARK; LEE, 2004)].

diâmetro do cilindro.

Com base em um sensoriamento por análise de imagens, via técnica de PIV (particle image velocimetry), o escoamento junto à extremidade livre dos quatro cilindros foi investigado em $R e=7500$, revelando que a bolha de recirculação sofre uma redução com os arredondamentos na extremidade livre. Além disso, as investigação também constatam uma maior área de circulação formada pelo cilindro com a extremidade em semi-esfera, e por outro lado, essa área mostrou-se menor que as demais para o cilindro com extremidade plana. Na Figura 2.23 é possível observar em perfil o escoamento junto às quatro geometrias de extremidade.

Mediante as várias investigações conduzidas até 2005, a Figura 2.24, retirada do trabalho de (PATTENDEN et al., 2005), ilustra os principais vórtices formados junto aos cilindros curtos fixos imersos em escoamento fluido. Nota-se a tridimensionalidade complexa da formação de vórtices que da origem ao padrão arch-type de emissão. A ilustração no canto 
superior esquerdo da Figura 2.24 descreve a recirculação na superfície plana do cilindro. Observa-se que, na verdade, ela se subdivide em duas bolhas de recirculação, a de jusante girando em sentido horário e a de montante, menor, girando em sentido anti-horário.

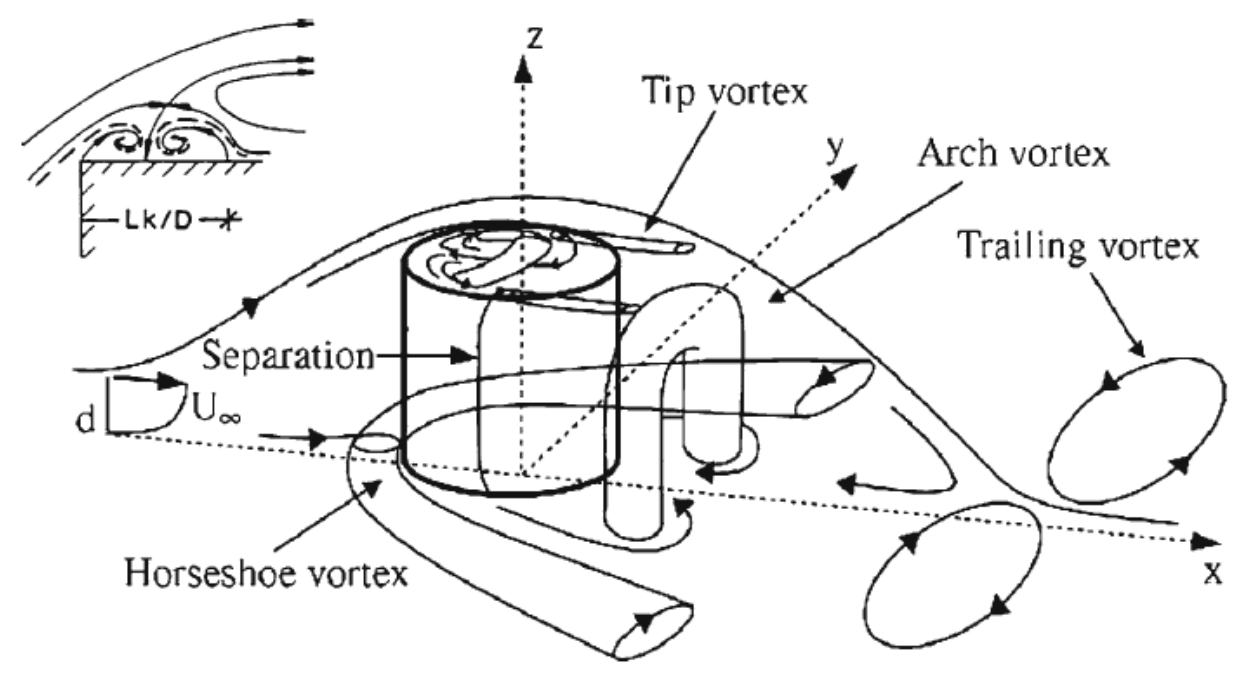

Figura 2.24: Síntese gráfica da emissão de vórtices junto aos cilindros curtos $\operatorname{com} L / D<$ 2,5. [Fonte: (PATTENDEN et al., 2005)].

As primeiras análises com cilindros curtos livres para oscilar são encontradas apenas recentemente, em trabalhos como (SOMEYA et al., 2010). Nesse trabalho, conduzido a partir da técnica de PIV aplicada ao escoamento junto a um cilindro curto com 2GL em canal de água circulante, as velocidades e vibrações do cilindro foram medidas e revelaram que o número de Strouhal na extremidade livre (Edge Flow) é significativamente maior que no restante do cilindro (WakeFlow), em uma clara demostração de que as emissões de vórtices na extremidade livre são de alta frequência; ver Figura 2.25.

Em se tratando de investigações quanto à caracterização fenomenológica do VIV agindo em cilindros curtos livres para oscilar, até onde se pode apurar, o trabalho de (GONçALVES, 2013) é o primeiro a descrever as amplitudes e frequências de resposta como função da velocidade reduzida $\left(1,5 \leq V_{r} \leq 14\right)$ e da razão de aspecto $(0,20 \leq L / D \leq 2)$, obtidas a partir de ensaios em canal de água circulante.

Segundo experimentos realizados por (GONçALVES, 2013) em modelos com 2GL, foi possível observar oscilações para cilindros com razão de aspecto inferiores a razão de aspecto critica $(L / D>2,5)$, além de apresentar um comportamento onde as amplitudes de oscilação diminuem conforme a redução da razão de aspecto. De acordo com o que foi descrito no início deste tópico, este comportamento pode estar atrelado aos efeitos causados pela aresta da superfície plana na extremidade livre, visto que os vórtices emitidos por esta região tendem a ter maiores influencias conforme a razão de aspecto diminui. 


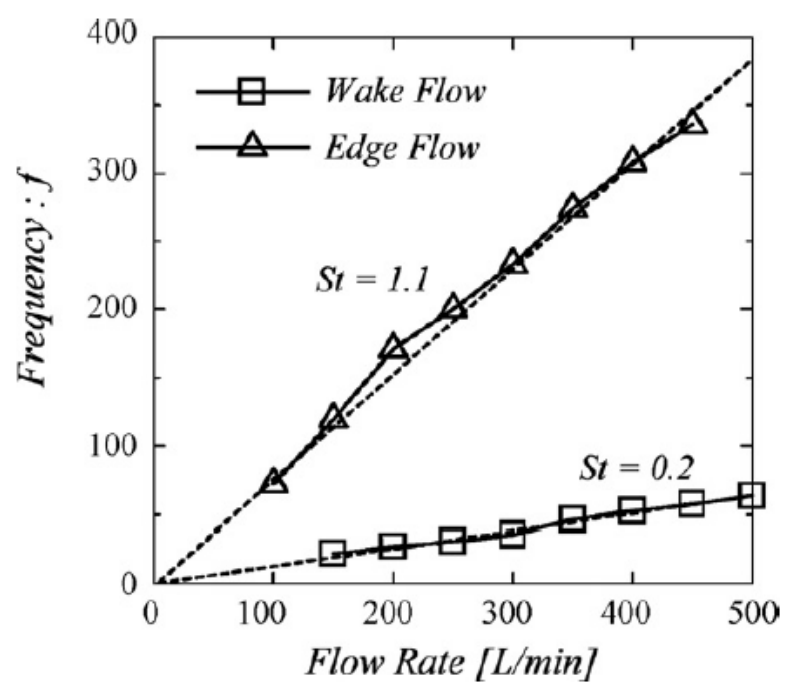

Figura 2.25: Frequências de emissão de vórtices da extremidade livre do cilindro (Edge Flow) e do corpo principal (WakeFlow). [Fonte: (SOMEYA et al., 2010)].

O trabalho apresentou imagens obtidas por PIV do escoamento em torno dos cilindros curtos, conforme exemplo da Figura 2.26, onde foi constatado o aparecimento de vórtices na extremidade livre e sua interação com a esteira formada nas paredes do cilindro, somado ao fato da análise conjunta dos espectros de forças nas direções transversal e longitudinal ter revelado uma relação com liberação de vórtices na extremidade livre, levando a crer em um mecanismo de emissão que atua também nos cilindros livres para oscilar. Consequentemente, devido ao campo de pressão criado ao redor do cilindro, a resposta do fenômeno VIV pode apresentar modificações.

O presente trabalho, como já descrito, foi baseado nos resultados obtidos por (GONçALVES, 2013), apresentando um estudo para cilindros flutuantes $\left(m^{*}=1\right)$ e 6 graus de liberdade. A partir dos estudos feito por (KAWAMURA et al., 1984) e (SAKAMOTO; ARIE, 1983), a razão de aspecto do cilindro foi definida como L/D = 2. Razão esta, que de acordo com os estudos de (SAKAMOTO; ARIE, 1983), pode-se esperar que os efeitos dos vórtices gerados pela extremidade livre já se fazem presente na esteira principal, portanto, espera-se uma diferença de comportamento quando se altera a geometria da extremidade livre. 


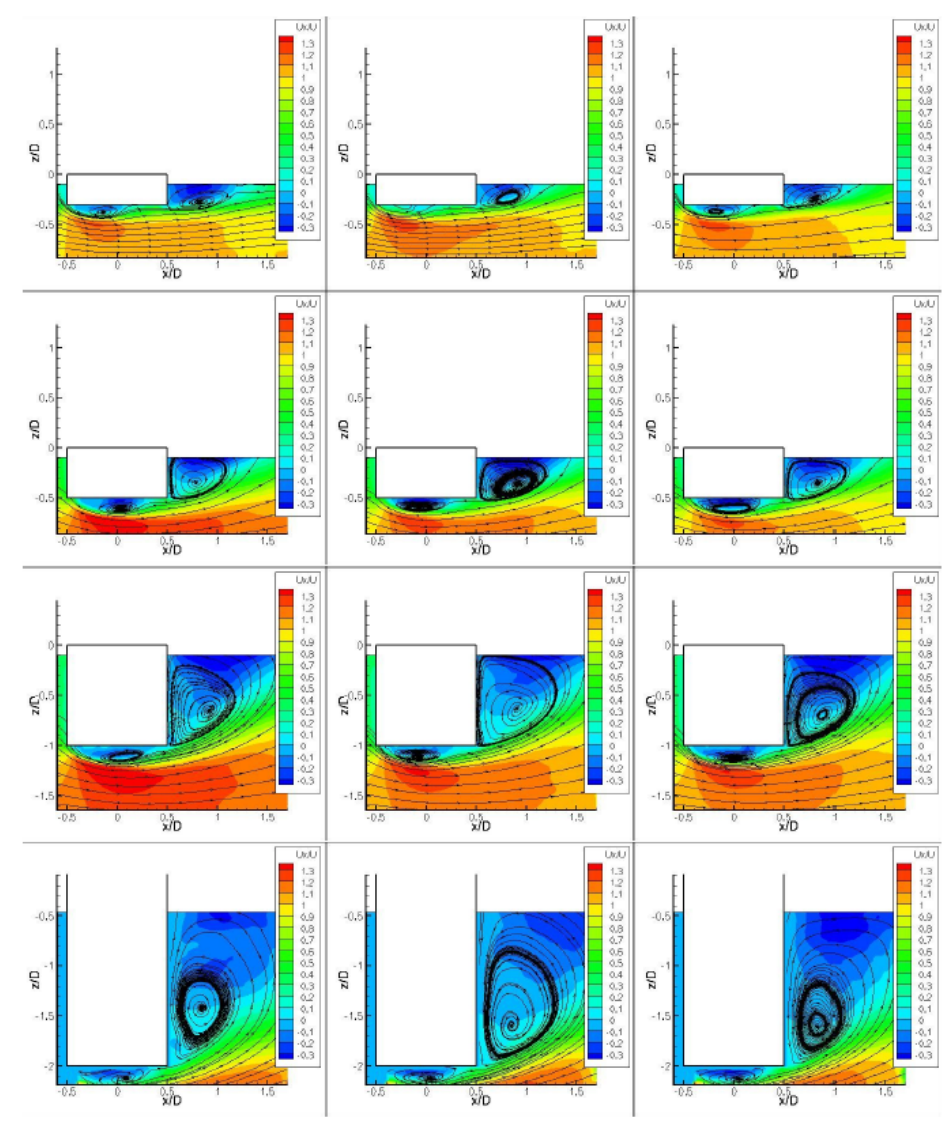

Figura 2.26: Campo de velocidade adimensional na direção longitudinal ao escoamento, no plano vertical central do cilindro, e respectivas linhas de corrente, para diferentes razões de aspecto e numero de Reynolds. [Fonte: (GONçALVES, 2013)].

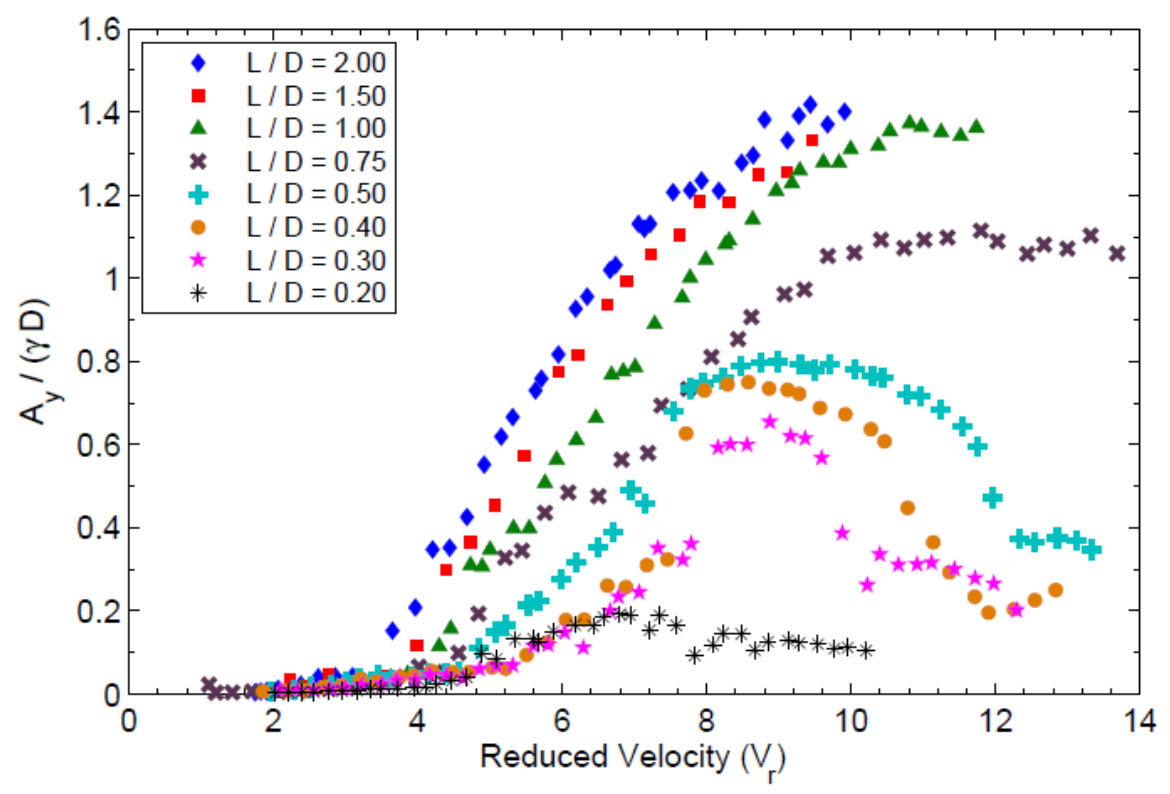

Figura 2.27: Amplitude adimensional transversal, $A_{y} / D$, como função da velocidade reduzida, $\mathrm{Vr}$, para cilindros flutuantes com razão de massa $\mathrm{m}^{*}=1,0$ e diferentes razões de aspecto. [Fonte: (GONçALVES, 2013)]. 


\section{Metodologia de Ensaio}

Mediante o objetivo de investigar o VIV em cilindros curtos flutuantes e a emissão alternada de vórtices a partir de sua extremidade imersa, desenvolveu-se a metodologia eminentemente experimental detalhada adiante. Seu conteúdo contempla descritivos quanto: aos materiais utilizados na construção dos modelos; ao aparato experimental elaborado para a execução dos ensaios em tanque de reboque; ao sistema de aquisição de dados utilizado e ao método utilizado para a obtenção dos resultados trazidos no capítulo subsequente.

\subsection{DESCRIÇÃO DOS MODELOS}

Os parâmetros adimensionais dos modelos assumem valores coerentes com a linha de pesquisa desenvolvida na Universidade de São Paulo, particularmente aquelas destinadas à investigação dos fundamentos do VIM, respeitando as restrições dimensionais impostas pela infraestrutura experimental do tanque de reboque.

Sendo assim, a razão de aspecto predefinida para os cilindros curtos investigados foi $L / D=$ 2, dimensionalmente conseguida com base em cilindros de seção circular com diâmetro $D=125 \mathrm{~mm}$ e comprimento imerso $L=250 \mathrm{~mm}$. Essa razão de aspecto foi selecionada com base nos resultados apresentados em (SAKAMOTO; ARIE, 1983) e (GONçALVES, 2013), onde os vórtices gerados pela extremidade livre podem ter influência no comportamento da esteira principal e, consequentemente, na resposta do VIV.

Por sua vez, a definição dos formatos de extremidade livre foi feita com base nos trabalhos experimentais descritos em (PARK; LEE, 2004). De acordo com esse trabalho, como o chanfro angular reto não apresentou resultados muito diferentes do cilindro de extremidade reta, optou-se pela utilização apenas arredondamentos com variações de raio.

Definiu-se, então, quatro modelos para ensaio, um deles (o de referência) com arestas "vivas" e os outros três com diferentes relações de raio de adoçamento $r$ e o raio do cilindro $R$. Desta forma, o modelo com $r / R=0$ corresponde à geometria sem arredondamento 
e, a partir desse, os demais apresentam raio de arredondamento de $15,63 \mathrm{~mm}(r / R=$ $0,25), 31,25 \mathrm{~mm}(r / R=0,50)$ e $62,50 \mathrm{~mm}(r / R=1,00)$, este último correspondendo à semicircunferência em sua extremidade livre.

O material para fabricação dos modelos foi o Policloreto de Vinila (PVC), selecionado pela facilidade de construção dos corpos cilíndricos por torneamento. A Figura 3.1 mostra as três peças torneadas a partir de tarugos maciço de PVC e posteriormente acopladas aos corpos dos modelos, obtidos a partir tubos também de PVC.

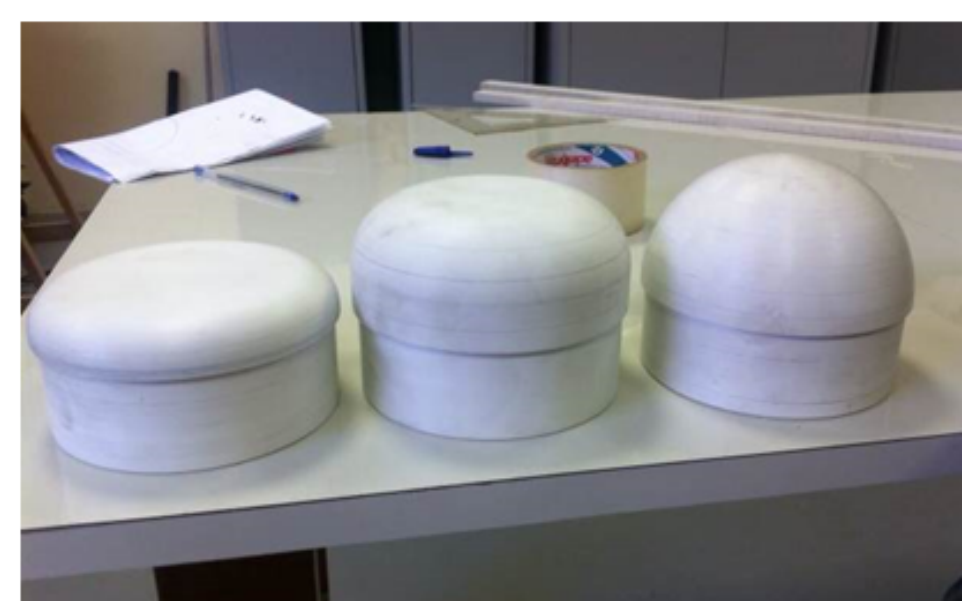

Figura 3.1: Extremidades livres usinadas em PVC.

Com as extremidades acopladas aos tubos por cola específica para a adesão do PVC, efetuou-se a vedação interna dos modelos com silicone.

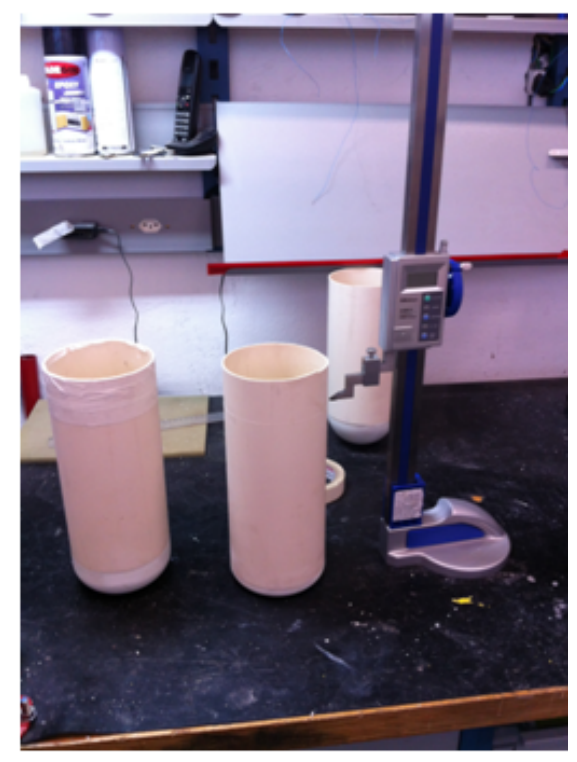

Figura 3.2: Marcação dos calados e locais de amarração nos cilindros.

Em seguida, as superfícies foram lixadas para ficarem lisas e uniformes, permitindo que, finalmente, os modelos passassem por um graminho eletrônico, onde foram precisamente 
marcados os comprimentos de imersão $(L=250 \mathrm{~mm})$ e, na sequência, incorporadas as anilhas de fixação das molas utilizadas para suporte das molas de restauração. A Figura 3.2 , ilustra o processo de marcação dos modelos montados com as peças da extremidade livre já coladas aos tubos de PVC.

As precisão dos processos de medição e usinagem trabalharam dentro da capacidade dos equipamentos, ou seja, $\pm 0,05 \mathrm{~mm}$.

A Figura 3.3, mostra os cilindros finalizados, sendo que em:

(1) Tem-se o cilindro de referência, denominado $\mathbf{C 1}$, com $r / R=0,0$;

(2) $\mathrm{O}$ cilindro denominado $\mathbf{C 2}$, com arredondamento na razão $r / R=0,25$;

(3) O cilindro denominado C3, com arredondamento na razão $r / R=0,50$;

(4) E o cilindro com extremidade em formato de semiesfera denominado C4, com arredondamento na razão $r / R=1,00$;

(1)

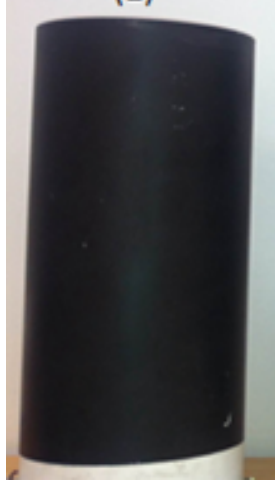

(2)

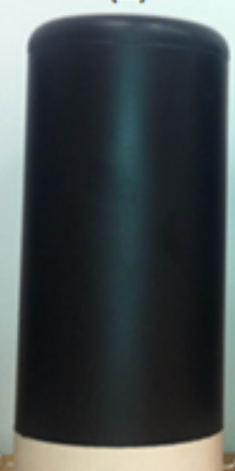

(3)

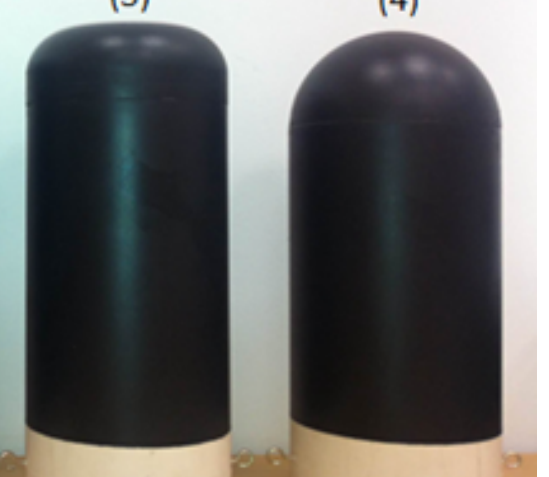

Figura 3.3: Cilindros finalizados: em (1), C1 - arestas "viva"; em (2), C2 - arredondamento $r / R=0,25$; em (3), C3 - arredondamento $r / R=0,50 ;$ e em (4), C4 - arredondamento $r / R=1,00$.

Uma mistura composta de areia e cola foi utilizada para preenchimento dos modelos, com o objetivo de lastreá-los até o comprimento de imersão (calado) indicado. Os centros de gravidade foram determinados a partir do método de apoio em lâmina, que consistem em posicionar o corpo em uma lâmina de madeira, como ilustra a Figura 3.4.

A Figura 3.5 ilustra os cilindros com suas principais características geométricas. A Tabela 3.1, por sua vez, apresenta essas características: razão de aspecto $L / D$; razão entre raios $r / R$; posição vertical do Centro de Gravidade, denominada de $K_{G}$; e, por fim, a massa com lastro $M$. 


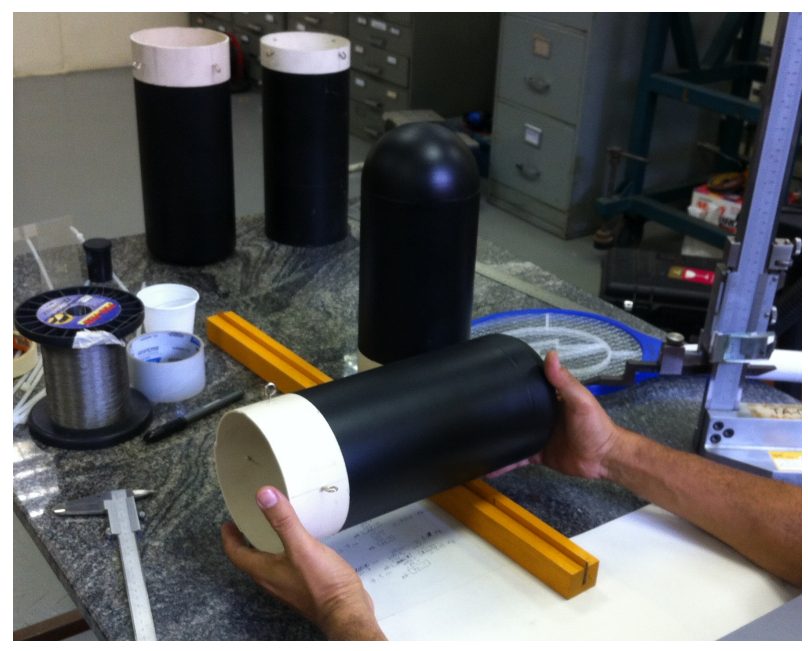

Figura 3.4: Determinação da posição vertical do Centro de Gravidade (CG) dos modelos pelo método de apoio em lâmina.

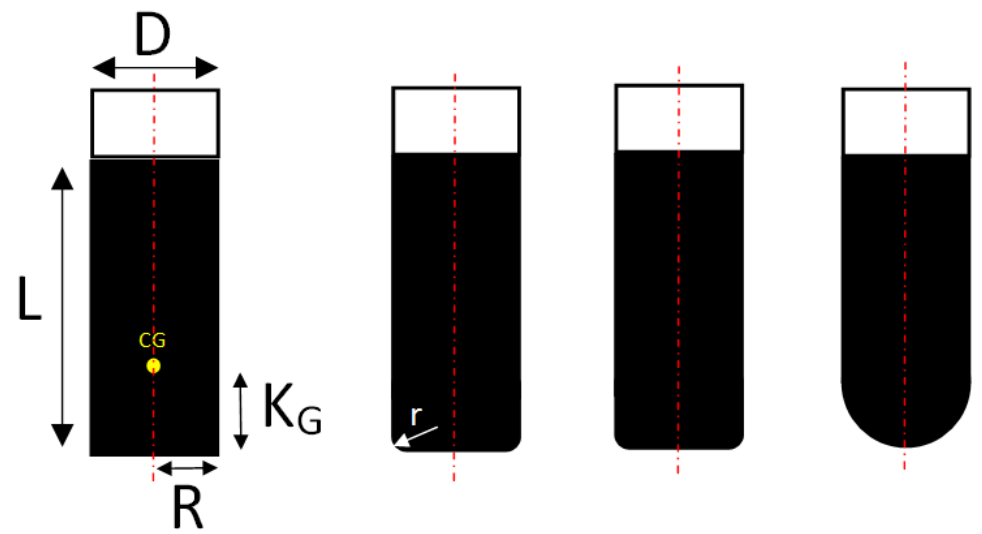

Figura 3.5: Esquema para definição das dimensões dos modelos.

Tabela 3.1: Características dimensionais dos modelos.

\begin{tabular}{ccccc} 
Modelo & $\mathbf{L} / \mathbf{D}$ & $\mathbf{r} / \mathbf{R}$ & $K_{G}[\mathbf{m m}]$ & $\mathbf{M}[\mathrm{kg}]$ \\
\hline C1 & 2,0 & 0,00 & 92,1 & 2,915 \\
C2 & 2,0 & 0,25 & 81,5 & 2,912 \\
C3 & 2,0 & 0,50 & 86,3 & 2,906 \\
C4 & 2,0 & 1,00 & 98,3 & 2,731 \\
\hline
\end{tabular}

A Figura 3.6 mostra os modelos preparados para ensaio em tanque de reboque. Importante destacar que os valores de período natural $T_{n}$ e de coeficiente de amortecimento $\zeta_{w}$ dos cilindros em água, nos seis graus de liberdade ${ }^{1}$, são apresentados na Tabela 3.2.

\footnotetext{
${ }^{1}$ Por conveniência, em algumas passagens deste texto, particularmente sempre que outros graus de liberdade que não o longitudinal e o transversal ao escoamento estiverem envolvidos nas descrições, análises e/ou discussões, também será adotada a nomenclatura utilizada nas engenharias naval e oceânica. Assim, serão também adotadas as designações:
} 
O Apêndice A detalha os procedimentos para a obtenção desses valores, assim como os gráficos que descrevem os decaimentos registrados.

Tabela 3.2: Parâmetros obtidos com base nos ensaios de decaimento.

\begin{tabular}{ccc|cc|cc|cc} 
Modelo & \multicolumn{2}{c}{ C1 } & \multicolumn{2}{c}{ C2 } & \multicolumn{2}{c}{ C3 } & \multicolumn{2}{c}{ C4 } \\
$G L /$ parâmetros & $T_{n y}(s)$ & $\zeta_{w}(\%)$ & $T_{n y}(s)$ & $\zeta_{w}(\%)$ & $T_{n y}(s)$ & $\zeta_{w}(\%)$ & $T_{n y}(s)$ & $\zeta_{w}(\%)$ \\
\hline Surge & 9,459 & 4,29 & 8,856 & 3,4550 & 9,618 & 5,3408 & 8,638 & 4,3810 \\
Sway & 10,07 & 3,1000 & 10,2 & 2,9414 & 9,05 & 3,8505 & 9,908 & 3,7741 \\
Heave & 1,059 & 1,1300 & 1,054 & 0,7907 & 1,028 & 0,7843 & 0,9835 & 1,2866 \\
Roll & 0,9824 & 0,4399 & 0,8836 & 1,0161 & 0,8985 & 1,1043 & 0,8805 & 2,0963 \\
Pitch & 0,9626 & 1,3025 & 0,8604 & 2,7669 & 0,9076 & 1,8078 & 0,8879 & 1,4569 \\
Yaw & 1,54 & 2,5400 & - & - & - & - & 1,444 & 2,0160 \\
\hline
\end{tabular}

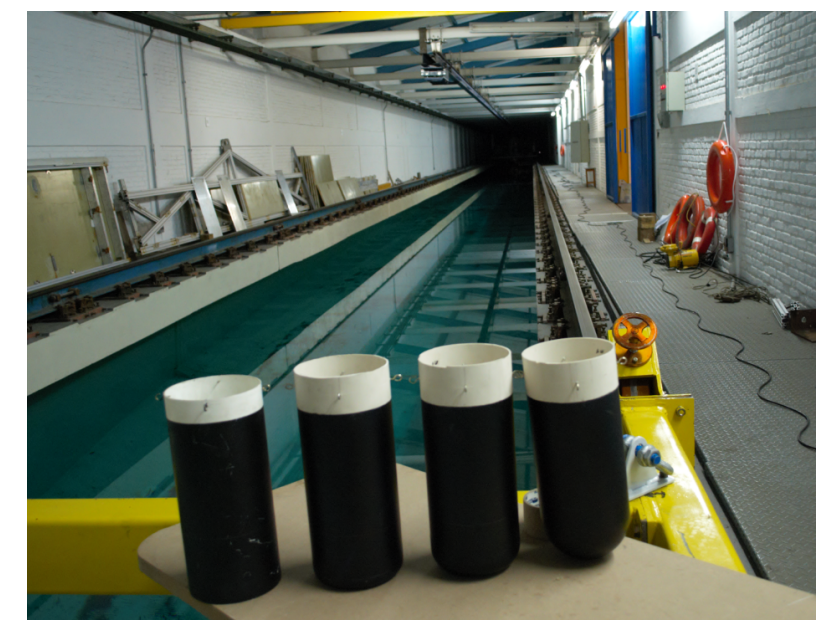

Figura 3.6: Modelos posicionados no local de ensaio.

1 - surge o movimento de translação na direção do escoamento; 2 - sway o movimento de translação transversal ao escoamento; 3 - heave movimento de translação vertical;

4 - roll movimento de rotação ao redor da direção longitudinal; 5 - pitch movimento de rotação ao redor da direção transversal; 6 - yaw movimento de rotação ao redor da direção vertical. 


\subsection{DESCRIÇÃO do APARATO EXPERIMENTAL}

O Instituto de Pesquisas Tecnológicas do Estado de São Paulo (IPT) foi o local escolhido para a realização dos ensaios. Tal escolhar se deu em virtude de seu Centro de Engenharia Naval (CNAVAL) contar com um tanque de reboque de $280 m$ de comprimento, 6,6m e largura e $4 m$ de profundidade, infraestrutura bastante adequada para a realização dos ensaios de VIV mais adiante descritos.

Para esses ensaios um comprimento de apenas $170 \mathrm{~m}$ do tanque foram necessários, contando com um carro dinamométrico de alta precisão para o reboque dos modelos e, assim, a simulação de um escoamento incidente com nível de turbulência praticamente nulo.

De fato, dada a característica dos ensaios de VIV realizados, um carro secundário acoplado ao dinamométrico principal foi utilizado para melhorar o posicionamento do arranjo de molas responsável pela restauração da condição de equilíbrio dos modelos, bem como do sistema de câmeras para rastreamento óptico dos alvos passivos utilizados.

A Figura 3.7 mostra o tanque do IPT e os carros utilizados: o principal, estrutura em azul; e secundário, estrutura em amarelo, onde foi posicionado o quadro estrutural de fixação das molas.

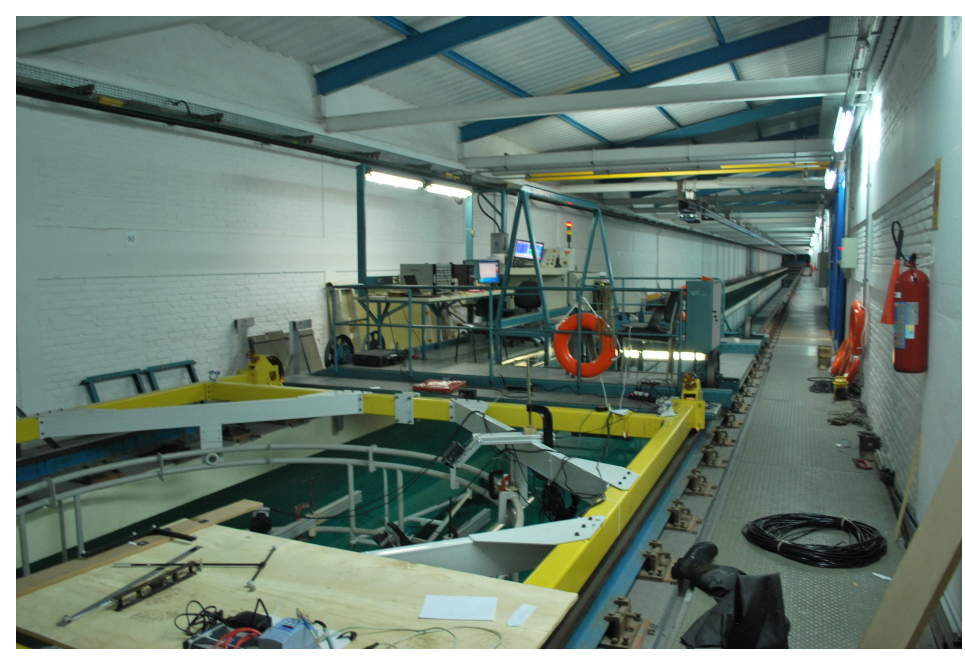

Figura 3.7: Tanque de reboque do IPT com o carro dinamométrico principal (em azul), rebocando o carro secundário com os equipamentos experimentais (em amarelo).

Dada sua particularidade e importância, o sistema de amarração é detalhado no próximo tópico deste capítulo (quadro estrutural e molas). 


\subsection{DESCRIÇÃO DO SISTEMA dE AMARRAÇÃO}

Tratando-se de ensaios com modelos flutuantes, portanto dotados de 6GL, uma estrutura portante com um quadro de fixação interno foi montada ao centro do carro de reboque secundário.

Para o posicionamento vertical das molas o mais próximo possível da superfície livre (interface ar-água) foram adicionadas barras extras em balanço, conforme ilustração em vista lateral na Figura 3.8. Essas barras também tiveram o objetivo de minimizar a pré-tensão nas molas e a dinâmica própria das mesmas.
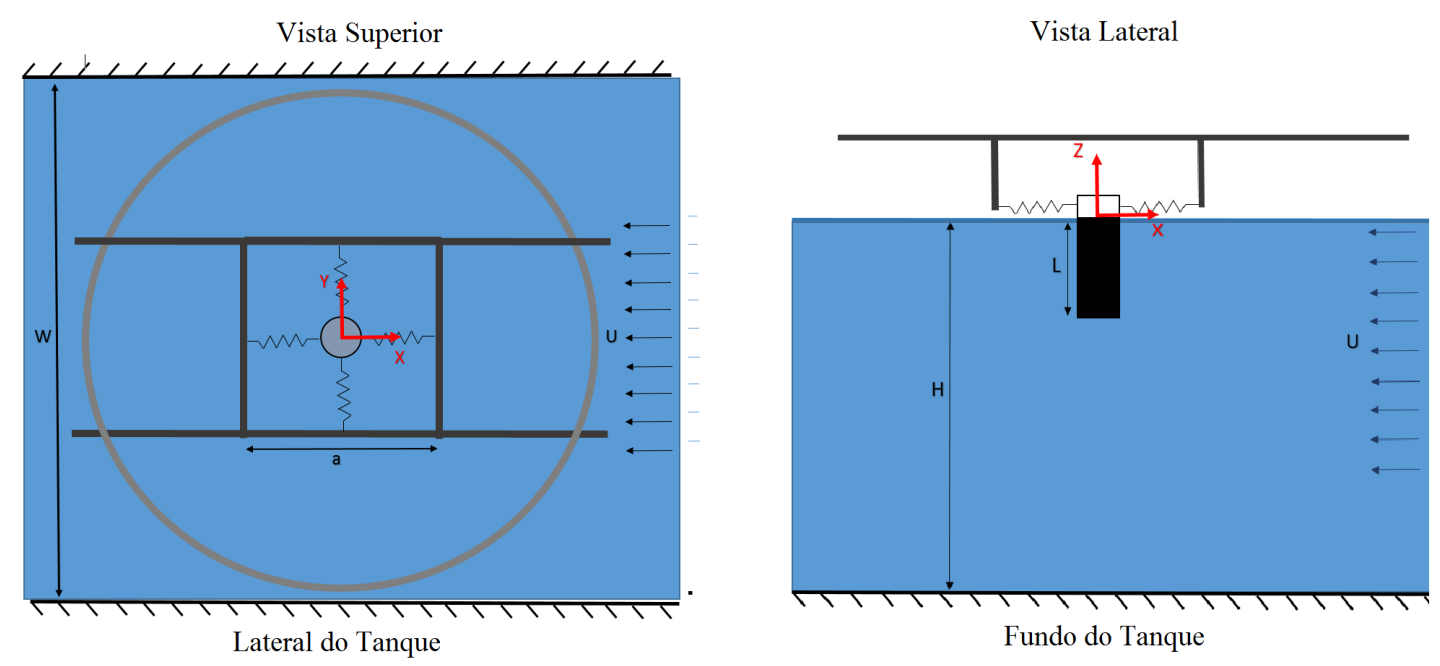

Figura 3.8: Esquema do aparato experimental montado no carro de reboque secundário do IPT.

Ainda de acordo com a Figura 3.8, destaca-se a geometria quadrada da estrutura de sustentação das molas (dotada de lados $a=1,110 \mathrm{~m}$ ), fixada ao centro da estrutura circular do carro de reboque secundário. As demais dimensões ilustradas na Figura 3.8 são apresentadas na Tabela 3.3.

Tabela 3.3: Dimensões principais do arranjo experimental montado no carro de reboque secundário no IPT.

\begin{tabular}{lcc} 
Parâmetros & Sigla & Dimensões $[\mathbf{m}]$ \\
\hline Largura do Tanque & $\mathrm{w}$ & 6,6 \\
Profundidade do Tanque & $\mathrm{H}$ & 4 \\
Comprimento do Tanque & $L_{T}$ & 280 \\
Comprimento imerso do modelo & $\mathrm{L}$ & 0,250 \\
Aresta do quadro suporte & $\mathrm{a}$ & 1,110 \\
\hline
\end{tabular}


Como descrito anteriormente, o aparato experimental foi montado no carro secundário, e este rigidamente ligado ao carro dinamométrico principal para realização do reboque, simulando o escoamento uniforme atuante sobre os modelos. A estrutura portante foi montada a partir de vigas de alumínio, centralizada na estrutura circular própria do carro secundário. A Figura 3.9 mostra essa montagem, convenientemente realizada sobre uma das praias do tanque de provas do IPT.

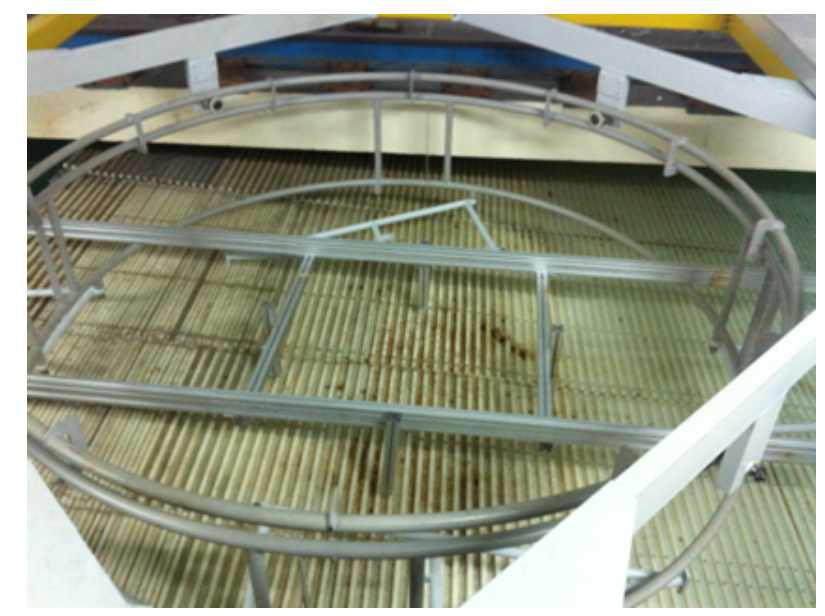

Figura 3.9: Quadro para posicionamento do aparato experimental montado no carro secundário de reboque no tanque do IPT.

O sistema de restauração foi construído a partir de quatro molas iguais de tração, praticamente lineares, obedecendo a razão unitária entre constantes elásticas equivalentes nas direções longitudinal e transversal, $k_{x} / k_{y}=1$. Assim, em termos dimensionais, foram utilizadas quatro molas fabricadas de aço inox que se caracterizaram por constantes elásticas individuais $k=0,8 \mathrm{~N} / \mathrm{m}$. A Figura 3.10 e a Tabela 3.4 apresentam mais detalhes das molas utilizadas.

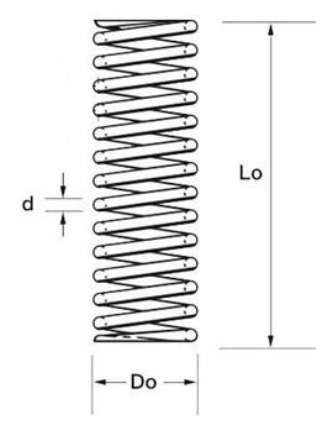

Figura 3.10: Desenho esquemático com as principais dimensões das molas de tração utilizadas nos experimentos.

Na Figura 3.11 tem-se a apresentação geral do arranjo experimental completo, assim composto pelo cilindro flutuante preso as molas e estas à estrutura portante solidária ao 
Tabela 3.4: Dimensões principais das molas de tração utilizadas.

\begin{tabular}{ll} 
Parâmetros & Dimensões \\
\hline Do & $8,50 \mathrm{~mm}$ \\
d & $0,35 \mathrm{~mm}$ \\
$\mathrm{k}$ & $0,80 \mathrm{~N} / \mathrm{m}$ \\
Lo & $191 \mathrm{~mm}$ \\
\hline
\end{tabular}

carro secundário de reboque, onde também se nota a presença das câmeras de rastreamento óptico dos alvos dispostos na extremidade emersa do cilindro.

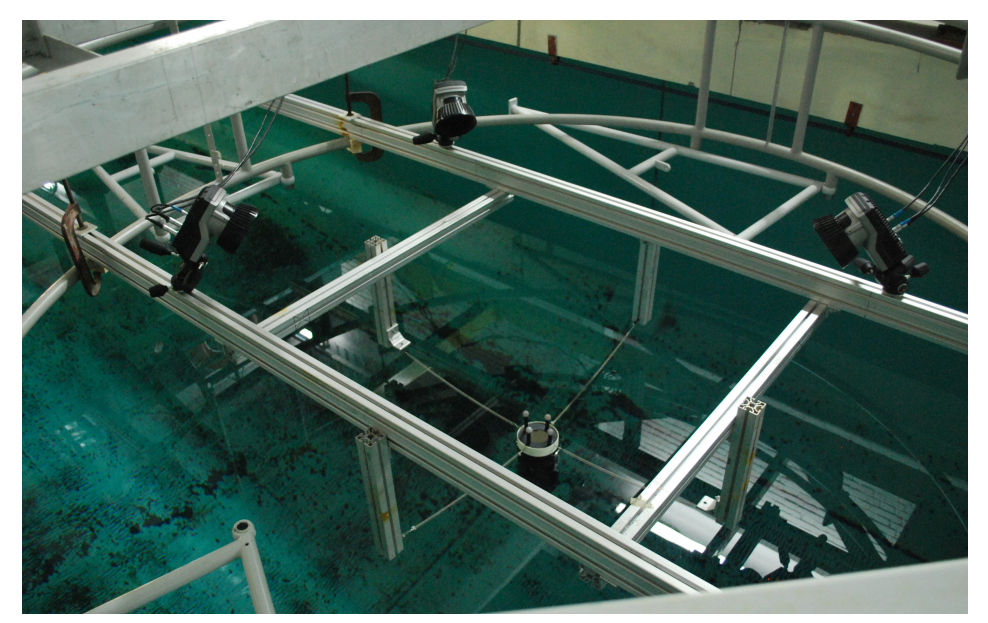

Figura 3.11: Aparato experimental completo para os ensaios (cilindro, molas, suporte e câmeras no carro secundário de reboque).

Neste ponto torna-se importante discutir a linearidade do sistema de restauração adotado.

Sabe-se que, dependendo da magnitude dos deslocamentos dentro do quadro de suporte, a restauração importa aos modelos pode apresentar contribuições não-lineares que impactariam na investigação do fenômeno de VIV.

Para verificar os limites de linearidade do arranjo de molas, um estudo foi realizado aplicando deslocamentos conhecido ao modelo e verificando por intermédio das forças envolvidas o grau de não-linearidade apresentado pelo conjunto como um todo.

Mediante este procedimento de avaliação, a Figura 3.12 deixa claro que durante os ensaios os modelos que devem oscilar com amplitudes da ordem de um diâmetro, permaneceram na região verde onde as não-linearidade são sempre inferiores a 5\% da restauração total imposta, o que, de antemão, valida o sistema de restauração projetado.

Maiores detalhes sobre o sistema de monitoramento de movimentos por rastreamento de 


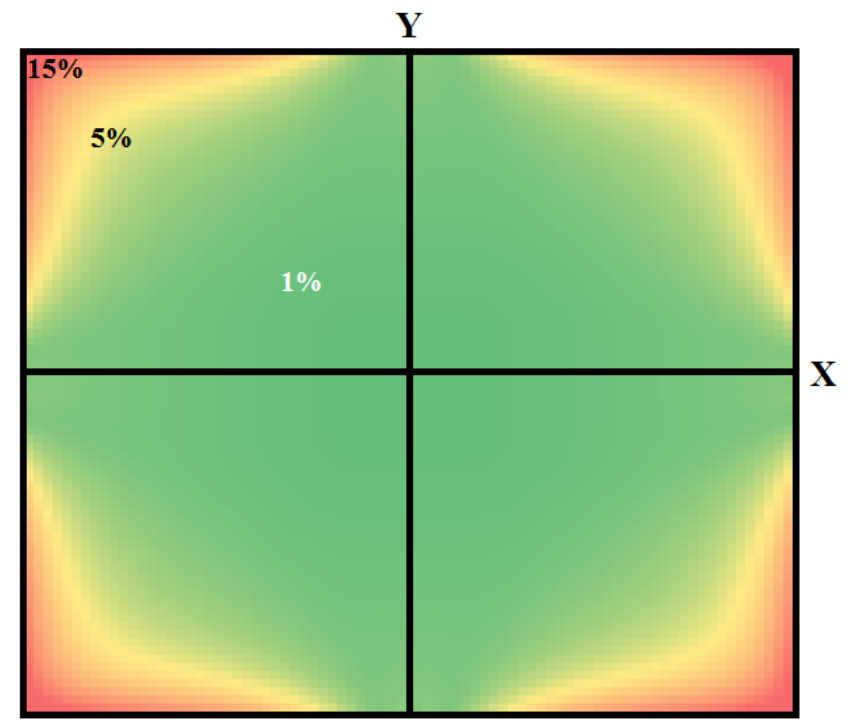

Figura 3.12: Resultado da avaliação quanto à não-linearidade das forças de restauração impostas aos modelos suportados no quadro de molas.

alvos é apresentado no próximo tópico. 


\subsection{DescriçÃo do Sistema de AQuisiçÃo de Dados}

O sistema utilizado para a aquisição dos movimentos dos modelos nos 6GL foi composto por câmeras de iluminação infravermelha, fabricadas pela Qualisys ${ }^{\mathrm{TM}}$.

Esse sistema é composto por um programa dedicado que rastreia alvos refletivos fixos ao modelo e que, se combinados (ao menos três deles), constituem um corpo rígido. Devidamente calibradas, essas câmeras são capazes de medir deslocamentos em $400 f p s$ (frames per second), com alta precisão.

Conforme indicação do fabricante, foram utilizadas três câmeras posicionadas e fixadas na estrutura de suporte, com o propósito de cobrir toda área de oscilação do modelo. Arranjo das câmeras é apresentado na Figura 4.18(a), enquanto uma delas é exibida com detalhes em 4.18(b).

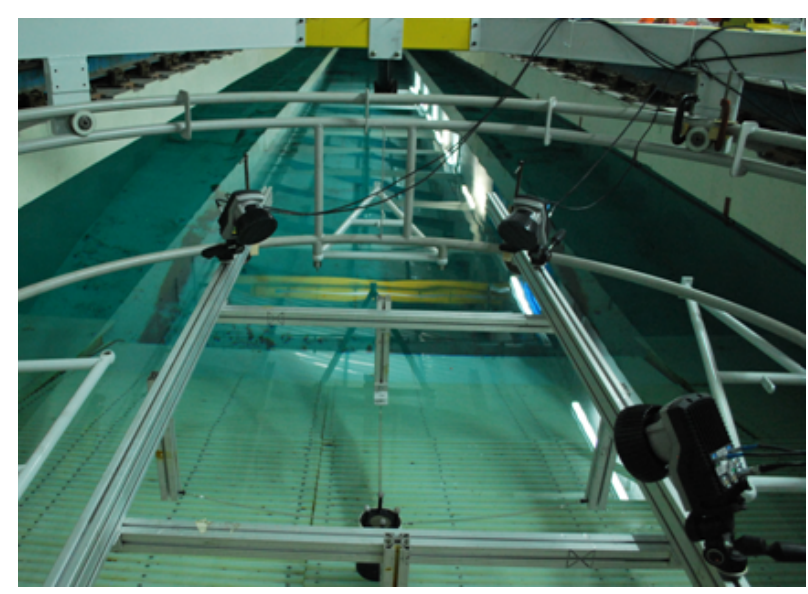

(a) Sistema de monitoramento

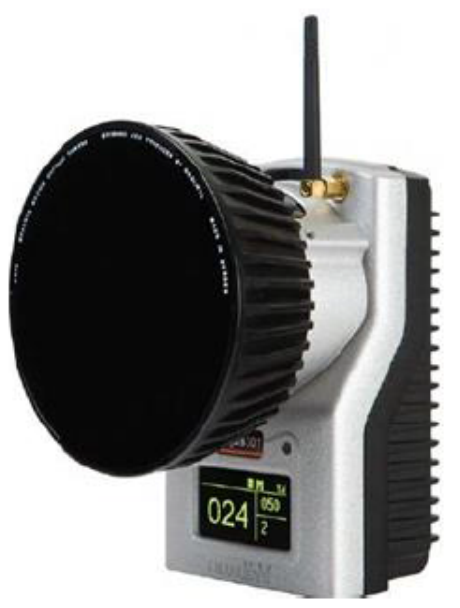

(b) Câmera Qualisys

Figura 3.13: Sistema de medição de movimentos por rastreamento de alvos passivos da Qualisys $^{\text {TM }}$. Em (a), vista geral das três câmeras utilizadas nos ensaios. Em (b), detalhes de uma das câmeras utilizadas.

As velocidades de reboque do carro dinamométrico foram definidas via sistema de controle do próprio equipamento.

A medição das velocidade efetivamente impostas aos modelos foi realizada via transdutor de posição angular, encoder analógico-digital solidário a uma das rodas do carro dinamométrico principal. Este dispositivo mediu opticamente o deslocamento e velocidade do carro com precisão.

A Figura 3.14 mostra um exemplo de registro no tempo de uma das velocidades utilizadas nos ensaios de VIV com os cilindros curtos, especificamente a velocidade nominal $U_{\text {nom }}=$ 
$125 \mathrm{~mm} / \mathrm{s}$. De acordo com essa figura, percebe-se que, embora hajam alguns pequenos ruídos, após os instantes iniciais de aceleração gradativa, o registro é bastante preciso no valor nominal definido. Sinais desta natureza, formam a base de análise apresentada no próximo capítulo deste texto.

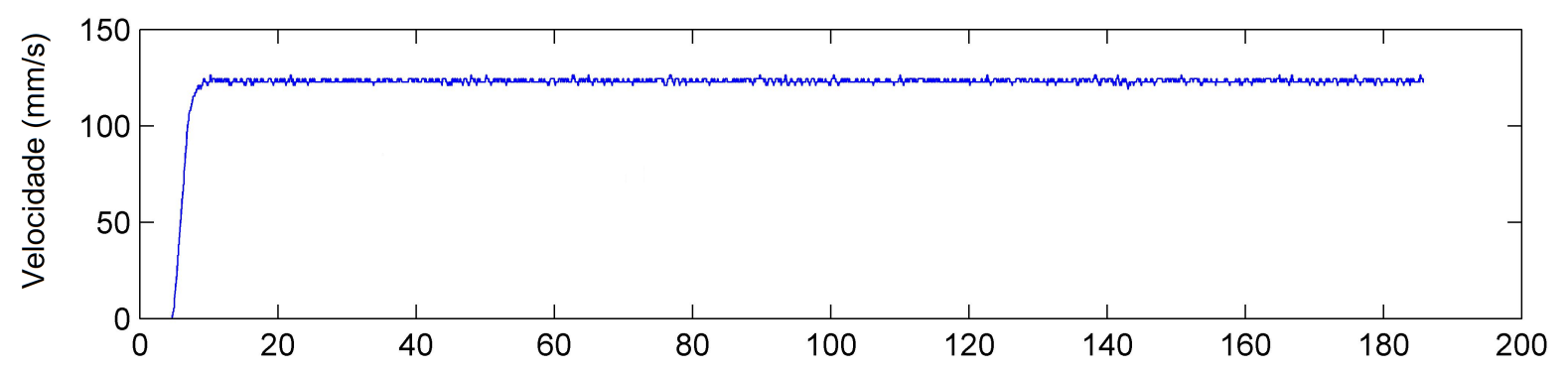

Figura 3.14: Resposta do encoder para série temporal setada para velocidade de $125 \mathrm{~mm} / \mathrm{s}$

\subsection{DESCRIÇÃO DO MÉTOdO EXPERIMENTAL}

No sentido de concluir a apresentação da metodologia experimental de investigação adotada neste trabalho, descreve-se a seguir o método adotado para os ensaios em tanque de reboque.

De um maneira geral, os ensaios de VIV realizados foram definidos com base na velocidade reduzida (calculada pela equação 2.6), sempre que possível, buscando varrer um intervalo deste parâmetro capaz de excitar ao máximo o fenômeno nos cilindros curtos flutuantes (intencionalmente, $2 \lesssim V_{r} \lesssim 15$ ).

Com a realização dos reboques, no entanto, observou-se que as velocidades reduzida superiores a 12 causavam inclinação excessiva em alguns cilindros, fazendo com que as molas longitudinais ao escoamento tocassem a superfície livre da água e, assim, invalidassem os resultados a partir desse ponto. Buscando evitar este tipo de problema, as análises com $V_{r}>12$ foram desconsideradas. A Tabela 3.5 apresenta os valores de velocidade reduzida, respectivas velocidades dimensionais nominais e respectivos intervalos de número de Reynolds dos ensaios para cada modelo.

Para determinação das velocidades reduzidas com base nas velocidades de reboque medidas, foram antecipadamente realizados ensaios de decaimento para a obtenção das frequências naturais dos modelos em água parada na direção transversal $\left(f_{0}\right)$, o Apêndice A traz detalhes da execução e análise dos ensaios de decaimento. Lembrando que este é o grau de liberdade mais importante no VIV (daí sua adoção como referência), cujo período 
Tabela 3.5: Intervalos de velocidade reduzida, velocidade dimensional nominal e número de Reynolds dos ensaios com os quatro modelos considerados.

\begin{tabular}{ccccc} 
Modelo & $\mathrm{r} / \mathrm{R}$ & $V_{r}$ & $U[\mathrm{~m} / \mathrm{s}]$ & $R e \times 10^{4}$ \\
\hline $\mathrm{C} 1$ & 0,0 & $1,84 \rightarrow 11,48$ & $0,0242 \rightarrow 0,1511$ & $0,33 \rightarrow 1,89$ \\
$\mathrm{C} 2$ & 0,25 & $1,95 \rightarrow 11,20$ & $0,0265 \rightarrow 0,1511$ & $0,33 \rightarrow 1,89$ \\
$\mathrm{C} 3$ & 0,50 & $1,80 \rightarrow 11,43$ & $0,0242 \rightarrow 0,1535$ & $0,30 \rightarrow 1,92$ \\
$\mathrm{C} 4$ & 1,0 & $1,91 \rightarrow 11,05$ & $0,0265 \rightarrow 0,1534$ & $0,33 \rightarrow 1,92$ \\
\hline
\end{tabular}

natural será $T n=1 / f_{0}$. A Tabela 3.6 apresenta os valores das frequências naturais transversais utilizadas para a apresentação, comparação e discussão dos resultados do próximo capítulo.

Tabela 3.6: Frequências naturais dos modelos ensaios.

\begin{tabular}{ccc} 
Modelo & $\mathrm{r} / \mathrm{R}$ & $f_{0}[\mathrm{~Hz}]$ \\
\hline $\mathrm{C} 1$ & 0,00 & 0,1053 \\
$\mathrm{C} 2$ & 0,25 & 0,1079 \\
$\mathrm{C} 3$ & 0,50 & 0,1074 \\
$\mathrm{C} 4$ & 1,00 & 0,1110 \\
\hline
\end{tabular}

Com relação ao posicionamento das câmeras de monitoração, este foi realizado de maneira a possibilitar o registro dos movimentos dos modelo mediante reboque nos dois sentidos do tanque, o que provocou uma redução significativa no tempo de ensaio. Além disso, apesar dos $280 m$ de comprimento do tanque, conforme mencionado, apenas uma extensão de aproximadamente $170 \mathrm{~m}$ foi utilizada para a realização das corridas.

Portanto, com base nesta metodologia experimental foram realizados todos os ensaios que deram origem aos resultados apresentados no próximo capítulo. 


\section{Resultados Experimentais}

\subsection{SíNTESE}

No capítulo anterior foi apresentada a metodologia de trabalho, descrevendo os principais materiais utilizados e o método experimental adotado.

Essa metodologia, voltada à investigação de cilindros com baixa razão de aspecto, motivouse na crença de que um dos possíveis fatores responsáveis por influenciar as amplitudes e frequências de resposta do fenômeno de VIV pode estar relacionado à emissão de vórtices a partir da extremidade imersa desses cilindros. Conforme descrito na revisão bibliográfica, alguns poucos estudos se dedicaram às variações da geometria da extremidade livre, ainda assim, sempre dedicados à visualização da emissão e/ou análise das forças resultantes em cilindros fixos.

Deste modo, é possível perceber a oportunidade aparentemente original prestada pelo presente trabalho, no sentido de identificar experimentalmente o que acontece com as respostas (amplitudes, frequências e forças) de VIV nos cilindros curtos flutuantes (6GL e $m^{*}=1$ ), ao mesmo tempo em que permite identificar eventual relação entre estas respostas e a emissão de vórtices na superfície e aresta da extremidade livre imersa.

Interessante motivar as análises que se seguem neste capítulo apresentando a Figura 4.1, onde a utilização de permanganato de potássio (mancha lilás na água do tanque de reboque) permite a observação bastante clara da esteira periódica formada à jusante do cilindro de referência (C1). Ainda que não se tenha condições de definir sua origem (emissão em forma de arco ou emissão relacionada aos vórtices que partem da superfície e aresta livres), esta esteira periódica certamente é a responsável pelas VIV nos cilindros curtos, que será investigada neste capítulo a partir das amplitudes, frequências e forças impostas aos mesmos.

Infelizmente, é importante antecipar também que a caracterização direta do modelo fluido junto à extremidade livre por intermédio de técnicas como, por exemplo, o PIV são extre- 


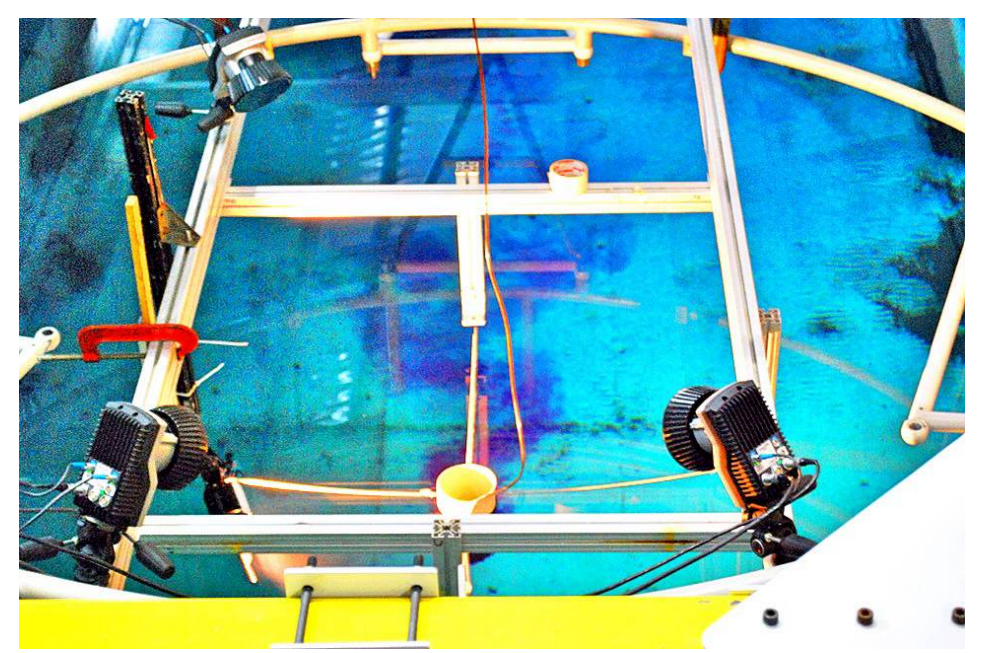

Figura 4.1: Esteira sendo formada a jusante do cilindro

mamente difíceis em cilindros flutuantes, ainda mais nas condições desfavoráveis apresentadas pelo tanque de reboque. Por esta razão, as análises e discussões que se seguem são baseadas nas amplitudes, frequências e forças devidas ao VIV nos cilindros com as quatro geometrias diferentes de extremidade imersa (C1, C2, C3 e C4).

\subsection{Amplitudes Adimensionais de Resposta}

As amplitudes de resposta adimensionalizadas pelo diâmetro do cilindro são muito utilizadas por permitir comparações entre experimentos de VIV que muitas vezes são realizados em diferentes escalas, ainda que envolvendo as mesmas características de razão de aspecto. Por este motivo, amplitudes adimensionais de resposta nas direções longitudinal $(\mathrm{X})$ e transversal $(\mathrm{Y})$ ao escoamento incidente foram os primeiros resultados analisados e comparados neste trabalho.

Seguindo o mesmo procedimento de análise adotado pelo grupo de pesquisa onde este trabalho foi desenvolvido (se necessário, consultar (GONçALVES, 2013)), a determinação da amplitude para cada velocidade reduzida foi realizada a partir do cálculo da média entre $20 \%$ dos valores extremos de resposta (máximos e mínimos); método escolhido por sua melhor representatividade dentre dois outros comumente utilizados (média entre todos os valores extremos $Y / D_{\max }$ e valor eficaz $Y / D^{*}$ a partir do valor rms - root mean square).

A Figura 4.2, retirada de (GONçALVES, 2013), compara os resultados de amplitude adimensional pelos três métodos mencionados. Para efeitos de aplicação ao VIM de plataformas, o valor baseado na média entre $20 \%$ dos valores extremos de resposta parece mais razoável devido a precisão de média obtida para casos extremos,como por exemplo 
a alta flutuabilidade dos sinais apresentado na Figura 4.2.

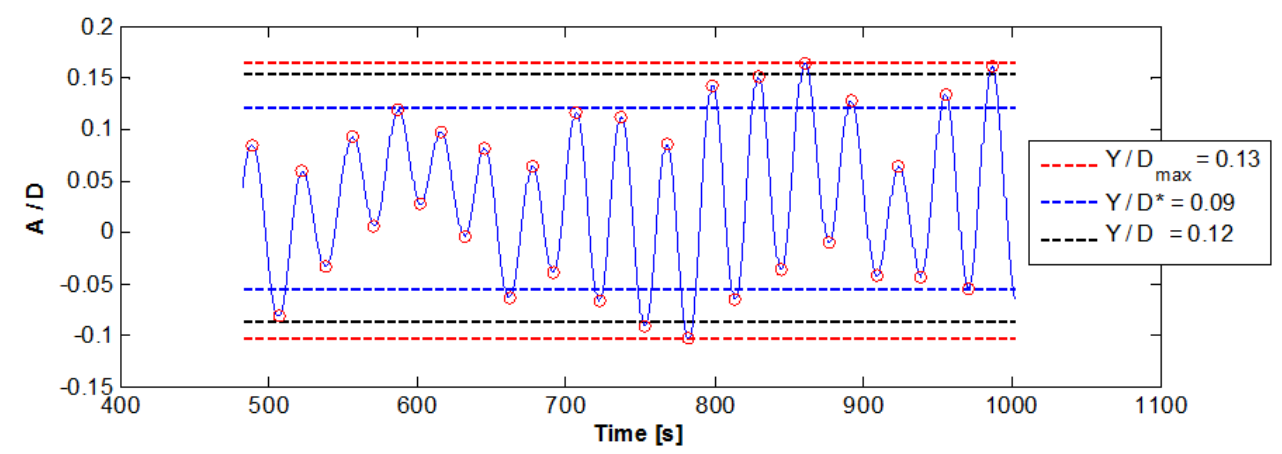

Figura 4.2: Comparação entre os métodos de determinação das amplitudes adimensionais de resposta devidas ao VIV em cilindros curtos. Fonte:(GONçALVES, 2013)]

Exemplos de series temporais obtidas nos ensaios deste trabalho são apresentados nas duas figuras que se seguem. Na primeira, Figura 4.3, tem-se a resposta transversal adimensional do cilindro $\mathrm{C} 1$ em $V_{r}=9,55$ e na segunda, Figura 4.4, a resposta longitudinal adimensional do cilindro $\mathrm{C} 2$ com $V_{r}=2,50$.

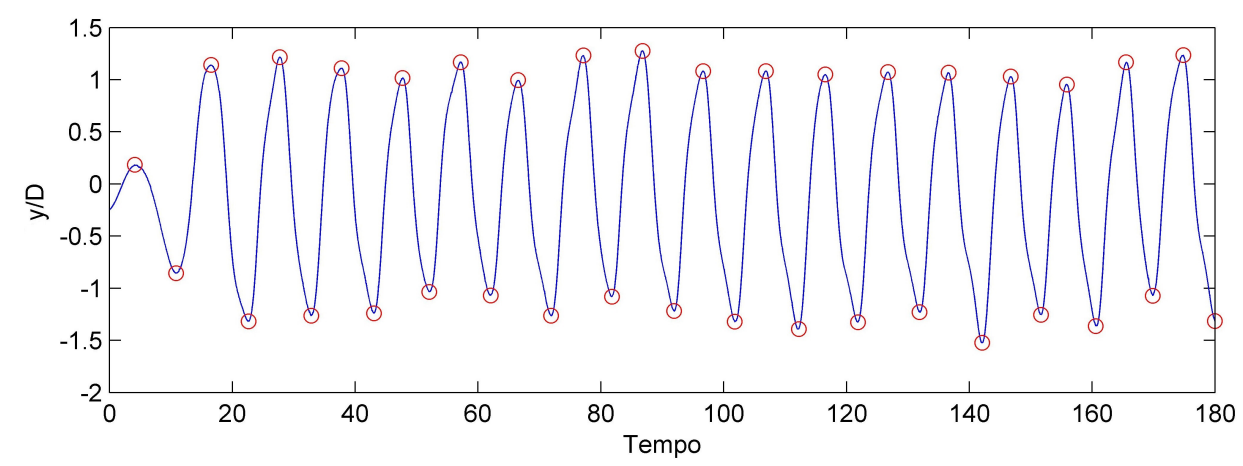

Figura 4.3: Exemplo de série temporal do deslocamento transversal adimensional. Gráfico referente ao VIV no modelo $\mathrm{C} 1 \mathrm{com} V r=9,55$.

De acordo com essas figuras, nota-se que as séries temporais de deslocamento nas direções transversal e longitudinal ao escoamento são bastante representativas do comportamento ressonante promovido pelo fenômeno de VIV, ainda que referente a cilindros com baixíssima razão de aspecto.

A Figura 4.5, por sua vez, mostra um exemplo de medição simultânea do comportamento nos seis graus de liberdade do modelo $\mathrm{C} 4 \mathrm{em} V r=8,5$. Em seu gráfico superior são apresentados os comportamentos referentes aos graus de liberdade de translação (direções X, Y e Z); ao centro o gráfico apresenta os comportamentos referentes aos graus de liberdade de rotação (roll, pitch e yaw) e no gráfico inferior é registrada a velocidade de reboque. 


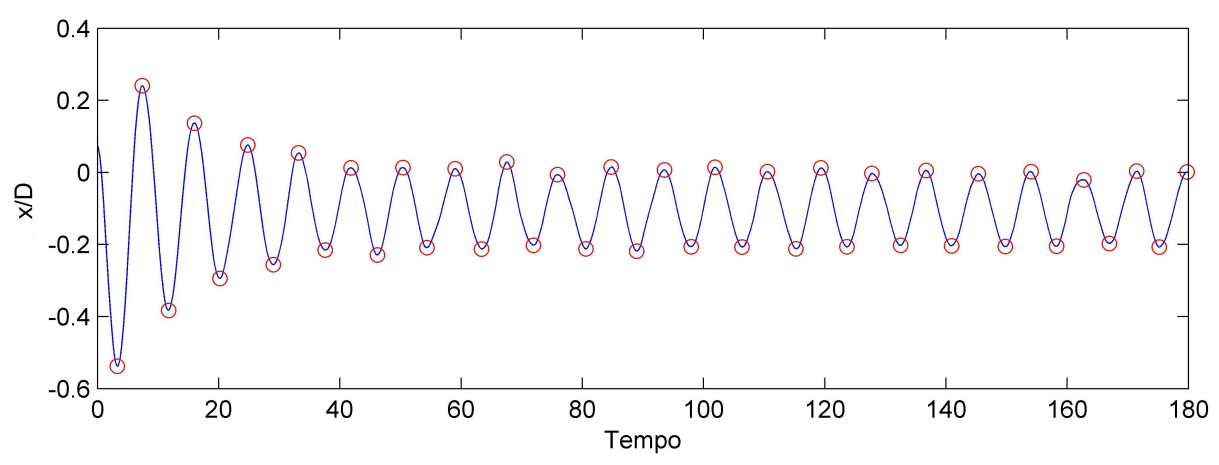

Figura 4.4: Exemplo de série temporal do deslocamento longitudinal adimensional. Gráfico referente ao VIV no modelo $\mathrm{C} 2$ com $V r=2,50$.
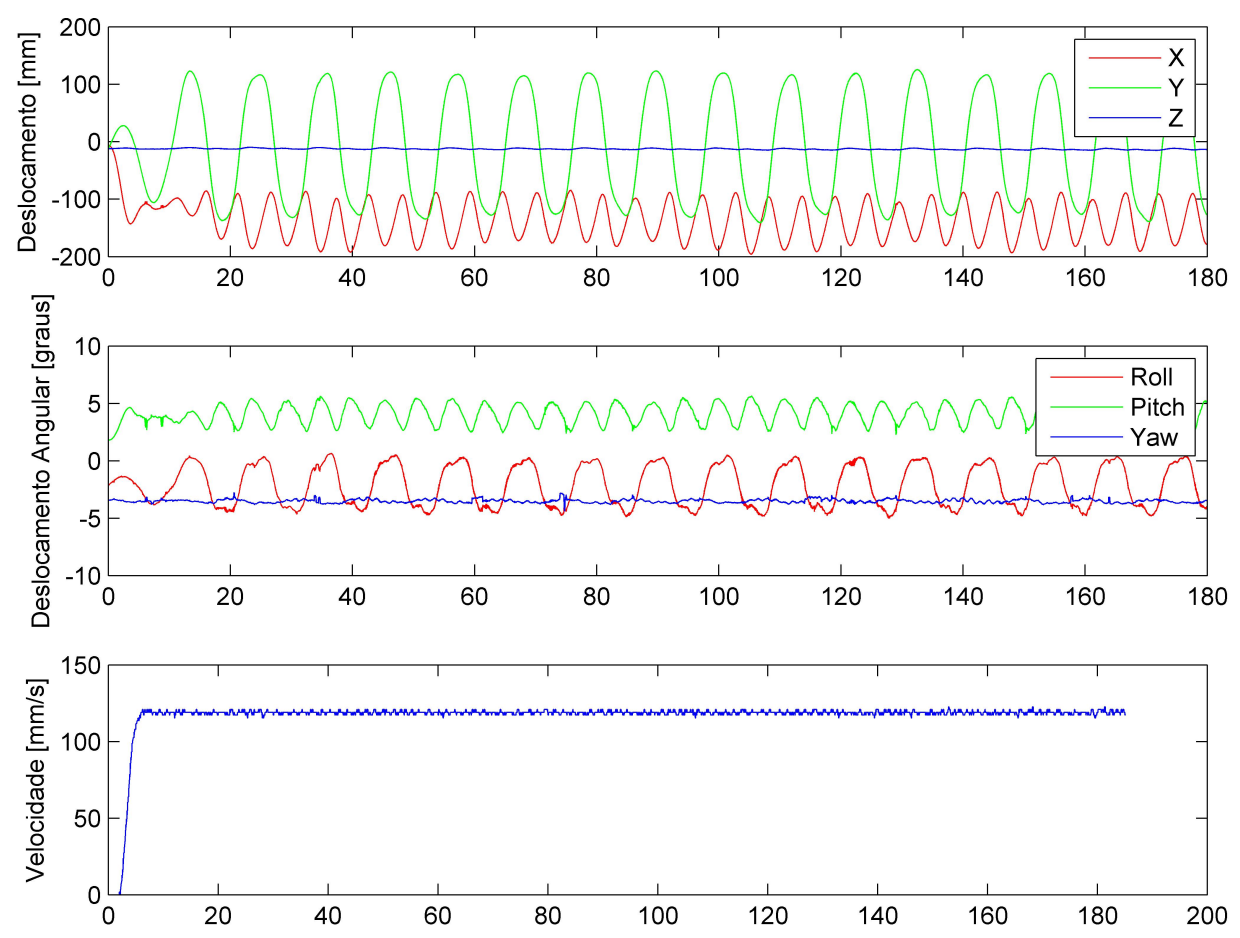

Figura 4.5: Exemplo de registro simultâneo dos comportamentos nos 6GL do cilindro C4 em $V r=8,5$ : no alto, translações em X, Y e Z; ao centro, rotações de roll, pitch e yaw; e abaixo o registro da velocidade imposta pelo carro de reboque.

Note que, conforme esperado, os movimentos de rotação ao redor da direção X (roll) acompanham os movimentos de translação na direção transversal ao escoamento incidente (sway ou movimento na direção Y) - comparar a série temporal em verde do gráfico superior com a série temporal em vermelho do gráfico central na Figura 4.5. Além disso, também conforme as expectativas quanto aos acoplamentos, os movimentos de translação na direção longitudinal (surge ou movimento na direção X) são acompanhados pelos movimentos de rotação ao redor da direção Y (pitch) - comparar a série temporal em 
vermelho do gráfico superior com a série temporal em verde do gráfico central na mesma figura.

Tais acoplamentos, surge-pitch e sway-roll, se caracterizam inclusive em termos dos respectivos períodos de oscilação, sendo que aqueles movimentos (surge-pitch) se estabelecem com aproximadamente metade do período desses (sway-roll) - comportamento dinâmico em perfeita consonância com a fenomenologia conhecida do VIV.

A Figura 4.6 mostra os resultados da amplitude adimensional na direção transversal ao escoamento como função das velocidades reduzidas $\left(A_{y} / D\right.$ versus $\left.V_{r}\right)$, considerando os cilindros curtos flutuantes com diferenças na geometria da extremidade imersa (C1 - aresta "viva"; C2 - com razão de arredondamento $r / R=0,25$; C3 - com razão de arredondamento $r / R=0,50$ e $\mathrm{C} 4-$ com a extremidade semi-esférica).

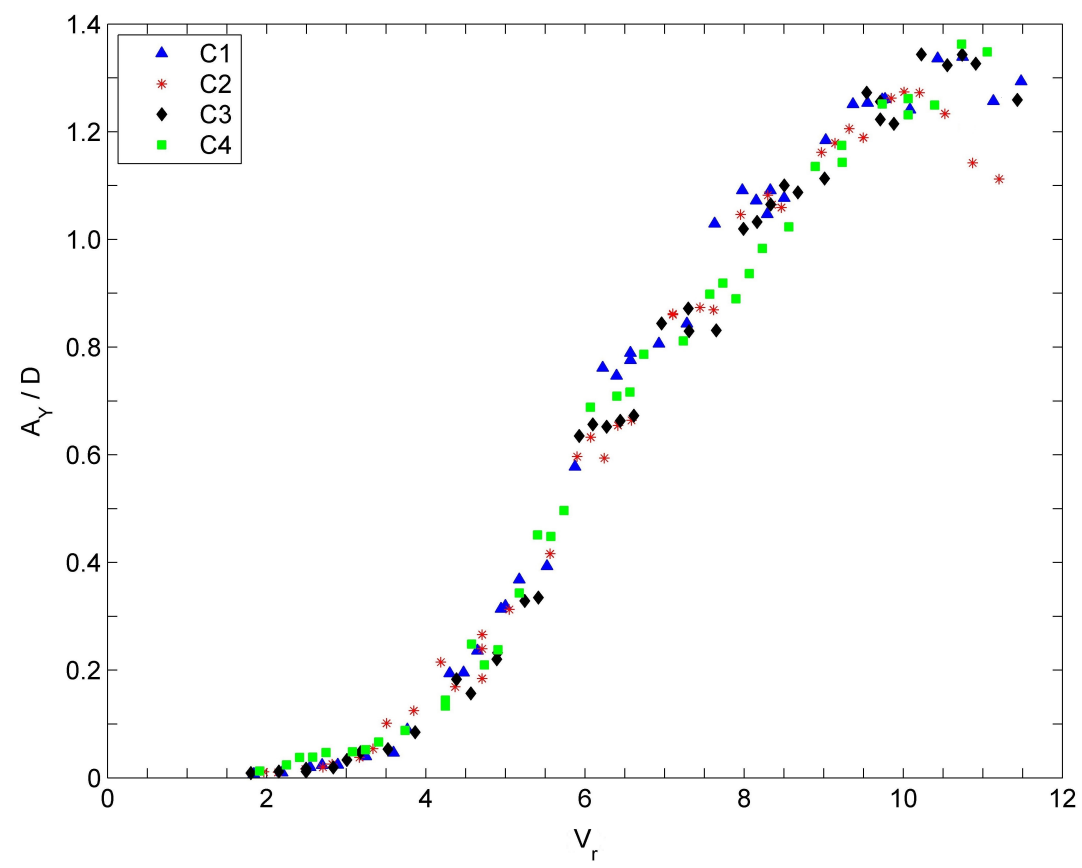

Figura 4.6: Amplitude adimensional transversal, $A_{y} / D$, como função da velocidade reduzida, $V_{r}$, para os cilindros curtos flutuantes: $\mathrm{C} 1, \mathrm{C} 2, \mathrm{C} 3$ e $\mathrm{C} 4$.

De uma maneira geral, o gráfico da Figura 4.6 mostra que os comportamentos dinâmicos dos quatro modelos na direção transversal ao escoamento são bastante semelhantes entre si, com um crescimento típico das respostas a partir de $V_{r} \approx 4$, que se desenvolve até $V_{r} \approx 8$. A partir desta velocidade reduzida, o comportamento geral parece se desenvolver segundo um ramo distinto de resposta, comprovado pela análise conjunta desta com aquela na direção longitudinal ao escoamento - mais adiante.

Há, contudo, uma diferença no valor de velocidade em que as respostas seus valores máximos. Percebe-se que o modelo $\mathrm{C} 2$ inicia a queda das amplitude adimensionais transversais 
em $V_{r} \approx 10$, velocidade reduzida menor que a respectiva para os cilindros $\mathrm{C} 1$ e $\mathrm{C} 3$, em $V_{r} \approx 11$. O cilindro $\mathrm{C} 4$, por sua vez, apresentou o mesmo comportamento que os cilindros C1 e C3, entretanto, exibindo amplitudes de resposta transversal ligeiramente maiores.

Com relação as amplitudes adimensionais na direção longitudinal ao escoamento $\left(A_{x} / D\right)$, a Figura 4.7 também mostras as análises em ralação a velocidade reduzida $\left(V_{r}\right)$ calculada com base na frequência natural transversal.

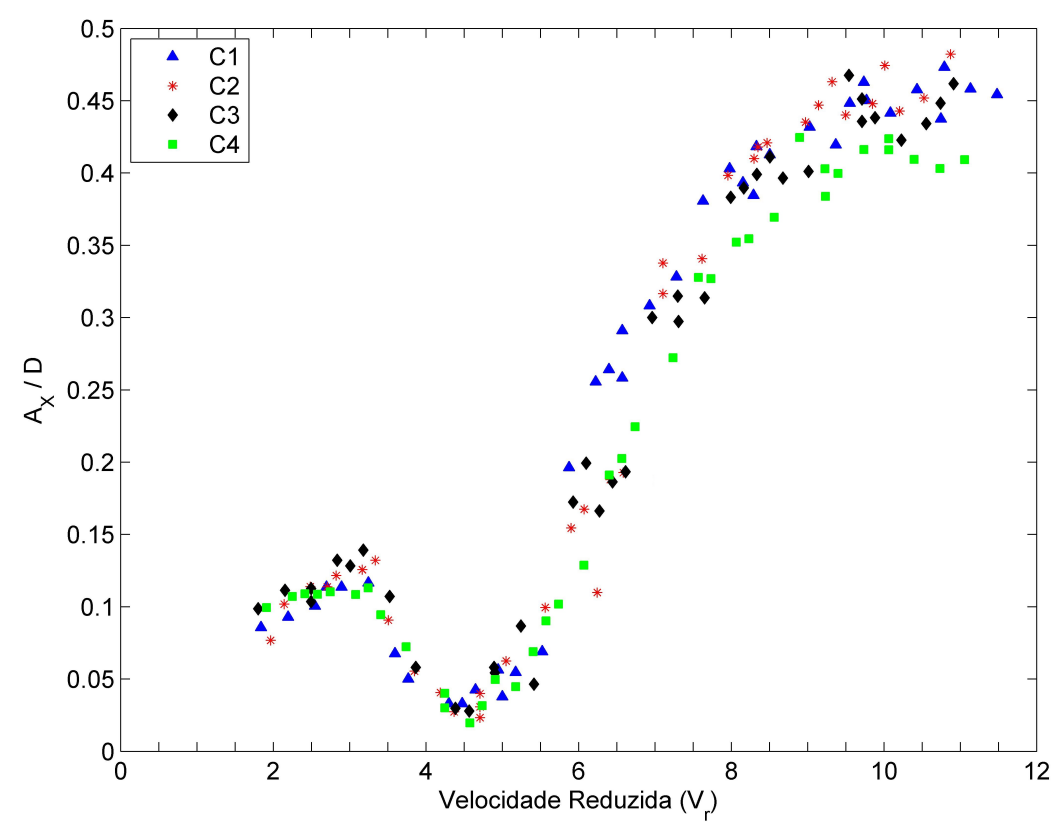

Figura 4.7: Amplitude adimensional longitudinal, $A_{x} / D$, como função da velocidade reduzida, $V_{r}$, para os cilindros curtos flutuantes: $\mathrm{C} 1, \mathrm{C} 2, \mathrm{C} 3$ e $\mathrm{C} 4$.

Como primeiro aspecto importante observado a partir da Figura 4.7, destaca-se a região de ressonância do movimento longitudinal em $2 \lesssim V_{r} \lesssim 4,5$. Além disso, comparando as Figuras 4.6 e 4.7, nota-se que o possível ramo distinto de resposta transversal é, de fato, resultado de um forte acoplamento entre oscilações nas duas direções X e Y.

Comparando os comportamento gerais das respostas longitudinais exibidas pelos quatro cilindros, é possível observar o comportamento do modelo $\mathrm{C} 4(r / R=1,0)$ apresenta amplitudes adimensionais de oscilação 16\% menores que aquelas dos demais modelos em $V_{r}>8$.

Um movimento pouco abordado nas análises de VIV diz respeito às rotações no plano da superfície livre (ao redor do eixo vertical ou, simplesmente, yaw). Tal desconsideração decorre do fato que a grande maioria dos experimento são realizados com apenas $2 \mathrm{GL}$ (cilindros ou sistema suportados por apoios elásticos nas direções X e Y), onde o grau de 
liberdade de rotação no plano horizontal acaba sendo restringido pelos pesquisadores.

Segundo investigações mais recentes, entretanto, sabe-se da importância desse movimento na interação fluido-estrutural, não só para as análises de sistemas com seções transversais não circulares, onde inclusive pode ocorrer o fenômeno de galloping, como também nas análises de VIV em sistemas com seções transversais circulares (caso específico deste trabalho), onde parte da energia fornecida pelo escoamento incidente é compartilhada entre os movimentos longitudinal (surge), transversal (sway) e de rotação no plano horizontal (yaw).

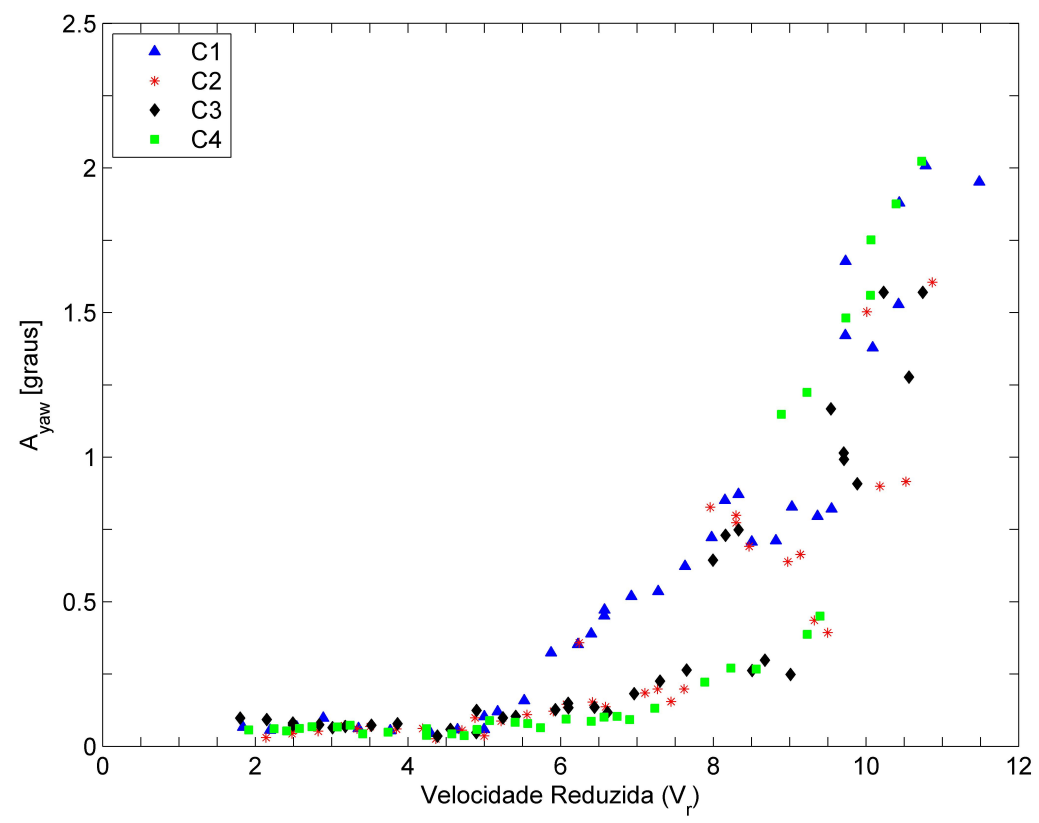

Figura 4.8: Amplitudes angulares do movimento de yaw, $A_{y a w}$, como função da velocidade reduzida calculada com base na frequência natural desse grau de liberdade, $V_{r}$, para os cilindros curtos flutuantes: C1, C2, C3 e C4.

Assim, a Figura 4.8 apresenta as amplitudes angulares do movimento de yaw como função das velocidade reduzidas calculadas com base na frequência natural nesse grau de liberdade.

De acordo com essa figura, observa-se que para o movimento de yaw há uma influência considerável da geometria da extremidade imersa no comportamento geral dos modelos. O cilindro $\mathrm{C} 1(r / R=0)$ apresenta amplitudes angulares superiores até velocidades reduzidas aproximadamente iguais a 9, quando então, os maiores movimentos angulares de yaw são observados no cilindro $\mathrm{C} 4(r / R=1)$.

Independente desta diferença, há que se destacar que, em geral, as amplitudes angulares máximas de yaw não superam os 2,5 graus, valor que, em princípio, não parece ter impor- 
tância decisiva para os objetivos deste trabalho. Ainda assim, reforça-se sua importância nas aplicações tecnológicas, como por exemplo no VIM de plataformas oceânicas, que impacta nos sistemas de risers, umbilicais e de amarração.

Um último resultado relacionado aos deslocamentos dos modelos diz respeito à deriva, isto é, o deslocamento provocado pela força de arrasto no sentido do escoamento. Resultados desta natureza podem ser observados na Figura 4.9, onde o valor da deriva também é adimensionalizado pelo diâmetro do modelo e apresentado como função das velocidades reduzidas considerando a frequência natural na direção transversal ao escoamento incidente.

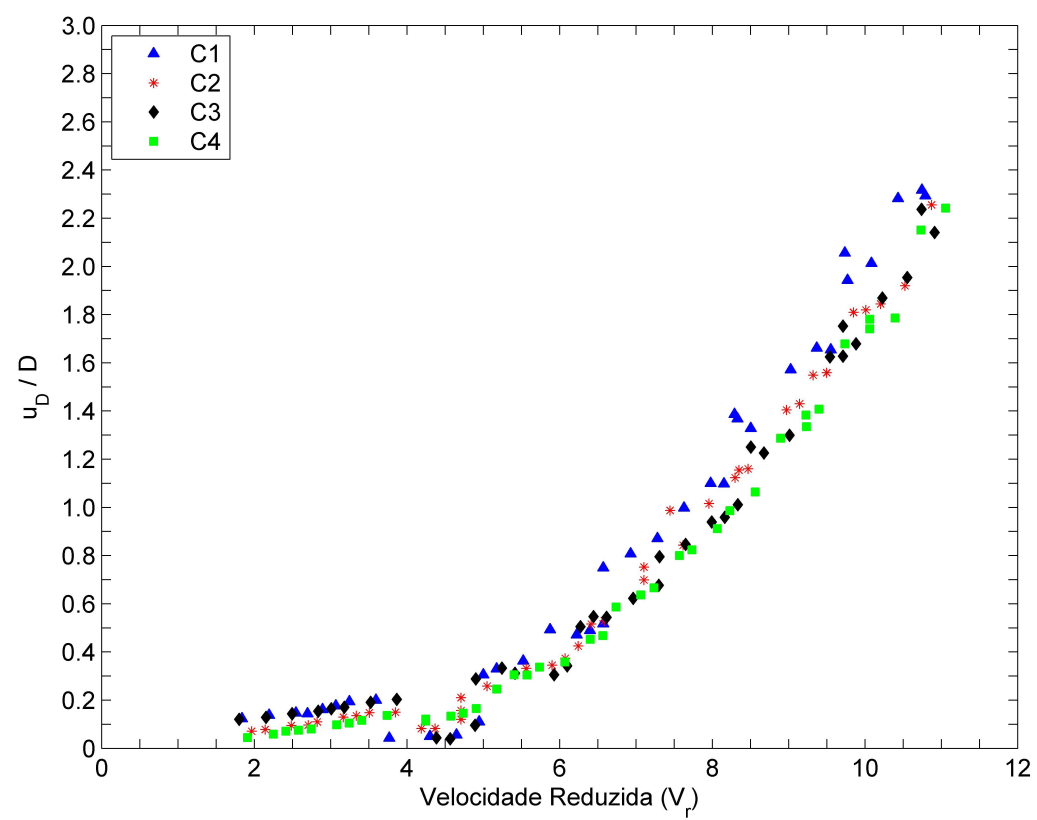

Figura 4.9: Deriva adimensional, $u_{D} / D$, como função da velocidade reduzida, $V_{r}$, para os cilindros curtos flutuantes: C1, C2, C3 e C4.

De maneira coerente, o aumento da velocidade do escoamento acarreta o crescimento da deriva para todos os modelos, sem contudo, desrespeitar a expectativa de que valores menores de deriva devem ser observados quanto maior for o grau de arredondamento da extremidade livre.

Com aspecto interessante, a Figura 4.9 também revela que no intervalo de $2 \lesssim V_{r} \lesssim 4$ a deriva sofre influência clara da ressonância na direção longitudinal ao escoamento, rever Figura 4.7. Além disso, a queda no valor da deriva em $V_{r} \approx 4$ coincide exatamente com o início da ressonância na direção transversal.

Lembrando que a execução do ensaio foi realizada para os 6 GL, entretanto, apenas 
resultados referentes a três graus foram abordados neste capítulo por pertencerem ao foco do trabalho. O Apêndice B apresenta com maior riqueza os resultados de amplitudes e razões de frequência para os demais graus de liberdade.

O próximo tópico apresenta e discute a movimentação do cilindro no plano XY (horizontal), onde os comportamento até aqui descritos ficam ainda mais claros.

\subsection{AnÁlise dos Movimentos do Plano XY}

Como descrito na revisão bibliográfica deste trabalho, o fenômeno de VIV (ou VIM) com dois ou mais graus de liberdade pode descrever trajetórias de movimento em "formato de 8"; as quais geralmente respondem pelas maiores amplitudes de resposta. Para ilustrar este comportamento e completar a etapa de análise das amplitudes, montagem evolutiva das trajetórias no plano XY foi construída para cada um dos modelos ensaiados, apresentada com base no aumento da velocidade reduzida; ver Figura 4.10.

Ao todo, a movimentação no plano XY foi descrita em oito velocidades para cada modelo investigado, distribuídas ao longo do gráfico das amplitudes adimensionais transversais e similares para que permitam comparações entre os comportamentos dinâmicos registrados.

A observação mais importante feita com base na Figura 4.10 vem de maneira a auxiliar o entendimento das amplitudes máximas de resposta apresentadas e discutidas no tópico 4.2 .

Assim, observando as primeiras trajetórias exibidas pelos modelos em $V_{r} \geq 4$, nota-se que os movimentos são predominantemente na direção X (longitudinal ao escoamento), mais pronunciados no modelo C3. Para os caso de $V_{r} \leq 4$, as amplitudes na direção Y (transversal ao escoamento) tornam-se maiores, crescendo na medida em que cresce o acoplamento entre os dois graus de liberdade (X e Y), comportamento claramente identificado pelas trajetórias em "formato de 8", acentuadas com o aumento da velocidade reduzida.

Além disso, apesar da modificação acentuada na geometria da extremidade imersa dos modelos, não se verificam comportamentos muito diferentes entre as trajetórias nas velocidades reduzidas mais altas. Há, no entanto, uma aparente alternância entre vibrações longitudinais e transversais no registro feito para o modelo $\mathrm{C} 1$ em velocidades reduzidas de aproximadamente 4,5 e 5,5. Nada parecido acontece com os outros modelos nessas mesmas velocidades. 


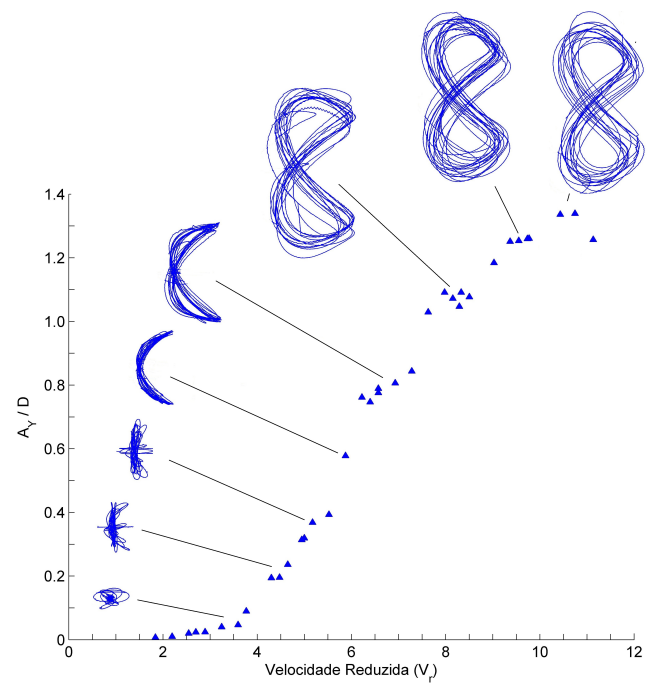

(a) Cilindro C1

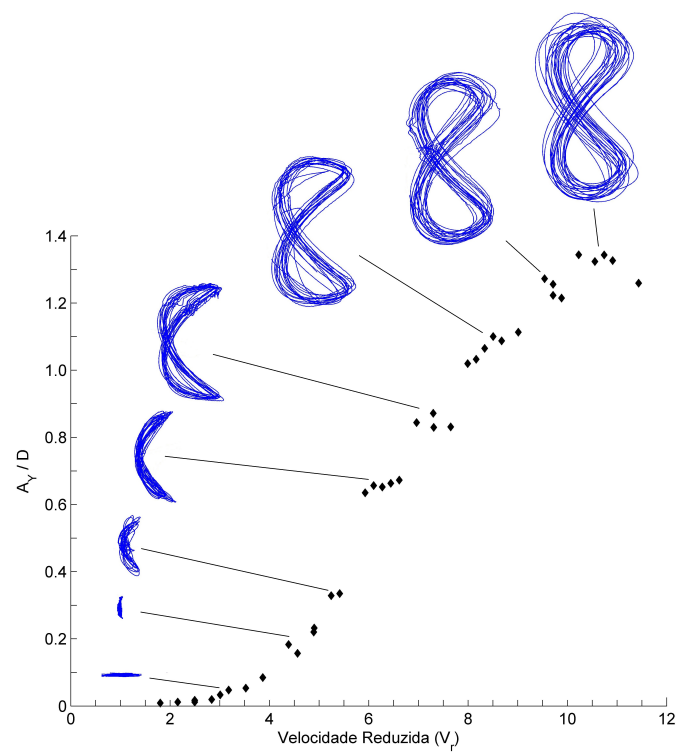

(c) Cilindro $\mathrm{C3}$

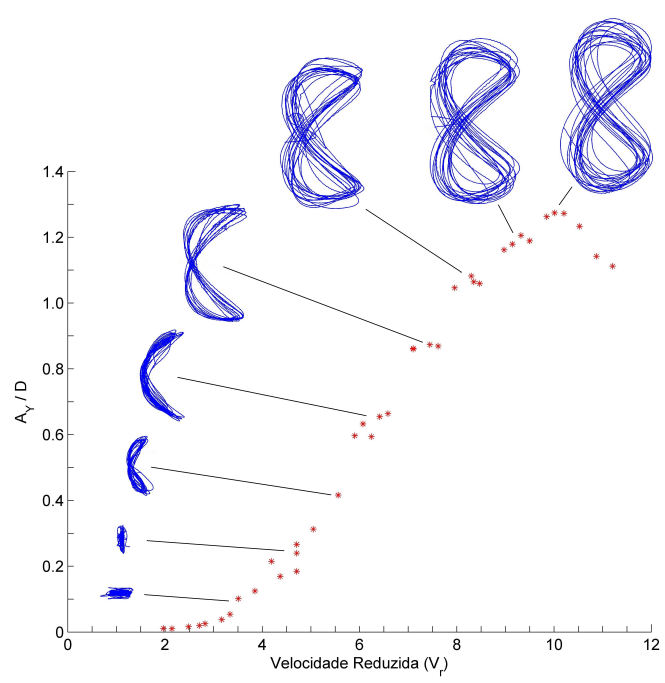

(b) Cilindro C2

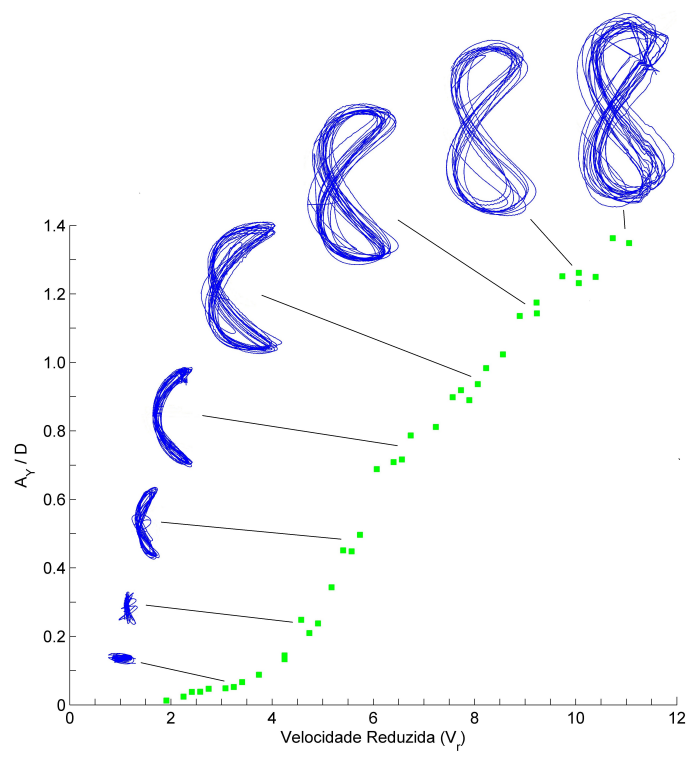

(d) Cilindro $C_{4}$

Figura 4.10: Evolução do movimento no plano XY para cada um dos cilindros curtos flutuantes, apresentada conforme a variação da amplitude adimensional transversa em função velocidade reduzida.

\subsection{FrEQUÊnCIAS AdIMENSIONAIS DE RESPOSTA}

Na Figura 4.11 são apresentados os resultados da razão entre a frequência de resposta transversal e frequência natural nesta mesma direção em águas paradas (obtida dos ensaios de decaimento), $f_{y} / f_{0}$.

De uma maneira geral, também em termos dessa razão entre frequências, o comportamento dos quatro cilindros é bastante semelhante, caracterizado por um valor análogo ao número 
de Strouhal, aproximadamente igual a 0,10 para velocidades reduzidas acima de 6. Para a obtenção do valor de St não foi mensurada a frequência de liberação de vórtices e sim a frequência de oscilação do cilindro na direção transversal, sendo assim análogo ao número de Strouhal.

O comportamento dos modelos próximos a reta linear traçada para $S t=0,10$ mostra que a frequência de emissão de vórtices ocorre de maneira similar para as diferentes extremidades imersas consideradas. Isto revela que, em se tratando de cilindro curtos flutuantes (com $6 \mathrm{GL}$ ), o valor de $S t=0,2$ tipicamente adotado para os cilindros longos com 2GL não pode ser adotado.

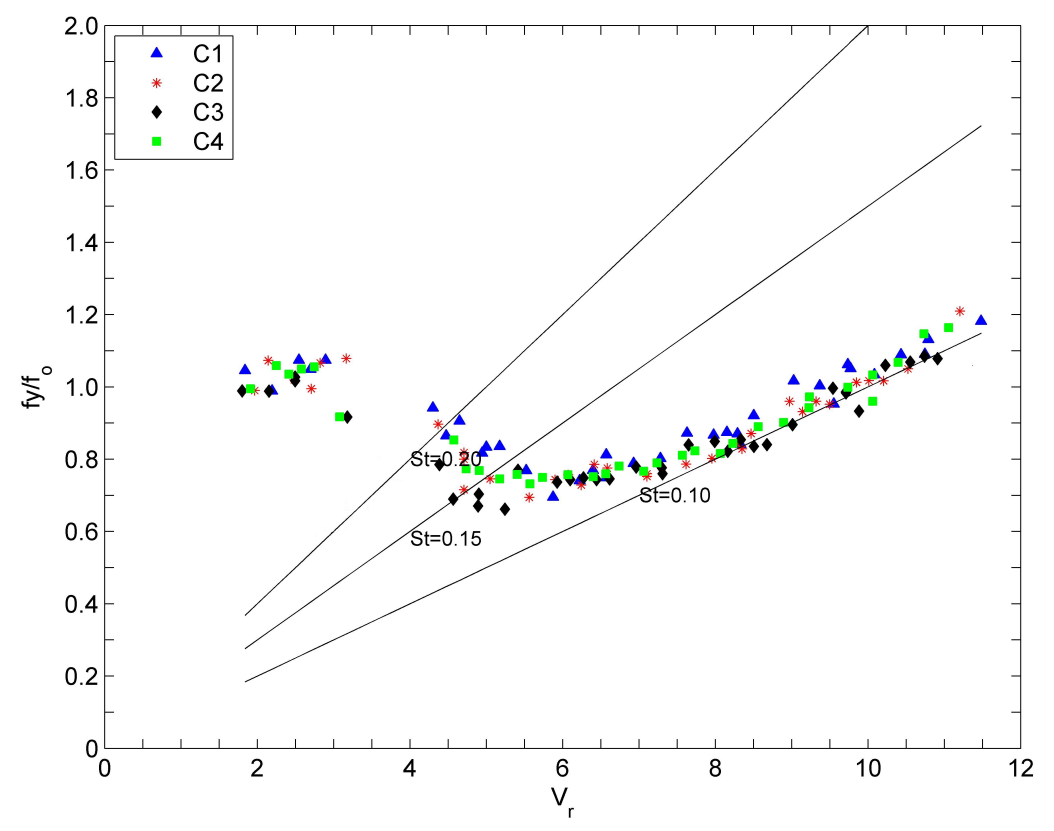

Figura 4.11: Razão entre frequência de resposta transversal e frequência natural em águas paradas, $f_{y} / f_{0}$, como função da velocidade reduzida, $V_{r}$

Os resultados para a razão entre frequência de respotas longitudinal e frequência de resposta transversal $\left(f_{x} / f_{y}\right)$ podem ser observados a Figura 4.12. Conforme esperado e em acordo com a fenomenologia do VIV relativa ao acoplamento, oscilações longitudinais apresentam frequências de oscilação duas vezes maiores que aquelas observadas na direção transversal, o que da origem ao padrão aproximadamente constante de $f_{x}=2 f_{y}$ em velocidades reduzidas maiores do que 5 .

É importante notar que, na região de ressonância longitudinal a relação entre frequências é aproximadamente unitária. 


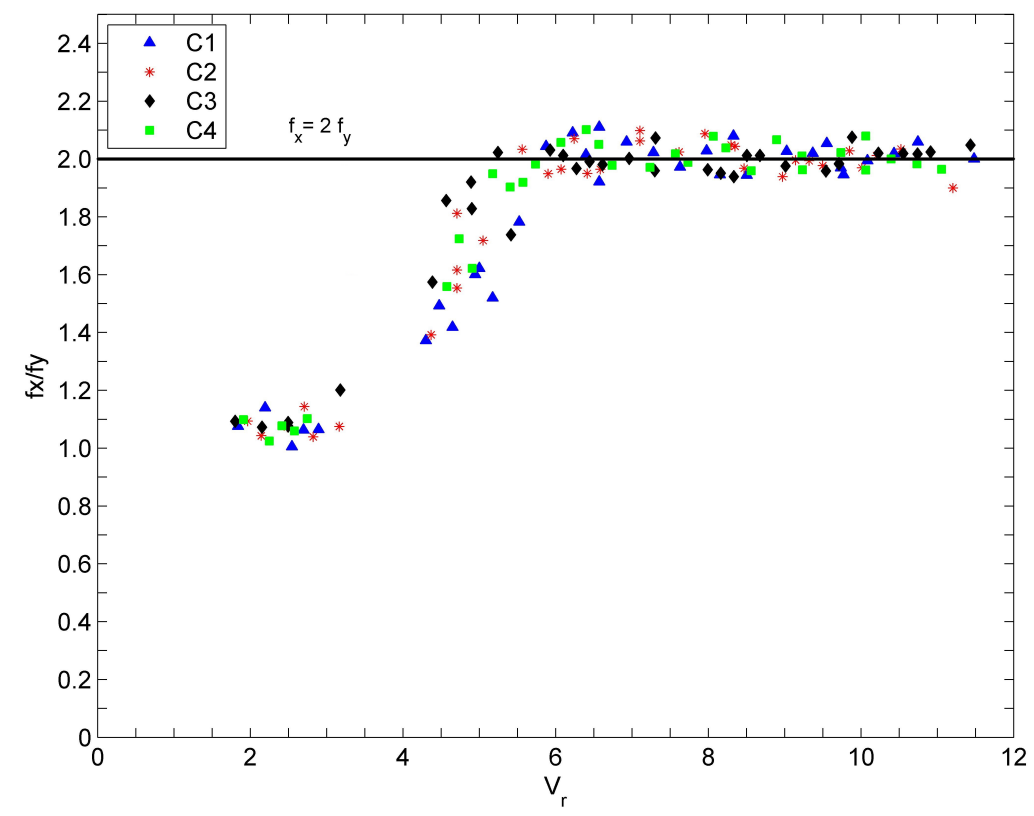

Figura 4.12: Razão entre frequência de reposta longitudinal pela frequência de resposta transversal, $f_{x} / f_{y}$, como função da velocidade reduzida, $V_{r}$

\subsection{COEFICIENTES DE FORÇA}

Os coeficientes de força foram indiretamente determinados a partir dos esforços fluidodinâmicos atuantes sobre os cilindros nas direções longitudinal e transversal, conforme as equações 2.5 e 2.4 .

Esses esforços, por sua vez, foram obtidos com base na equação diferencial que rege a dinâmica em cada um dos graus de liberdade, desconsiderando as contribuições dissipativas em virtude das baixas velocidade de oscilação e dos baixos coeficientes de amortecimento envolvidos.

Os coeficientes de arrasto médio e de sustentação, $C_{x}$ e $C_{y}$, são respectivamente apresentados nas Figuras 4.13 e 4.14 .

Para a maior parte da faixa de velocidades reduzidas considerada, os coeficientes de arrasto médio para o cilindro $\mathrm{C} 1(r / R=0)$ mostraram-se superiores aos valores exibidos pelos demais cilindros. Em termos quantitativos, essa diferença chega a ser de aproximadamente 0,7 , se $\mathrm{C} 1$ é comparado com os modelos $\mathrm{C} 2(r / R=0,25)$ e $\mathrm{C} 3(r / R=0,5)$, e ainda maior, aproximadamente 1,3, se comparado com modelo C4. Conforme esperado, o modelo C4 é aquele que apresenta os menores valores de coeficiente de arrasto.

Em relação aos coeficientes de sustentação, o cilindro C1 também é aquele que apresenta 


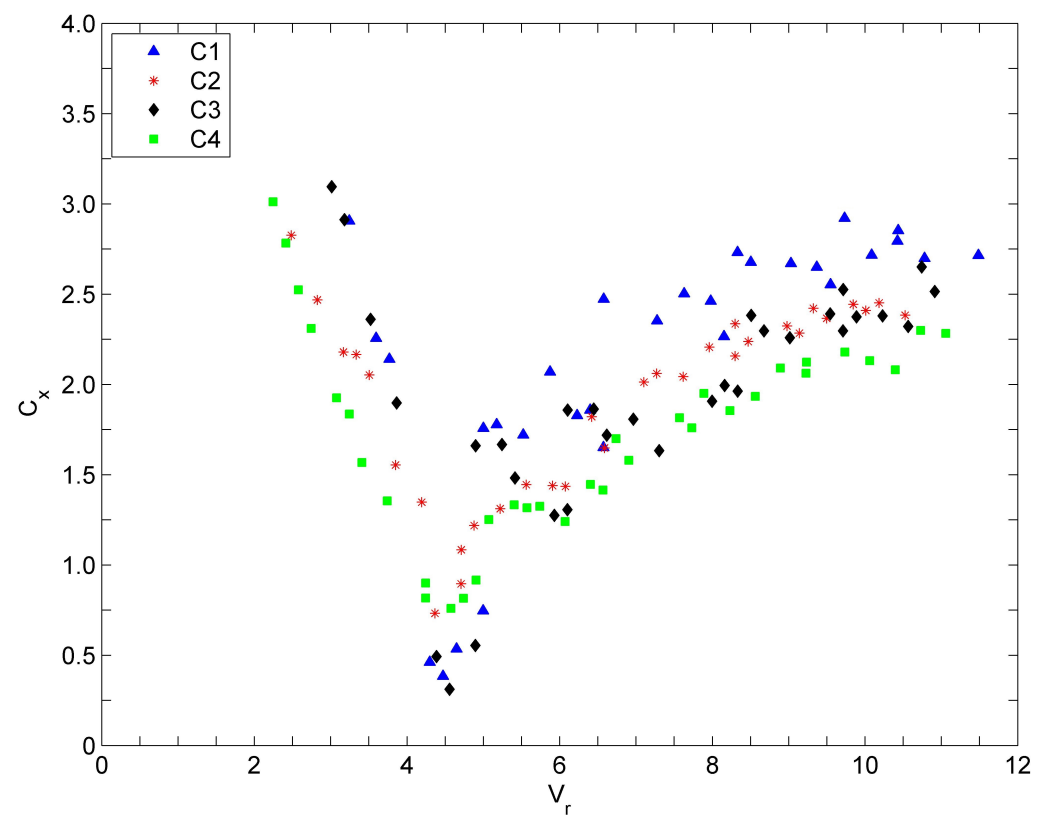

Figura 4.13: Coeficientes de arrasto médio, $C_{x}$, apresentados como função da velocidade reduzida, $V_{r}$.

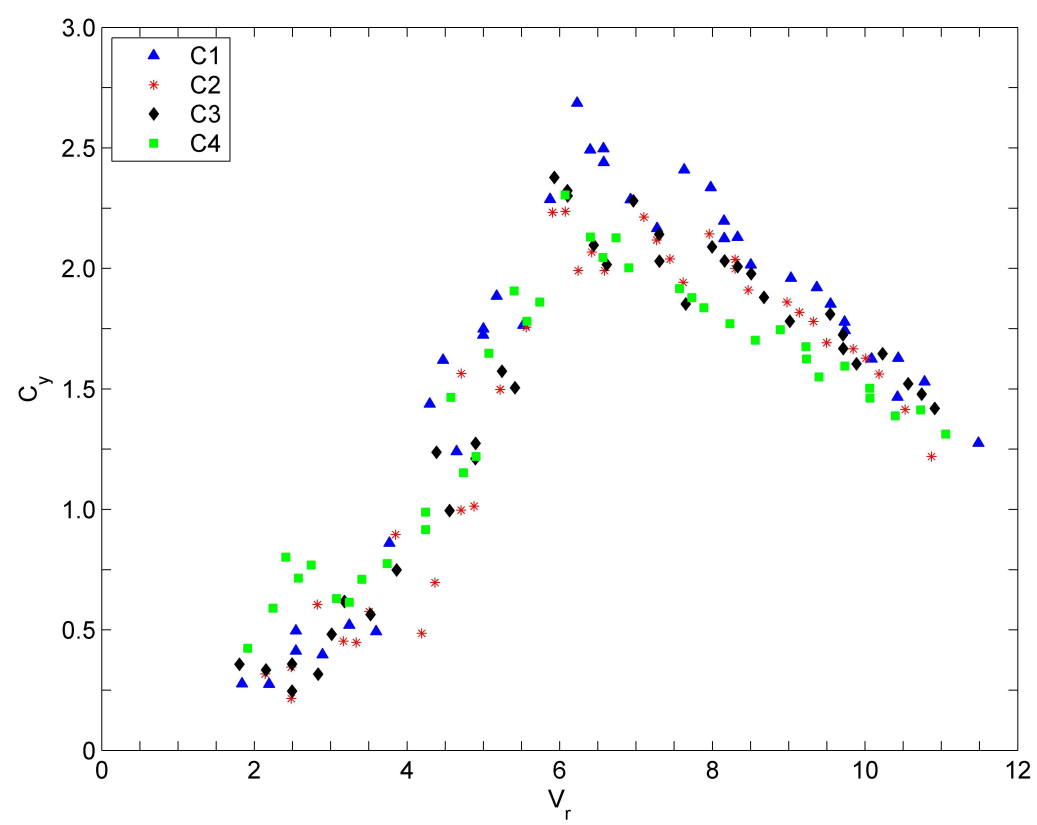

Figura 4.14: Coeficientes de sustentação, $C_{y}$, apresentados como função da velocidade reduzida, $V_{r}$.

valores superiores aos demais para $V_{r}>4$. A maior diferença pode ser observada em $V_{r} \approx 6,5$, quando os valores para o $\mathrm{C} 1$ chegam próximos a $C_{y}=2,5$, que curiosamente corresponde ao maior coeficiente encontrado dentre as velocidades ensaiadas. Por outro lado, os modelos $\mathrm{C} 2$, C3 e $\mathrm{C} 4$ alcançam um valor máximo de $C_{y} \approx 2$. Após os pontos 
máximos, a curva de todos os cilindros decresce para $V_{r}>7$. O cilindro $\mathrm{C} 4(\mathrm{r} / \mathrm{R}=1)$, entretanto, inicia esse decréscimo de maneira antecipada, apresentando valores ligeiramente menores. Importante observar que as curvas do coeficiente de sustentação para cada um dos cilindros se aproximam bastante quando $V_{r}=10$.

A Figura 4.15, finalmente, mostra os resultados do coeficiente de arrasto dinâmico para os cilindros ensaiados. Os comportamentos, em geral, se assemelham e deixam claro o efeito da amplificação dinâmica do arrasto quando ocorre o acoplamento entre oscilações nos dois graus de liberdade. Analogamente, o cilindro C1 e aquele que apresenta os maiores valores de arrasto dinâmico, definido, ao menos em termos das forças, um efeito mais destacado da aresta "viva" na extremidade imersa.

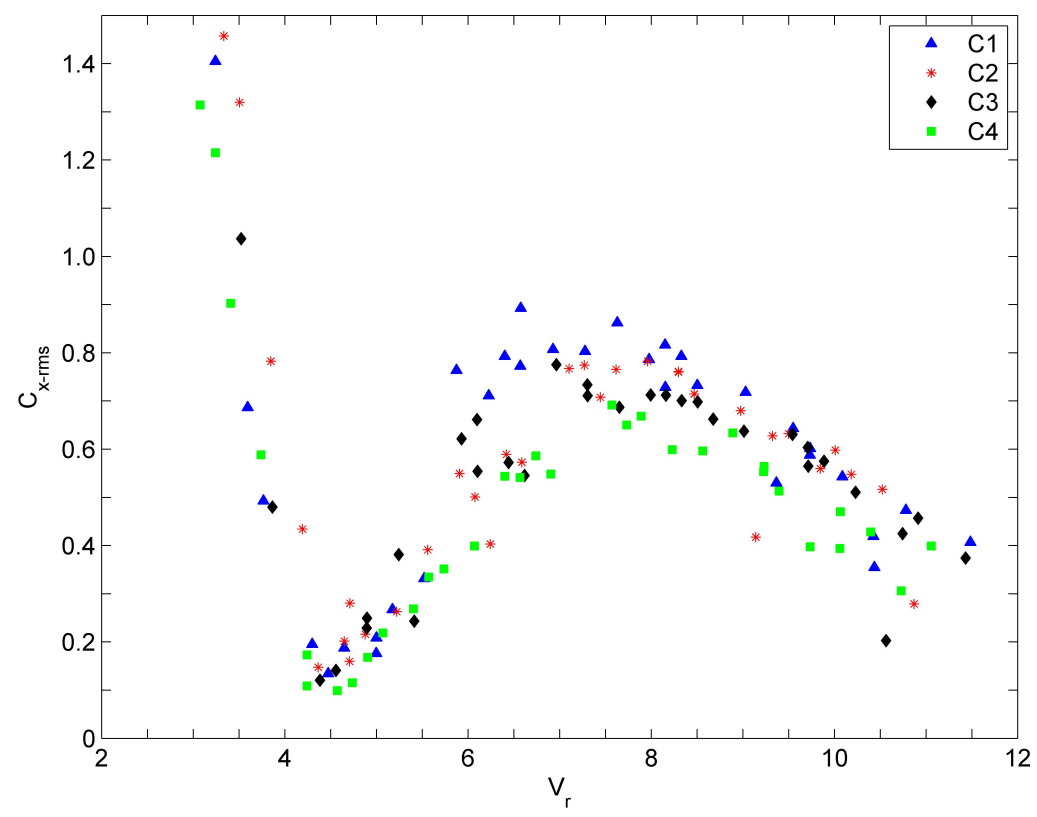

Figura 4.15: Coeficientes de arrasto dinâmico, $C_{x-r m s}$, apresentados como função da velocidade reduzida, $V_{r}$.

\subsection{EXPERIMENTOS DE VISUALIZAÇÃO DO ESCOAMENTO}

Para uma visualização do escoamento próximo à superfície imersa dos cilindros, foram realizados ensaios com os cilindros $\mathrm{C} 1(\mathrm{r} / \mathrm{R}=0.0)$, $\mathrm{C} 3(\mathrm{r} / \mathrm{R}=0.5)$ e $\mathrm{C} 4(\mathrm{r} / \mathrm{R}=1.0)$. O objetivo foi tentar mostrar como o escoamento afeta na esteira principal, assim, vale deixar claro que as imagens obtidas têm o propósito de apenas ilustrar o fenômeno e não de quantificar e analisar as características do escoamento ao redor dos modelos.

Para tanto, os cilindros foram fixos e rebocados em três números de Reynolds distintos, 
são eles: $R e=1,0 \times 10^{4} ; \operatorname{Re}=1,4 \times 10^{4}$ e $R e=1,8 \times 10^{4}$. Para melhor visualização do escoamento na aresta, um estreito jato de uma solução de permanganato de potássio foi posicionado e lançado continuamente na extremidade do cilindro para diferentes velocidades.

Um pequeno tubo, fixado no quadro a montante do cilindros, direcionou a solução de permanganato para as arestas de maneira idêntica para os três casos. As Figuras 4.16, 4.17 e 4.18 ilustram instantes desses ensaios.

Note, Figura 4.16, que no caso do cilindro C1 (aquele com aresta "viva"), a solução de permanganato passa mais longe da superfície plana na extremidade imersa do modelo, comportamento resultante da ação da bolha de recirculação formada nesta região, que não apresenta grandes variações de tamanho nas velocidades ensaiadas. É possível observar também o fenômeno de downwash no escoamento à jusante do cilindro (discutido no Capítulo 2), presente em todos os valores de número de Reynolds ensaiados.

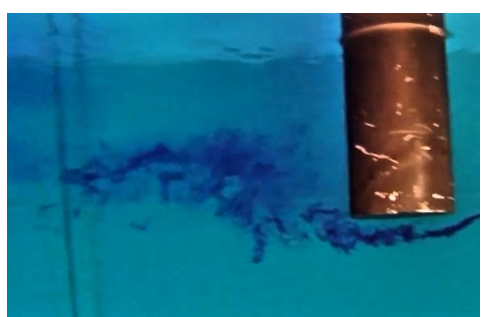

(a) $\operatorname{Re}=1,0 \times 10^{4}$

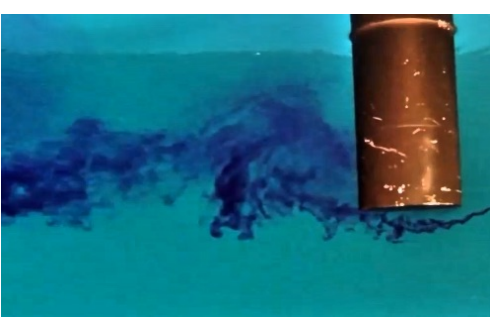

(b) $R e=1,4 \times 10^{4}$

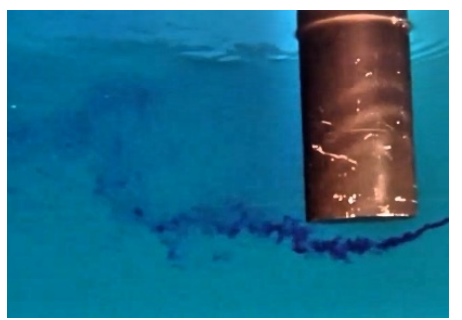

(c) $\operatorname{Re}=1,8 \times 10^{4}$

Figura 4.16: Ensaio de visualização do escoamento para o cilindro $\mathrm{C} 1, r / R=0.0$, para três diferentes números de Reynolds.

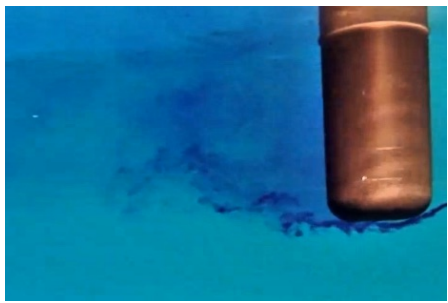

(a) $\operatorname{Re}=1,0 \times 10^{4}$

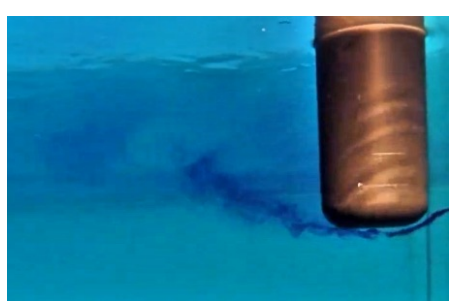

(b) $R e=1,4 \times 10^{4}$

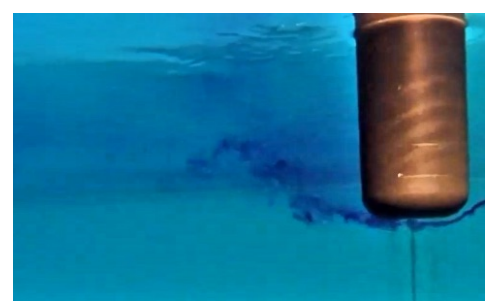

(c) $R e=1,8 \times 10^{4}$

Figura 4.17: Ensaio de visualização do escoamento para o cilindro $\mathrm{C} 3, r / R=0.5$, para três diferentes números de Reynolds.

Pela figura 4.17, é possível se observar que a solução de permanganato claramente tangencia com maior proximidade a aresta submersa do cilindro C3, o que reforça a ideia de que a aresta arredondada diminui a bolha de recirculação formada na parede inferior do cilindro. 
Já para o caso do modelo C4, o comportamento de downwash do escoamento continua sendo observado, porém com algumas modificações se comparado àquele observado no escoamento junto aos modelos C1 e C3.

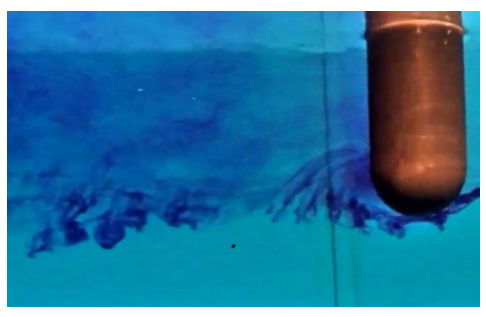

(a) $R e=1,0 \times 10^{4}$

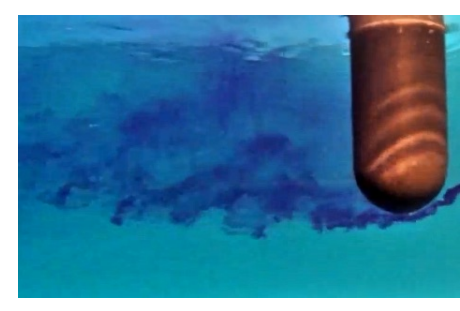

(b) $R e=1,4 \times 10^{4}$

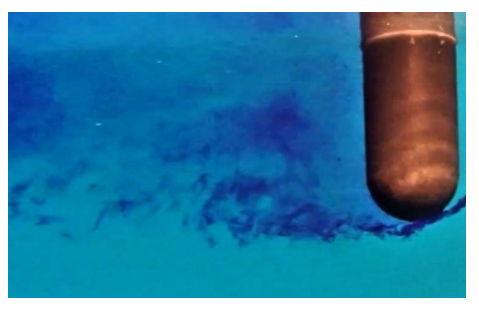

(c) $R e=1,8 \times 10^{4}$

Figura 4.18: Ensaio de visualização do escoamento para o cilindro $\mathrm{C} 4, r / R=1.0$, para três diferentes números de Reynolds.

Visualmente, portanto, os resultados das trajetórias com solução de permanganato se assemelham aos resultados de (PARK; LEE, 2000), obtidos em túnel de vento e monitorados por PIV.

De uma maneira geral, fica claro que o fenômeno de downwash, está presente nos três casos ensaiados, entretanto, algumas alterações podem ser observadas conforme a aresta foi modificada pelos arredondamentos.

A modificação da aresta não impôs grandes alterações para o cilindro curto, o que também leva a crer que o mecanismo de vibração está relacionado com uma emissão do tipo archtype e não com os vórtices que partem da superfície imersa. 


\section{Conclusões e Perspectivas}

O propósito fundamental deste trabalho foi contribuir para o entendimento da ação da extremidade imersa na resposta do fenômeno de Vibração Induzida por Vórtices (VIV) agindo em cilindros com pequena razão de aspecto $(L / D$, onde $L$ é comprimento imerso e $D$ o diâmetro do cilindro).

Para tanto, foram realizados experimentos de VIV no tanque de reboque do Instituto de Pesquisas Tecnológicas do Estado de São Paulo (IPT), considerando quatro diferentes cilindros curtos com $L / D=2$ e diferentes graus de arredondamento da extremidade imersa, varrendo $0 \leq r / R \leq 1$, onde $r / R$ diz respeito à razão entre os raios de "adoçamento" e do cilindro circular. Todos os cilindros flutuantes foram rebocados com auxílio de um suporte elástico composto por molas helicoidais de tração, permitindo a movimentação em seis graus (6GL).

Esta proposição de investigação se fez com base em uma revisão bibliográfica a respeito da fenomenologia do VIV, apresentando os fundamentos e parâmetros utilizados para entendimento desse problema no cenário da indústria naval e oceânica - onde é conhecido como Movimentos Induzidos por Vórtices (VIM). A revisão bibliográfica também permitiu verificar que a extremidade livre pode ter um efeito decisivo nas respostas de VIV em cilindro curtos - tema particularmente pouco explorado na literatura científica.

Com os primeiros resultados deste trabalho, mostrou-se que o comportamento das amplitudes adimensionais na direção transversal é bastante similar entre cilindros curtos com diferentes geometrias de extremidade imersa. De uma maneira geral, as amplitudes transversais $\left(A_{Y} / D\right)$ crescem de forma pronunciada a partir de $V_{r} \geq 4$, atingindo valores máximos de até $1,35 D$ em $V_{r} \approx 10,5$; pequena diferença encontrada no comportamento do cilindro $\mathrm{C} 2(r / R=0,25)$, que apresentou um valor máximo de aproximadamente $1,30 \mathrm{D}$ em velocidade reduzida ligeiramente menor, $V_{r} \approx 10$.

Resultados de amplitude adimensional longitudinal $\left(A_{X} / D\right)$ também mostraram comportamentos semelhantes entre os cilindros curtos sujeitos ao VIV, inclusive na ressonância 
desse movimento, em $2 \lesssim V_{r} \lesssim 4,5$. Diferenças ligeiramente acentuadas deveram-se ao fato do cilindro $\mathrm{C} 4(r / R=1,00)$ obedecer o mesmo comportamento geral dos cilindros $\mathrm{C} 1$ $(r / R=0,00)$ e C3 $(r / R=0,50)$, entretanto, com amplitudes menores.

Um terceiro grau de liberdade pouco explorado pela literatura, ainda que de suma importância para as aplicações oceânicas, foi o movimento de rotação em torno da direção vertical, ou yaw. Para esse movimento angular, diferenças mais pronunciadas foram identificadas quando na comparação entre os comportamentos das diferentes geometrias da extremidade imersa. Segundo os resultados, o cilindro C1 apresentou amplitudes angulares superiores para velocidades reduzidas de até 9, valor a partir do qual, o cilindro C4 passou a exibir as maiores amplitudes. Vale destacar que os ângulos apurados não ultrapassaram 2,5 graus, valor considerado sem importância apreciável para as conclusões deste trabalho.

A comparação da deriva dos modelos na direção do escoamento também foi analisada, revelando que os resultados do cilindro $\mathrm{C} 1$ se mostram superiores àqueles dos outros modelos.

Apesar da mudança pronunciada realizada na extremidade imersa, as trajetórias referentes aos movimentos devidos ao VIV no plano XY não mostraram grandes diferenças. De maneira geral, o movimento para $V_{r} \leq 4$ possui uma predominância de oscilações na direção do escoamento incidente e, com o aumento gradativo da velocidade reduzida, os movimentos na direção transversal passam a ser maiores, até darem origem a trajetórias em "formato de 8", típicas do acoplamento responsável pelas grandes amplitudes e intensamente descrito nos trabalhos de VIV em cilindros com 2GL.

Em termos das frequências de oscilação na direção transversal, os resultados mostraram que para velocidades reduzidas acima de 6, a constante análoga ao número de Strouhal característico dos cilindros $\operatorname{com} L / D=2$, independente da geometria na extremidade imersa, se manteve em aproximadamente 0,10. Isto significa que o comportamento de emissão de vórtices nos cilindros curtos ocorre de maneira similar àquela nos cilindros longos $(L / D>13)$, porém com padrões de emissão caracterizados por períodos maiores.

Os resultados para a razão entre frequências de resposta longitudinal e transversal $\left(f_{x} / f_{y}\right)$ mostraram comportamentos de acordo com a fenomenologia esperada para o VIV, isto é, frequências de oscilação longitudinal com valores aproximadamente iguais ao dobro das frequências de oscilação transversal, $f_{x}=2 f_{y}$.

Também conforme as expectativas, na medida em que o raio de arredondamento da aresta 
na extremidade imersa foi aumentado, menores foram os coeficientes de arrasto atuantes nos cilindros, chegando a uma diferença de aproximadamente 1,3 na comparação entre os cilindros C1 e C4. Análises para o coeficiente de sustentação também mostraram que o cilindro sem modificações na extremidade apresentou os maiores valores para velocidades reduzidas acima de 4 . Em $V_{r} \approx 6,5$, os modelos apresentam seus valores máximos para o coeficiente de sustentação, velocidade em que também se acentua a diferença de resultados do cilindro $\mathrm{C} 1$ em comparação com os demais modelos.

Portanto, sob uma perspectiva mais abrangente, pode-se concluir que a dinâmica do VIV em cilindros curtos flutuantes exibe movimentos e coeficientes de força ligeiramente menores na medida em que a extremidade imersa vai se tornando mais arredondada. Isto é coerente com os resultados publicados em (ROH; PARK, 2003), onde os autores relatam que tal redução se deve à diminuição das bolhas de recirculação à jusante dos cilindros.

Esta diminuição das amplitudes e forças, no entanto, não acontece de maneira acentuada, o que permitiria a assertiva de que o VIV nos cilindros curtos flutuantes tem relação com os trailing vortices e os tip vortices.

Como perspectiva de continuidade das investigações que definirão o mecanismo exato responsável pelo fenômeno de VIV atuante em cilindros curtos, sugere-se a visualização do escoamento próximo (com a utilização de câmeras capazes de captar o movimento das particular no entorno dos cilindros - técnica de PIV) e/ou a medição do campo de pressões nessa mesma região.

Além disso, também seriam importantes simulações via método de volumes finitos pela dinâmica dos fluidos computacional, trazendo diferentes resultados quanto aos modelos fluidos envolvidos.

Finalmente, apesar das magnitudes dos movimentos nos graus de liberdade escassamente exploradas nas investigações do VIV não se mostrarem acentuadas (heave, roll, pitch e yaw), o simples fato de existirem abre margem para investigações mais aprofundadas, visto que os acoplamentos aqui identificados podem contribuir para o próprio modelo fluido responsável pelas oscilações transversais e longitudinais dos cilindros curtos flutuantes. 


\section{REFERÊNCIAS BIBLIOGRÁficAS}

ACHENBACH, E.; HEINECKE, E. On vortex shedding from smooth and rough cylinders in the range of reynolds numbers. Journal of Fluid Mechanics, p. 239-251, 1981.

ASSI, G. R. S. Estudo Experimental do Efeito de Interferência no escoamento ao redor de Cilindros Alinhados. Dissertação (Mestrado) — Escola Politécnica da Universidade de São Paulo, São Paulo, 2005.

ASSI, G. R. S. Mechanisms for flow-induced vibration of interfering bluff bodies. Tese (Doutorado) — Imperial College London, Londres, 2009.

BEARMAN, P. W. Vortex shedding from oscillating bluff bodies. Annual Review of Fluid Mechanics, p. 195-222, 1984.

BLEVINS, R. D. Flow-Induced Vibration. 2nd edition ed. [si]. ed. [S.l.]: Krieger Pub Co, 2001.

FINN, L.; MAHER, J.; GUPTA, J. The cell spar and vortex induced vibrations. Offshore Technology Conference, n. OTC 15244, 2003.

FOURCHY, R. R. van D. A. V. P.; MIRZA, S. The effect of mooring system and sheared currents on vortex induced motions of truss spars. 22ND International Conference on Offshore Mechanics and Arctic Engineering, n. OMAE2003 - 37151, 2003.

FRANZINI, G. R. et al. Experimental investigations on vortex-induced vibrations with a long flexible cylinder. part i: Modal-amplitude analysis with a vertical configuration. 11th International Conference on Flow Induced Vibration and Noise, p. FIV 2016 The Netherlands, 2016.

FUJARRA, A. L. C. O Fenomeno de VIM em Plataformas Oceânicas. Dissertação (Livre Docência) — Escola Politécnica da Universidade de São Paulo, São Paulo, 2013.

GONçALVES, R. T. Vibrações Induzidas pela Emissão de Vórtices em cilindros com baixa razão de aspecto. Tese (Doutorado) - Escola Politécnica da Universidade de São Paulo, São Paulo, 2013.

HALKYARD, J. Analysis of vortex-induced motions and drag for moored bluff bodies. Offshore Technology Conference, n. OTC 6609, 1991.

JAUVTIS, N.; WILLIAMSON, C. H. K. The effect of two degrees of freedom on vortex-induced vibration at low mass and damping. Journal of Fluids Mechanics, p. 23-62, 2004.

KAWAMURA, T. et al. Flow around a finite circular cylinder on a flat plate. Bulletin of the Japan Society of Mechanical Engineers, p. 2142-2151, 1984. 
KHALAK, A.; WILLIAMSON, C. H. K. Motions forces and mode transitions in vortex-induced vibrations at low mass-damping. Journal of Fluids and Structures, p. 813-851, 1999.

KOKKINIS, T. et al. Development of a stepped line tensioning solution for mitigating vim effects in loop eddy currents for the genesis spar. 23rd International Conference on Offshore Mechanics and Arctic Engineering, n. OMAE2004 - 51546, 2004.

MALTA, E. Investigação Experimental das Vibrações Induzidas pela Emissão de Vortices em Catenárias sujeitas a perfis de Correnteza variável, Ortogonais ao plano de Lançamento. Tese (Doutorado) — Escola Politécnica da Universidade de São Paulo, São Paulo, 2015.

NORBERG, C. Flow around a circular cylinder: aspects of fluctuating lift. Journal of Fluids and Structures, p. 459-469, 2000.

PARK, C.; LEE, S. Free end effects on the near wake flow structure behind a finite circular cylinder. Journal of Wind Engineering, p. 231-246, 2000.

PARK, C.; LEE, S. Effects of free-end corner shape on flow structure around a finite cylinder. Journal of Fluids and Structures, p. 141-158, 2004.

PATTENDEN, R. J.; TURNOCK, S. R.; ZHANG, X. Measurements of the flow over a low-aspect-ratio cylinder mounted on a ground plane. Experiments in Fluids, p. 10-21, 2005.

PESCE, C. P. Mecânica de cabos e tubos submersos lançados em catenária: uma abordagem analítica e experimental. Dissertação (Livre Docência) - Escola Politécnica da Universidade de São Paulo, São Paulo, 1997.

RODDIER, D.; FINNIGAN, T.; LIAPIS, S. Influence of the reynolds number on spar vortex induced motions (vim): Multiple scale model test comparisons. 28th International Conference on Ocean, Offshore and Arctic Engineering, n. OMAE2009 - 79991, 2009.

ROH, S. C.; PARK, S. O. Vortical flow over the free end surface of a finite circular cylinder mounted on a flat plate. Experiments in Fluids, p. 63-67, 2003.

SAKAMOTO, H.; ARIE, M. Vortex shedding from a rectangular prism and a circular cylinder placed vertically in a turbulent boundary layer. Journal of Fluids Mechanics, p. 147-165, 1983.

SOMEYA, S. et al. Experimental investigation of a flow-induced oscillating cylinder with two degrees-of-freedom. Nuclear Engineering and Design, p. 4001-4007, 2010.

SUMNER, D.; HESELTINE, J.; DANSEREAU, O. J. P. Wake structure of a finite circular cylinder of small aspect ratio. Experiments in Fluids, p. 720-730, 2004.

TSUKADA, R.; MOROOKA, C. A numerical procedure to calculate the viv response of a catenary riser. Ocean Engineering, p. 145-161, 2016.

VANDYKE, M. D. An Album of Fluid Motion. [S.l.]: Stanford, CA: Parabolic Press, 1982. 
YUNG, T. W. et al. Advancement of spar viv prediction. Offshore Technology Conference, n. OTC 16343, 2004.

ZDRAVKOVICH, M. M. The effects of interference between circular cylinders in cross flow. Journal of Fluids and Structures, p. 239-261, 1987.

ZDRAVKOVICH, M. M. Comments on effects of three-dimencional flow near a cylinder's free end on ovalling oscillation. Journal of Fluids and Structures, p. 631-636, 1989. 


\section{APÊNDICE A - EnsaIOS DE DECAIMENTO}

\section{A.1 DESCRIÇÃo GERAL}

Este apêndice descreve os procedimentos adotados nos ensaios de decaimento e os resultados respectivamente obtidos para a caracterização dos arranjos experimentais com os quatro modelos construídos para a investigação do VIV nos cilindros curtos flutuantes.

Especificamente falando, os ensaios de decaimento se preocuparam com a obtenção das frequências naturais e dos coeficientes de amortecimento, medidos para os seis graus de liberdade (6GL), todos em água parada (com velocidade de escoamento nula, $U=0$ ).

Importante destacar que, como conduta geral, ensaios de decaimento foram executados e analisados ao início de todos os conjuntos de experimentos de VIV com os cilindros curtos flutuantes, particularmente para a determinação das frequências naturais exatas utilizadas no cálculo das velocidades reduzidas. As séries temporais de decaimento também foram importantes para a verificação das características do arranjo experimental, buscando a manutenção de condições mínimas de comparação entre os modelos ensaiados.

\section{A.2 Procedimento de Execução e Análise}

O primeiro passo na realização dos ensaios de decaimento foi garantir a condição de equilíbrio do modelo ensaiado sem a presença de perturbações externas, particularmente a presença de ondas.

A partir da condição de equilíbrio em água parada, uma condição inicial (deslocamento ou ângulo inicial em velocidade nula, dependendo do grau de liberdade) foi imposta ao modelo suportado pelo conjunto de quatro molas.

O modelo, então, foi liberado para oscilação completamente livre, tendo seus movimentos registrados até que o movimento natural fosse visivelmente desprezível. 
Executados os decaimentos nos 6GL, passou-se para a fase de análise das séries temporais registradas. Por intermédio de análises de Fourier, os primeiros parâmetros determinados foram os períodos naturais do sistema (ou, reciprocamente, as frequências naturais dos conjunto formados por modelo mais amarração), cujos resultados foram consolidados na Tabela 3.2, já apresentada no corpo deste texto.

Conforme ilustram as Figuras de A.1 a A.6, é importante salientar que foram realizadas pelo menos duas repetições do decaimento em cada grau de liberdade, buscando assim uma caracterização mais adequada dos parâmetros de interesse.

Na sequência, assumindo uma condição linear para o amortecimento dos sistemas, foram determinadas envoltórias dos registos temporais de decaimento, cujos parâmetros de ajuste permitiram a obtenção dos coeficientes de amortecimento em água parada, também consolidados na Tabela 3.2.

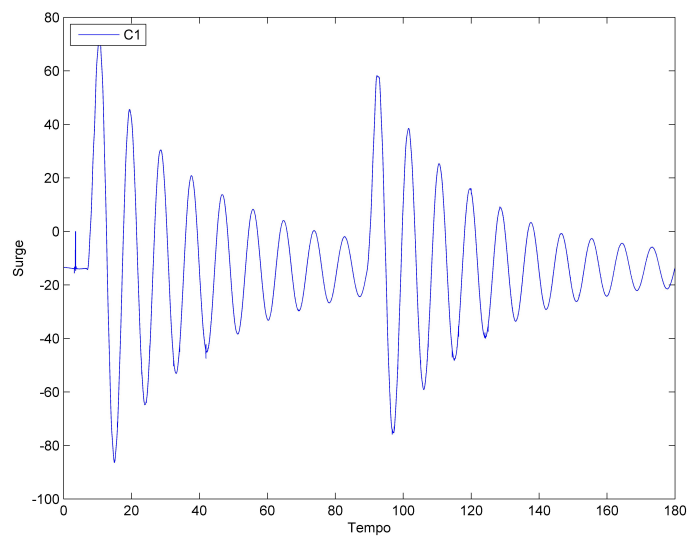

Figura A.1: Exemplo de registro dos ensaios de decaimento em surge realizados com o modelo C1.

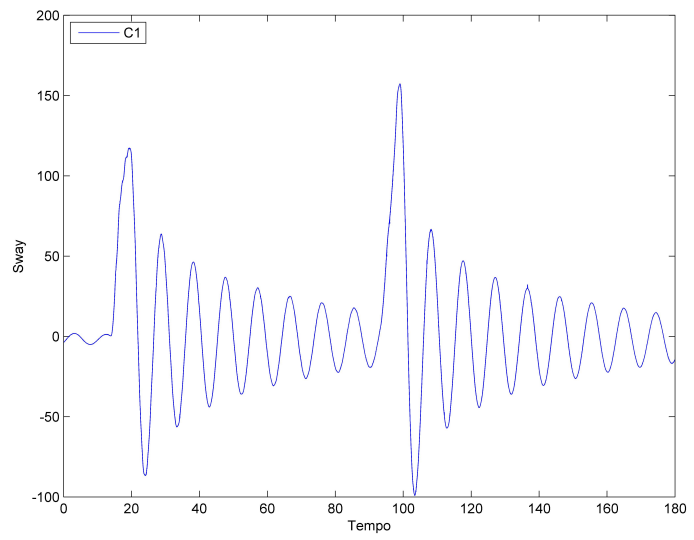

Figura A.2: Exemplo de registro dos ensaios de decaimento em sway realizados com o modelo C1. 
Qualitativamente, note que os decaimentos de surge e sway revelam, de fato, períodos naturais uma ordem de grandeza maiores $\left(T_{n=1 ; 2} \approx 10 s\right)$ do que aqueles identificados nos demais graus de liberdade, heave, roll, pitch e yaw $\left(T_{n=3 ; 4 ; 5 ; 6} \approx 1 \mathrm{~s}\right)$. Esta característica foi importante para identificação exata dos regimes de ressonância e os eventuais acoplamentos modais durante a ação do VIV nos modelos flutuantes.

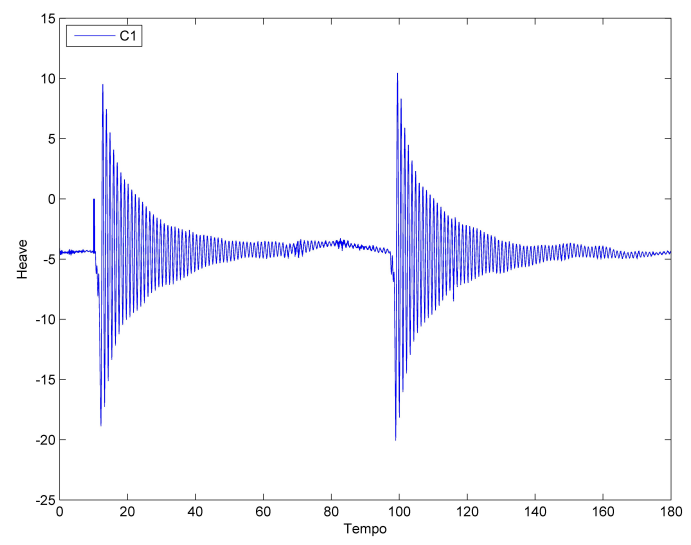

Figura A.3: Exemplo de registro dos ensaios de decaimento em heave realizados com o modelo C1.

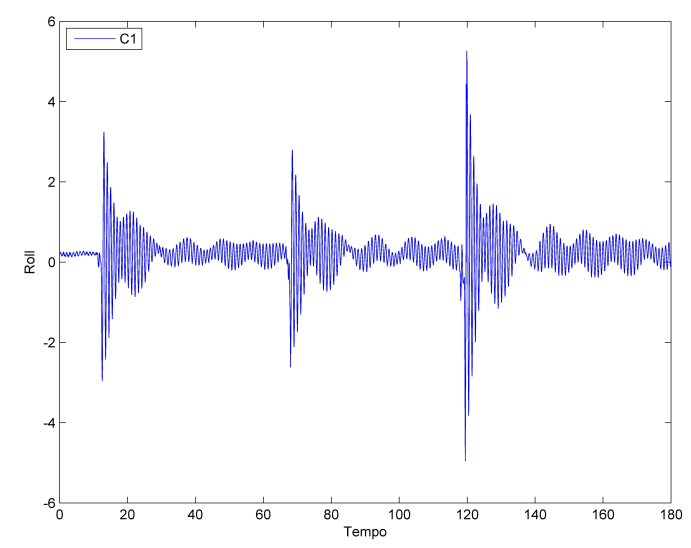

Figura A.4: Exemplo de registro dos ensaios de decaimento em roll realizados com o modelo C1.

Além disso, e ainda em termos qualitativos gerais, as Figuras de A.1 a A.6 também comprovam a hipótese de uma amortecimento predominantemente linear; exceção feita aos decaimentos de roll e pitch, Figuras A.4 e A.5, onde os respectivos acoplamentos com os movimentos de sway e surge foram inevitáveis, exigindo um trabalho adicional de filtragem dos registros antes das análises via envoltória.

Para finalizar, um aspecto merece esclarecimento. Em alguns ensaios de decaimento, pitch com o modelo $\mathrm{C} 1$ - por exemplo, Figura A.5, alguns ciclos atingiram os limites 
preestabelecidos para as oscilações. Essas ocorrências, no entanto, não comprometeram as análises de caracterização, por se concentraram nos instantes iniciais dos decaimentos, sendo facilmente descartadas.

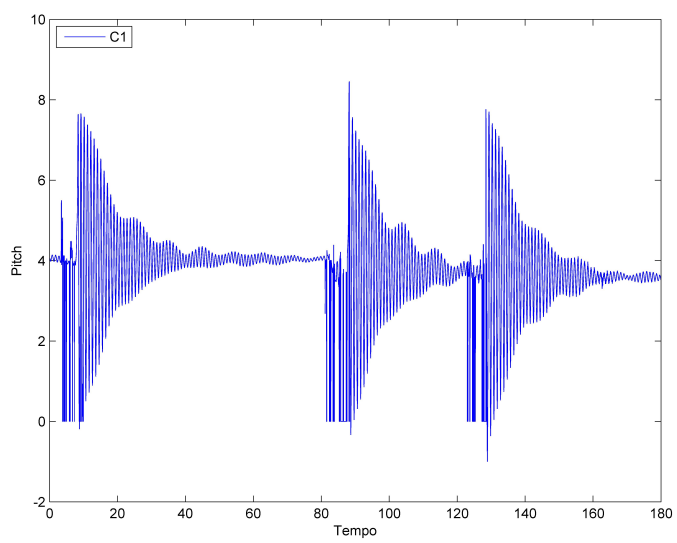

Figura A.5: Exemplo de registro dos ensaios de decaimento em pitch realizados com o modelo C1.

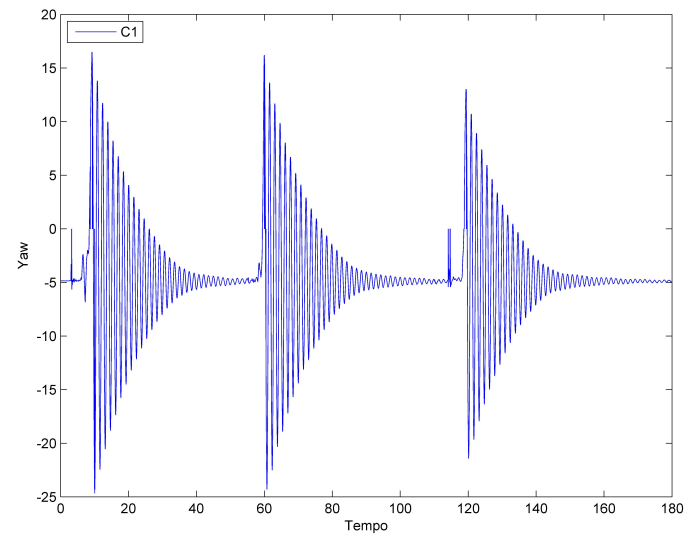

Figura A.6: Exemplo de registro dos ensaios de decaimento em yaw realizados com o modelo C1. 


\section{APÊNDICE B - Amplitudes PARA os Demais Graus DE LIBERDADE}

\section{B.1 DEscriçÃo GERAL}

Os resultados apresentados neste apêndice dizem respeito às amplitudes de resposta para o movimento na direção vertical (heave) e para os movimentos angulares ao redor das direções longitudinal e transversal (respectivamente, roll e pitch).

Lembrar que o experimentos de VIV (ou VIM em modelos de plataformas) geralmente se preocupam apenas com os movimentos de translação longitudinal ao escoamento (surge) e de translação transversal ao escoamento (sway), além de, eventualmente, também considerarem o movimento de rotação ao redor da direção vertical (yaw).

Desta forma, os movimentos descritos neste apêndice - que complementam a característica totalmente livre dos arranjos flutuantes - dificilmente são considerados e descritos na literatura (muitas vezes desprezados também por conta das pequenas magnitudes que exibem). A possibilidade de existirem, no entanto, pode ser de interesse para pesquisas futuras, daí sua inclusão neste apêndice com alguma discussão de natureza qualitativa.

\section{B.2 Respostas de Heave, Roll e Pitch}

A Figura B.1 compara os comportamentos dos modelos - cilindros C1 $(r / R=0,00)$, C2 $(r / R=0,25), \mathrm{C} 3(r / R=0,50)$ e $\mathrm{C} 4(r / R=1,00)$ - para o movimento na direção vertical (eixo Z). De uma maneira geral, mediante modificação da extremidade imersa dos cilindros, as diferenças entre amplitudes adimensionais $A_{z} / D$ não são significativas, pois não ultrapassam a amplitude adimensional vertical máxima de $\left(A_{z} / D\right)_{\max }=0,028$, ainda que sejam caracterizadas por um aumento com a elevação da velocidade reduzida ${ }^{1}$.

\footnotetext{
${ }^{1}$ Para efeito de comparação geral, as velocidade reduzidas neste apêndice também são definidas com base na frequência natural do grau de liberdade transversal ao escoamento incidente (direção Y).
} 


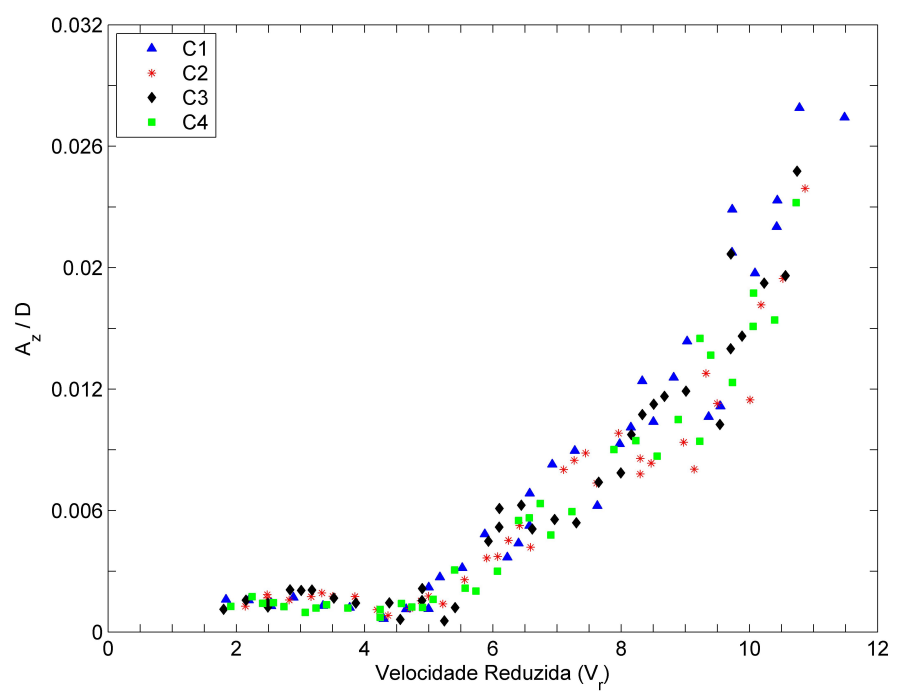

Figura B.1: Amplitude adimensional na direção vertical, $A_{z} / D$, como função da velocidade reduzida, $V_{r}$, para cilindros flutuantes: $\mathrm{C} 1, \mathrm{C} 2, \mathrm{C} 3$ e $\mathrm{C} 4$.

O gráfico da Figura B.2, apresenta as razões entre as frequências de oscilação na direção vertical (direção Z) e a frequência natural na direção transversal ao escoamento. A partir deste gráfico, verifica-se que as oscilações na direção vertical são resultado de um acoplamento heave-surge ou heave-sway para as velocidades reduzidas acima de 6 , visto que $f_{z} \approx f_{0 y}$.

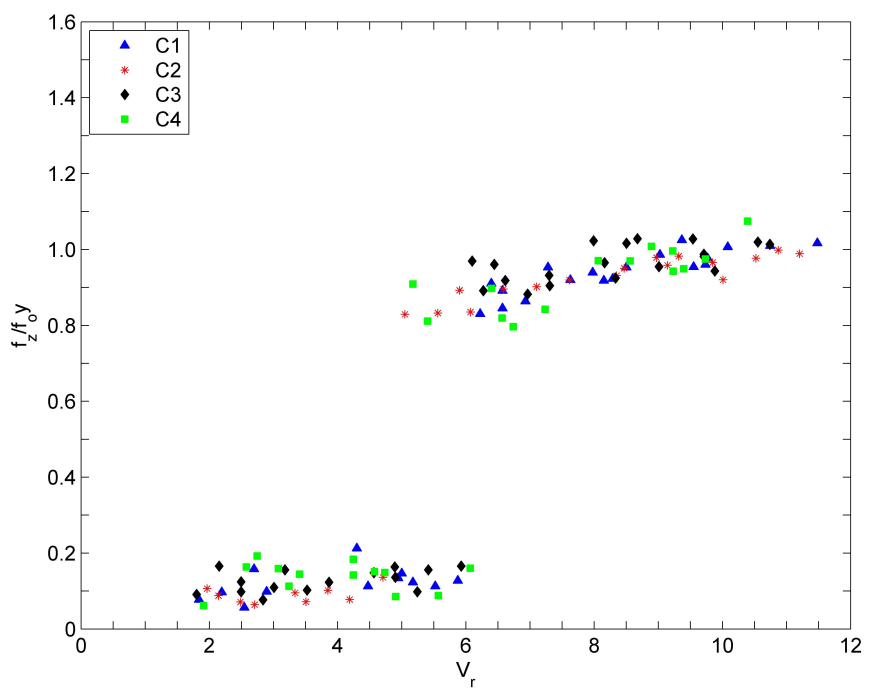

Figura B.2: Razão entre a frequência de oscilação na direção vertical e a frequência na direção transversal ao escoamento,$f_{z} / f_{\text {oy }}$, como função da velocidade reduzida, $V_{r}$, para cilindros flutuantes: C1, C2, C3 e C4.

A Figura B.3, por sua vez, compara os comportamentos do movimento angular ao redor do eixo longitudinal (roll), que particularmente apresenta uma resposta curiosa. 


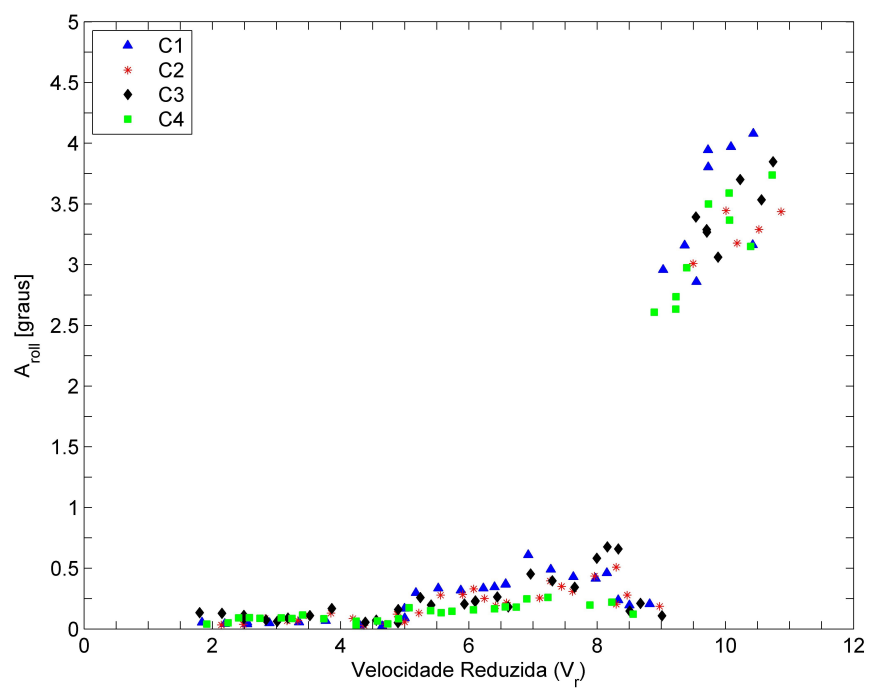

Figura B.3: Amplitude angular de roll, $A_{\text {roll }}$, como função da velocidade reduzida, $V_{r}$, para cilindros flutuantes: C1, C2, C3 e C4.

Na faixa de $2 \leq V_{r} \leq 9$, os cilindros apresentam movimentos de roll bastante diminutos (não maiores que 0,75 de grau). A partir de $V_{r}>9$, no entanto, as oscilações em roll aumentam repentinamente para 3 graus, crescendo até atingirem 4,5 graus na máxima velocidade de reboque conseguida. Aparentemente, este crescimento abrupto está relacionado com as grandes amplitudes de translação transversal nesta região, caracterizando o já mencionado acoplamento sway-roll.

O gráfico da respectiva razão entre frequências do movimento de roll e a frequência natural transversal $\left(f_{\text {roll }} / f_{0}\right)$ pode ser observada na Figura B.4. Pela curva, não é possível notar o aparecimento de zonas de ressonância, o que comprova que o crescimento abrupto das amplitudes é derivado do acoplamento sway-roll.

Finalmente, resultados referentes aos movimentos angulares ao redor do eixo transversal (pitch) são comparados na Figura B.5.

Um aspecto importante que se pode observar diz respeito à região de ressonância referente ao movimento na direção do escoamento, que ocorrem na faixa de $2 \lesssim V_{r} \lesssim 4,5$, o que confirma a hipótese de acoplamento surge-pitch. Tal acoplamento também se mantém para a velocidades reduzidas maiores, no entanto, com um aumento crescente dos ângulos de resposta, chegando a valores de Apitch $=2,25$ graus. Devido ao acoplamento, essas análises se assemelham àquelas observadas para as respostas na direção longitudinal, consequentemente, o formato dos gráficos tomam formas bem parecidas.

A Figura B.6 apresenta valores para razão entre as frequências de movimento de pitch e a 


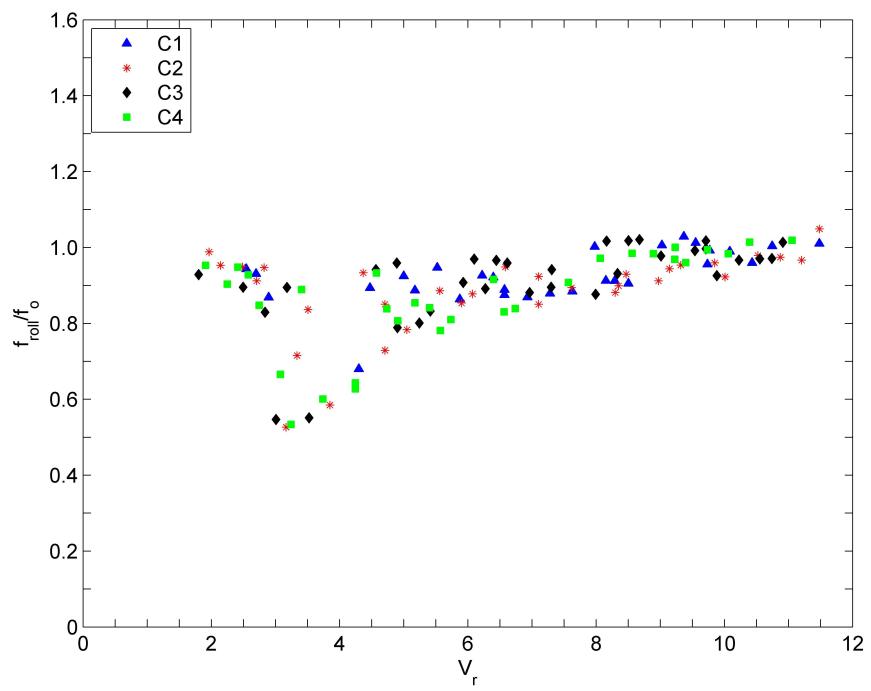

Figura B.4: Razão entre a frequência de oscilação angular em roll e a frequência natural do sistema, $f_{\text {roll }} / f_{o}$, como função da velocidade reduzida, $V_{r}$, para cilindros flutuantes: $\mathrm{C} 1, \mathrm{C} 2, \mathrm{C} 3$ e $\mathrm{C} 4$.

natural do sistema. É possível observar que há um comportamento crescente desta razão, entretanto, não há trecho de ressonância do movimento, o que nos reforça a ideia para o acoplamento surge-pitch.

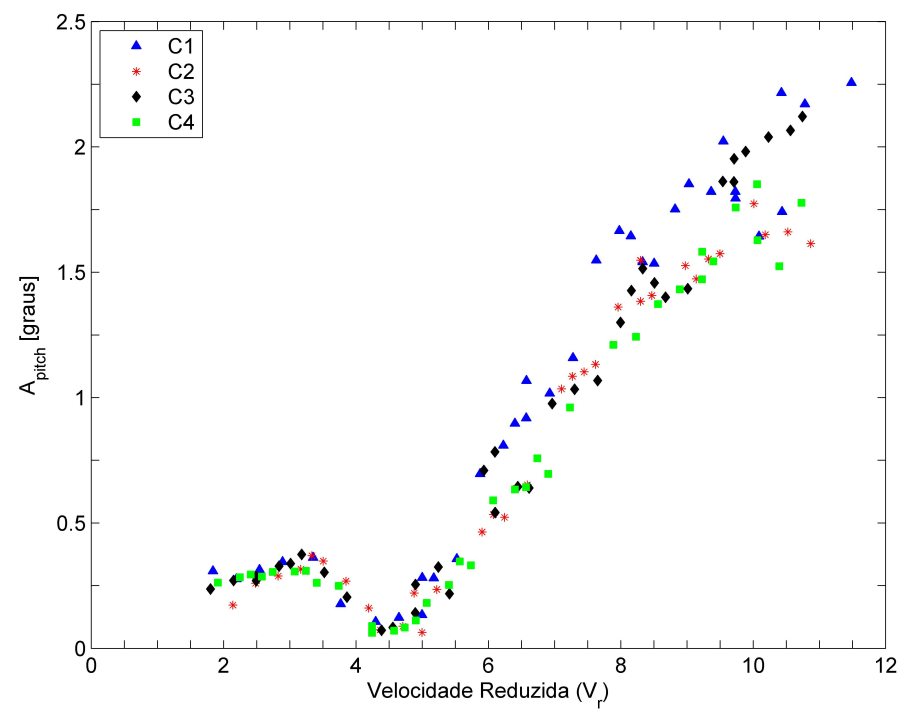

Figura B.5: Amplitude angular de pitch, $A_{\text {pitch }}$, como função da velocidade reduzida, $V_{r}$, para cilindros flutuantes: C1, C2, C3 e C4. 


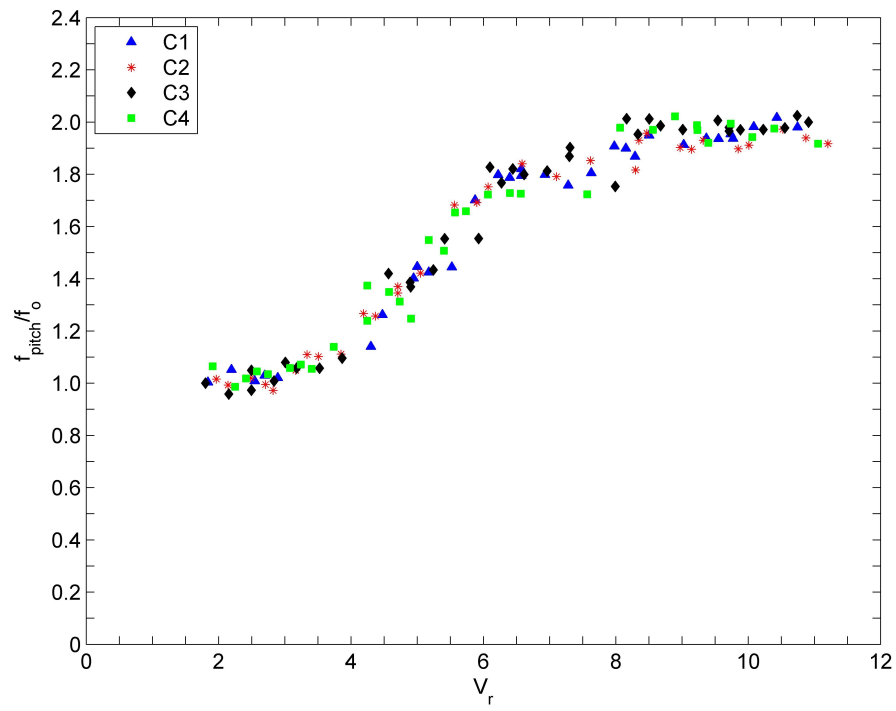

Figura B.6: Razão entre a frequência de oscilação angular em pitch e a frequência natural do sistema, $f_{\text {pitch }} / f_{o}$, como função da velocidade reduzida, $V_{r}$, para cilindros flutuantes: $\mathrm{C} 1, \mathrm{C} 2, \mathrm{C} 3$ e $\mathrm{C} 4$. 